Data de Depósito:

Assinatura:

\title{
PROREQ - Um Guia facilitador para a implantação dos Processos de Gestão de Requisitos
}

\author{
Alfraino de Souza Diniz
}

Orientador: Profa. Dra. Rosana Teresinha Vaccare Braga

Dissertação apresentada ao Instituto de Ciências Matemáticas e de Computação - ICMC-USP, como parte dos requisitos para obtenção do título de Mestre em Ciências de Computação e Matemática Computacional.

USP - São Carlos

Junho/2007 


\title{
Um Guia Facilitador para a Implantação dos Processos de Gestão de Requisitos
}

\author{
Alfraino de Souza Diniz
}




\title{
AGRADECIMENTOS
}

\begin{abstract}
A Deus por me permitir.
\end{abstract}
Aos meus pais por todo o incentivo e principalmente pelo exemplo de tudo de bom que eu consegui captar. Pela borracha, cartolina, caneta, lápis, pincel ou qualquer outro objeto esquecido em casa.

À Carol, pela paciência, pelo companheirismo e principalmente pelo amor e dedicação inquestionáveis.

Aos meus irmãos, pelo eterno companheirismo.

Aos meus amigos, pela sintonia, pelas risadas e por serem a família que eu tive a oportunidade de escolher.

Ao meu filho Caio, por ter nascido para iluminar a minha vida e me ensinar a ser pai.

À minha orientadora Rosana Braga, pelo incentivo e paciência.

Ao ICMC e aos professores, pelo conhecimento adquirido.

A todos que contribuíram, direta ou indiretamente, para a concretização de meu sonho. 


\section{RESUMO}

Os processos de gestão de requisitos têm influência direta na concepção do produto final e estão diretamente relacionados com a satisfação do cliente, pois é neles que se define o que o cliente espera do software. Seus produtos servem de base para os processos executados posteriormente e, portanto, a probabilidade de ocorrer falhas é maior caso haja falhas durante a elaboração dos requisitos do software. No entanto, temse observado que esses processos são uma das maiores fontes de problemas encontrados no desenvolvimento de software. Com o intuito de sistematizar os processos de desenvolvimento de software, a fim de se evitar prejuízos para as organizações desenvolvedoras e insatisfação para os adquirentes dos produtos desenvolvidos, surgiram os modelos para a melhoria de processo de desenvolvimento de software, tais como o Capability Matutity Model Integration - Development (CMMI-Dev). Esses modelos atuam como guias para a melhoria contínua dos processos de desenvolvimento das organizações. Entretanto, o nível de abstração dos modelos nem sempre é suficientemente específico para orientar colaboradores de organizações não familiarizados com o corpo de conhecimento da engenharia de software. Outro aspecto que dificulta a utilização de tais modelos é o financeiro, pois a implantação de tais melhorias apresenta alto custo, podendo ser inviável para organizações de pequeno e médio porte. Este trabalho apresenta um guia, denominado PROREQ, cujo objetivo é facilitar a implantação de melhorias nos processos de requisitos de pequenas organizações. É composto por um conjunto de boas práticas classificadas segundo a estrutura de organização das áreas de processo Desenvolvimento e Gerenciamento de requisitos do CMMI-Dev; uma estratégia de implantação, baseada na estratégia da norma ISO/IEC 15504 e em um conjunto de práticas retiradas de trabalhos empíricos relacionados à melhoria de processos de software; e um modelo de avaliação, baseado na norma ISO/IEC 15504 e no método de avaliação do modelo de melhoria de processo de software brasileiro (MPS.BR). Ao final é descrito um estudo de caso que apresenta os resultados da aplicação do guia PROREQ em uma pequena organização desenvolvedora de software. 


\begin{abstract}
Requirements management processes have a great impact on the final product conception and are directly related to customers' satisfaction, as the expected behavior of the software is defined during them. Their products serve as a basis for the processes executed subsequently and, thus, the probability of failure is higher when faults occur during the elaboration of the software requirements. However, it has been observed that these processes are one of the richest sources of problems found during software development. This motivated the appearance of models for improving software development processes, such as the Capability Matutity Model Integration Development (CMMI-Dev), which act as guides for continuously improving the organization development processes. Nevertheless, the abstraction level of the models is not always specific enough to guide the organization collaborators that are not familiar with the software engineering body of knowledge. Financial aspects also make the utilization of these models more difficult, because to deploy these improvements is often expensive and can be unfeasible for small and medium organizations. This work presents a guide, named PROREQ, whose main goal is to ease the deployment of improvements in the requirements processes of small organizations. It is composed of: a set of good practices classified according to the organization structure of CMMI-Dev process areas Requirements Development and Management; a deployment strategy, based on ISO/IEC 15504 strategy and on a set of practices coming from empirical works related to software process improvement; and an evaluation model based on ISO/IEC 15504 and on the evaluation method of the Brazilian software process improvement method (MPS.BR). A case study is described to present the results of applying the PROREQ guide in a small software development organization.
\end{abstract}




\section{LISTA DE FIGURAS}

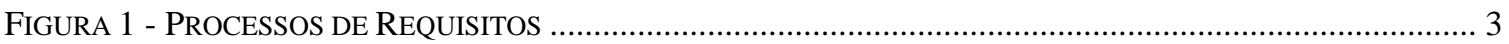

FIGURA 2 - ESTRUTURA DE ORGANIZAÇÃO DE ÁREA DE PROCESSO DO CMMI-DEV ……………………….... 13

FIGURA 3 - ELEMENTOS NORMATIVOS DO PADRÃO INTERNACIONAL (ISO/IEC 15504-2, 2003).................... 26

FIGURA 4 - PASSOS PARA UM PROGRAMA DE MELHORIA DE PROCESSO (ISO/IEC 15504-4, 2003)................ 30

FIGURA 5 - CONTRIBUIÇÃO DE CADA MODELO UTILIZADO PARA O CONJUNTO DE PRÁTICAS FUNDAMENTAIS 39

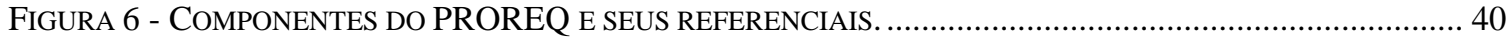

FIGURA 7 - ESTRUTURA DE ORGANIZAÇÃO DAS PRATICAS FUNDAMENTAIS NO CMMI-DEV ................... ERRo! INDICADOR NÃO DEFINIDO.2

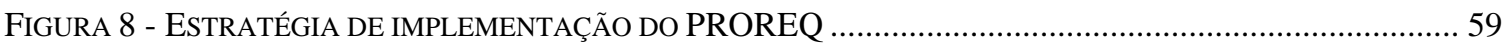

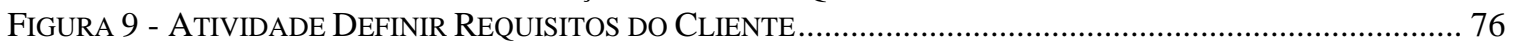

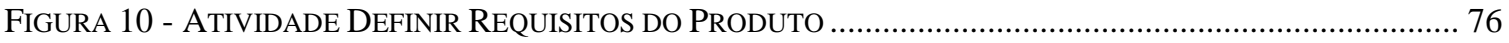

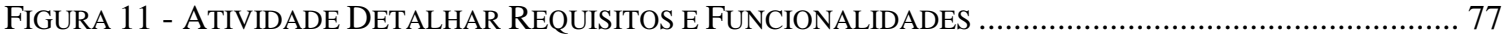

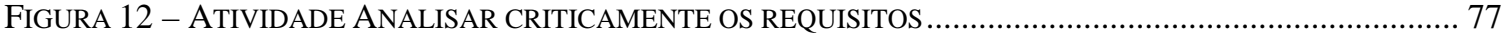

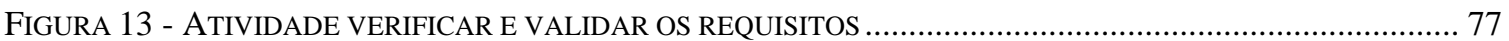




\section{LISTA DE QUADROS}

QUADRO 1 - REGRAS PARA CARACTERIZAÇÃO DO GRAU DE IMPLEMENTAÇÃO DE UM RESULTADO ESPERADO

Q

QUADRO 2 - ESCALA DE ATENDIMENTO DE ATRIBUTOS DE PROCESSO EM PERCENTUAL ..............................28

QUADRO 3 - CLASSIFICAÇÃO DE NÍVEIS DE CAPACIDADE ABRANGIDOS PELO TRABALHO .............................28

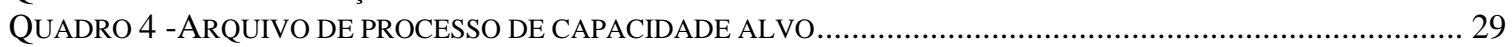

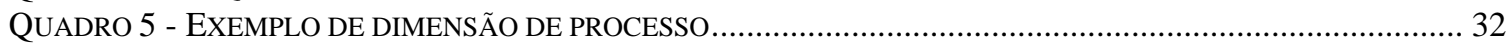

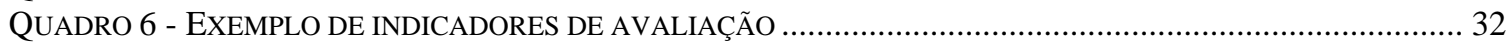

QUADRO 7 - OBJETIVOS GENÉRICOS, PRÁTICAS GENÉRICAS E SUBPRÁTICAS DO CMMI-DEV PARA O NÍVEL 1

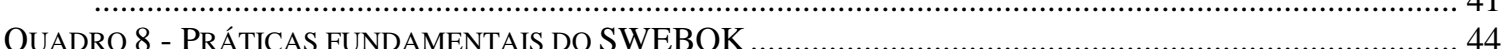

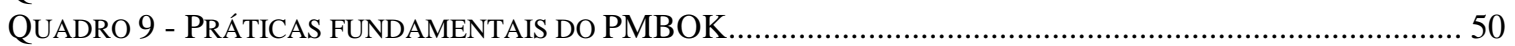

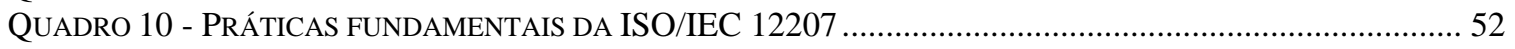

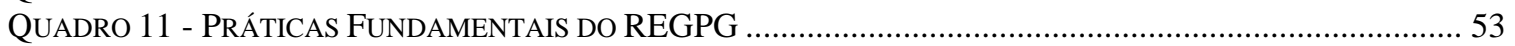

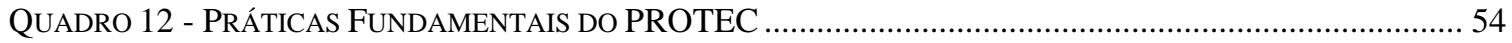

QUADRO 13 - RESULTADOS ESPERADOS DOS PROCESSOS DE REQUISITOS DO MPS.BR ................................ 55

QUADRO 14 - EXEMPLO DE PRÁTICA FUNDAMENTAL, ENTRADAS E SAÍDAS ............................................ 56

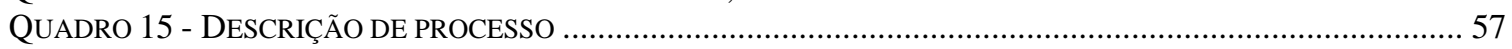

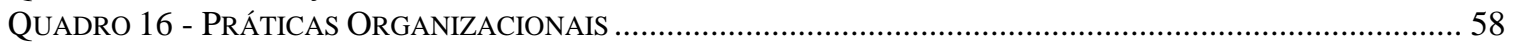

QUADRO 17 - PRÁTICAS ORGANIZACIONAIS DO PASSO DE PLANEJAMENTO...............................................60

QUADRO 18 - PRÁTICAS ORGANIZACIONAIS DO PASSO DE TREINAMENTO E MOTIVAÇÃO ..............................61

QUADRO 19 - EXEMPLO DE QUESTIONÁRIO UTILIZADO PARA AVALIAÇÃO DE UTILIZAÇÃO DE PRÁTICAS

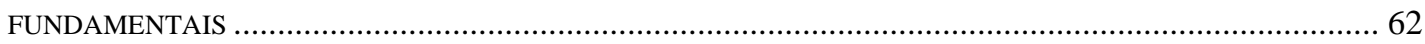

QUADRO 20 - PRÁTICAS ORGANIZACIONAIS DO PASSO DE AVALIAÇÃO DO ESTADO ATUAL ..........................6. 62

QUADRO 21 - EXEMPLO DE QUESTÃO DE PRIORIZAÇÃO DE PRÁTICA FUNDAMENTAL ....................................62

QUADRO 22 - PRÁTICAS ORGANIZACIONAIS DO PASSO DE PRIORIZAÇÃO DE PRÁTICAS ................................63

QUADRO 23 - PRÁTICAS ORGANIZACIONAIS DO PASSO DE MODELAGEM DE PROCESSO ................................64

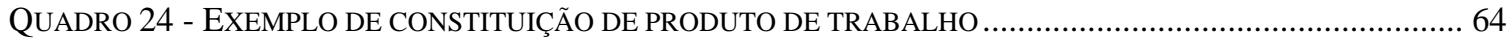

QUADRO 25 - PRÁTICAS ORGANIZACIONAIS DO PASSO DE TREINAMENTO DA EQUIPE NO PROCESSO CRIADO 65

QUADRO 26 - PRÁTICAS ORGANIZACIONAIS DO PASSO DE IMPLANTAÇÃO DO PROCESSO .............................6 65

QUADRO 27 - CARACTERIZAÇÃO DO GRAU DE ATENDIMENTO DE ATRIBUTO DE PROCESSO ..........................67

QUADRO 28 - EXEMPLO DE ATIVIDADE DO PROCESSO VENDER ........................................................ 76 


\section{SUMÁRIO}

\section{CAPÍTULO 1 Engenharia e Gerenciamento de Requisitos...................... 1}

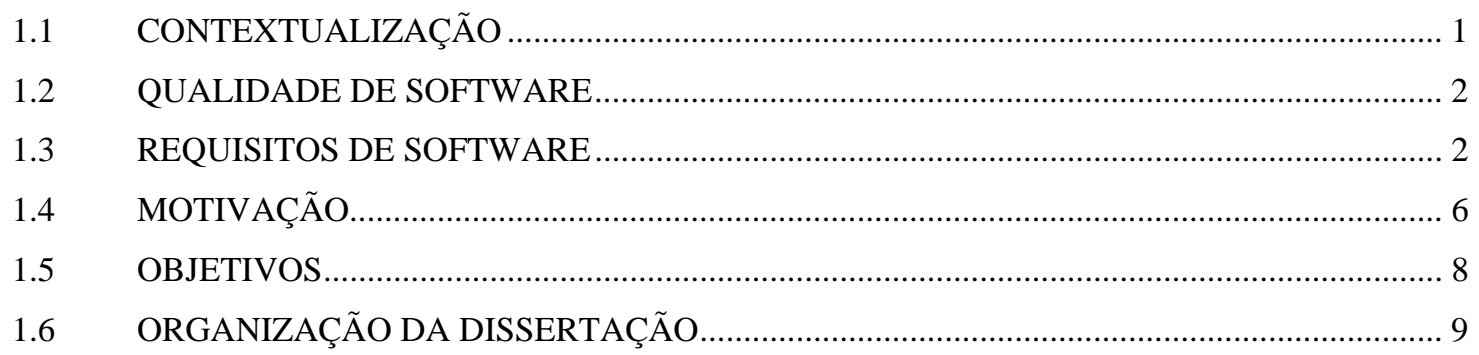

\section{CAPÍTULO 2 Revisão Bibliográfica ......................................................... 11}

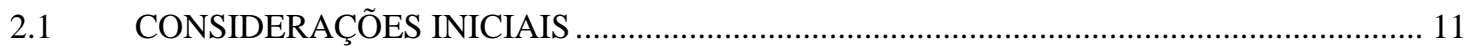

2.2 CMMI ${ }^{\circledR}$ FOR DEVELOPMENT, VERSION 1.2 (CMMI-DEV) ....................................... 12

2.2.1 Desenvolvimento de Requisitos............................................................................................. 13

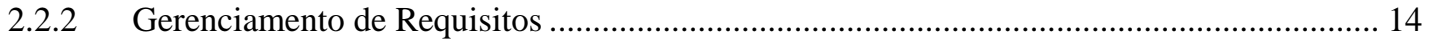

2.3 SEWBOK - SOFTWARE ENGINEERING BODY OF KNOWLEDGE ..................................... 15

2.4 PMBOK - PROJECT MANAGEMENT BODY OF KNOWLEDGE ….................................... 16

2.5 MELHORIA DE PROCESSO DE SOFTWARE BRASILEIRO - MPS.BR VERSÃO 1.1 .... 19

2.6 REQUIREMENTS ENGINEERING - A GOOD PRACTICE GUIDE - RE-GPG ..................... 21

2.7 REQUIREMENTS ENGINEERING - PROCESS AND TECHNIQUES................................. 22

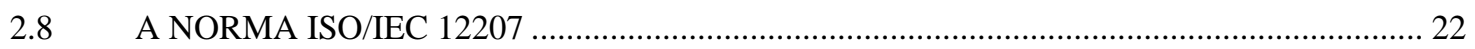

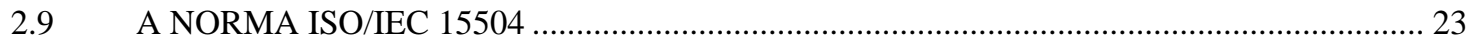

2.9.1 Parte 2 - Execução de uma avaliação ........................................................................................ 25

2.9.2 Parte 4 - Guia para usar no processo de melhoria contínua ..................................................... 29

2.9.3 Parte 5 - Um exemplo de modelo de avaliação baseado na norma ISO/IEC 12207............... 31

2.10 TRABALHOS EMPÍRICOS DA ÁREA DE MELHORIA DE PROCESSO............................ 33

2.10.1 An Empirical Study of Industrial Requirements Engineering Process Assessment and

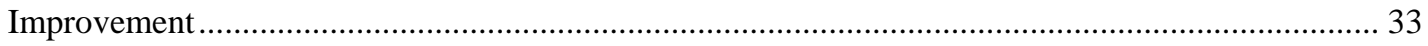

2.10.2 Implementing requirements engineering processes throughout organizations: success factors and challenges

2.10.3 Software Process Improvement Problems in Twelve Software Companies: An Empirical

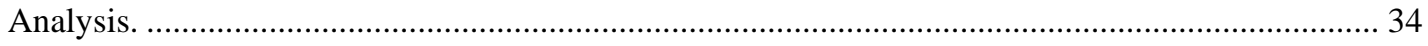

2.10.4 Defining a Requirements Process Improvement Model ....................................................... 35

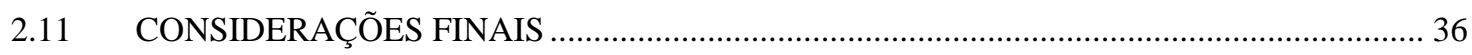


CAPÍTULO 3 O GUIA PROREQ .................................................... 37

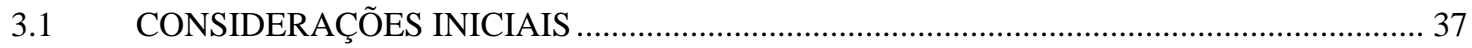

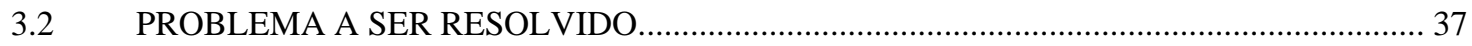

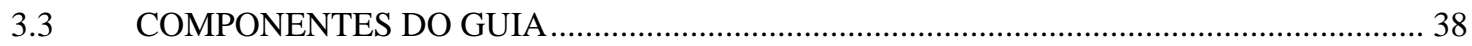

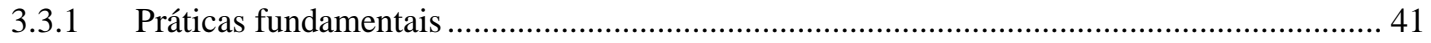

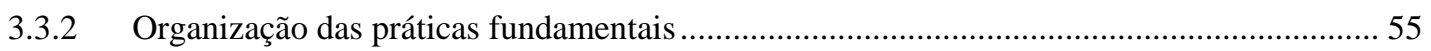

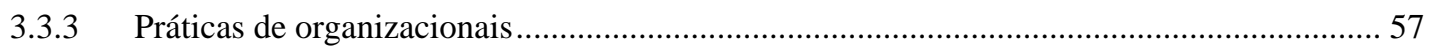

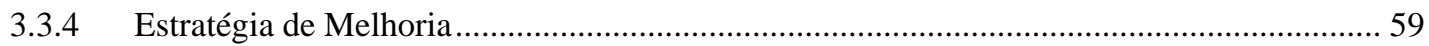

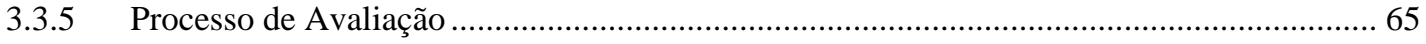

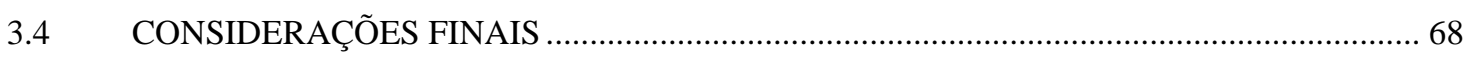

CAPÍTULO 4 Estudo de Caso ............................................................. 69

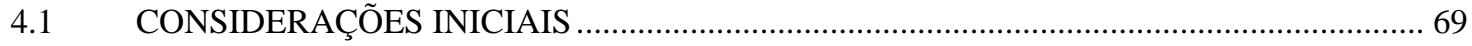

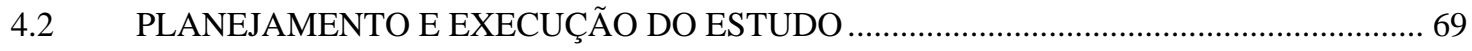

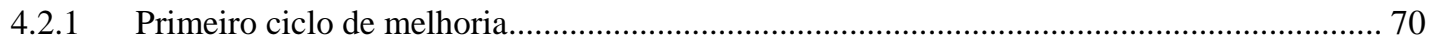

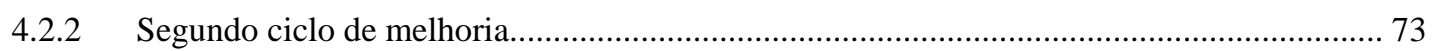

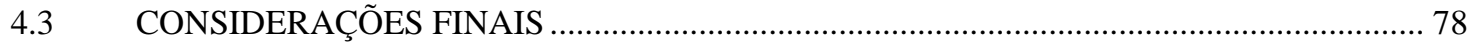

CAPÍTULO 5 Conclusões e trabalhos futuros ......................................... 79

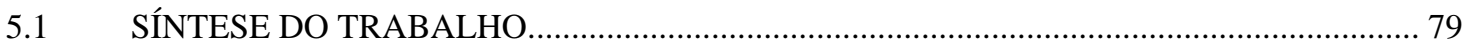

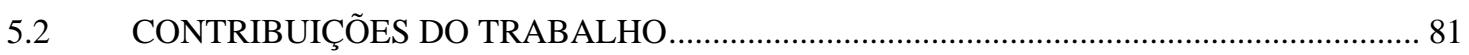

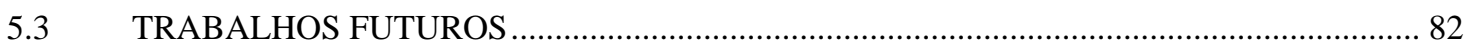

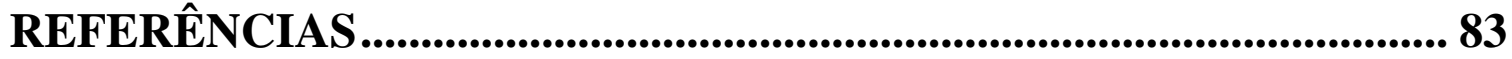
APÊNDICE A - Guia PROREQ - Facilitador de programa de melhoria de processo de software para os processos de requisitos ........................ 92 


\section{CAPÍTULO 1 ENGENHARIA E GERENCIAMENTO DE REQUISITOS}

\subsection{CONTEXTUALIZAÇÃO}

A literatura referente à engenharia de requisitos (ER) tem demonstrado de diversas maneiras a importância desse processo, seja por meio de evidências empíricas de benefícios ou de estudos de caso ou ainda por meio de resultados estatísticos que demonstram que a melhoria no processo de requisitos levará a uma melhoria na produtividade de organizações. Assim sendo, atualmente existem diversos modelos de processo de engenharia de requisitos e cada um usa várias técnicas para diferentes assuntos no desenvolvimento de software (JIANG et al., 2004).

Da perspectiva da engenharia de software, o processo de ER é o primeiro a ser executado e objetiva estabelecer quais serviços são esperados do sistema, bem como suas restrições de operação e desenvolvimento (SOMMERVILLE, 2003). Consequentemente, a execução indevida do processo pode acarretar erros na fase de projeto e codificação.

Muitos autores concordam que seguir um processo de ER bem definido utilizando técnicas adequadas, tem um impacto positivo na qualidade final do software (JIANG et al., 2004). No entanto, implantar processos e pedir às pessoas que apliquem práticas de ER em organizações que atuam sob pressão é um desafio (KAUPPINEN et al., 2004). 


\subsection{QUALIDADE DE SOFTWARE}

A abrangência de áreas de aplicação de produtos de software é cada vez maior, variando desde aplicações triviais até sistemas críticos, tais como sistemas de controle de tráfego aéreo ou de controle financeiro. Desta forma, pode-se afirmar que a qualidade de software é um tema fundamental, pois pode causar grande impacto na sociedade (GIMENES et al., 1999).

A demanda por qualidade dos produtos de software tem motivado a comunidade de software para o desenvolvimento de modelos de qualidade. Tais modelos são orientados por duas visões: a visão de qualidade de processo de software e a visão de qualidade de produto de software (TSUKUMO et al., 1997). A visão de qualidade de processo tem o objetivo de tratar a avaliação e a melhoria dos processos do ciclo de vida de desenvolvimento de software. A visão de qualidade de produto trata da avaliação do produto de software já produzido para garantir que ele tenha qualidade.

Dentro da visão orientada a processo de desenvolvimento de software destacamse os modelos CMMI-Dev (SEI, 2006), ISO/IEC 15504 (ISO-P1, 2003; ISO-P2, 2003; ISO-P3, 2003; ISO-P4, 2003; ISO-P5, 2003), ISO/IEC 12207 (ISO-A1, 2001; ISO-A2, 2001) entre outros. Já na visão orientada a produto destacam-se as normas ISO/IEC 9126 (ISO/IEC 9126, 1991), ISO/IEC 14598 (ISO/IEC 14598, 1998), entre outros.

A qualidade do processo tem relação direta com a qualidade do produto, pois se houver problemas na qualidade do processo, provavelmente haverá problemas na qualidade do produto (C1-MPS.BR, 2006).

Neste trabalho só serão tratados aspectos referentes à qualidade de processo de desenvolvimento de software.

\subsection{REQUISITOS DE SOFTWARE}

Segundo Pressman (2005), qualidade de software significa “conformidade a requisitos funcionais e de desempenho explicitamente declarados, a padrões de desenvolvimento claramente documentados e a características implícitas que são 
esperadas de todo software profissionalmente desenvolvido". Logo, requisitos de software são a base a partir da qual a qualidade é medida. Sendo assim, a falta de conformidade aos requisitos é sinônimo de falta de qualidade (CARVALHO et al., 2001).

A complexidade dos requisitos dos produtos de software atuais demanda o desenvolvimento sistemático apoiado por técnicas e mecanismos que sejam mensuráveis e com isso possibilitem a comprovação de não implicarem em riscos para a comunidade (GIMENES et al., 1999). Os processos de gestão de requisitos são representados por dois processos denominados Engenharia de Requisitos (ER) e Gerenciamento de Requisitos (GR), conforme ilustrado de maneira simplificada na Figura 1. Na fase de ER, os requisitos são coletados e documentados, enquanto na fase de GR faz-se o gerenciamento da evolução desses requisitos.

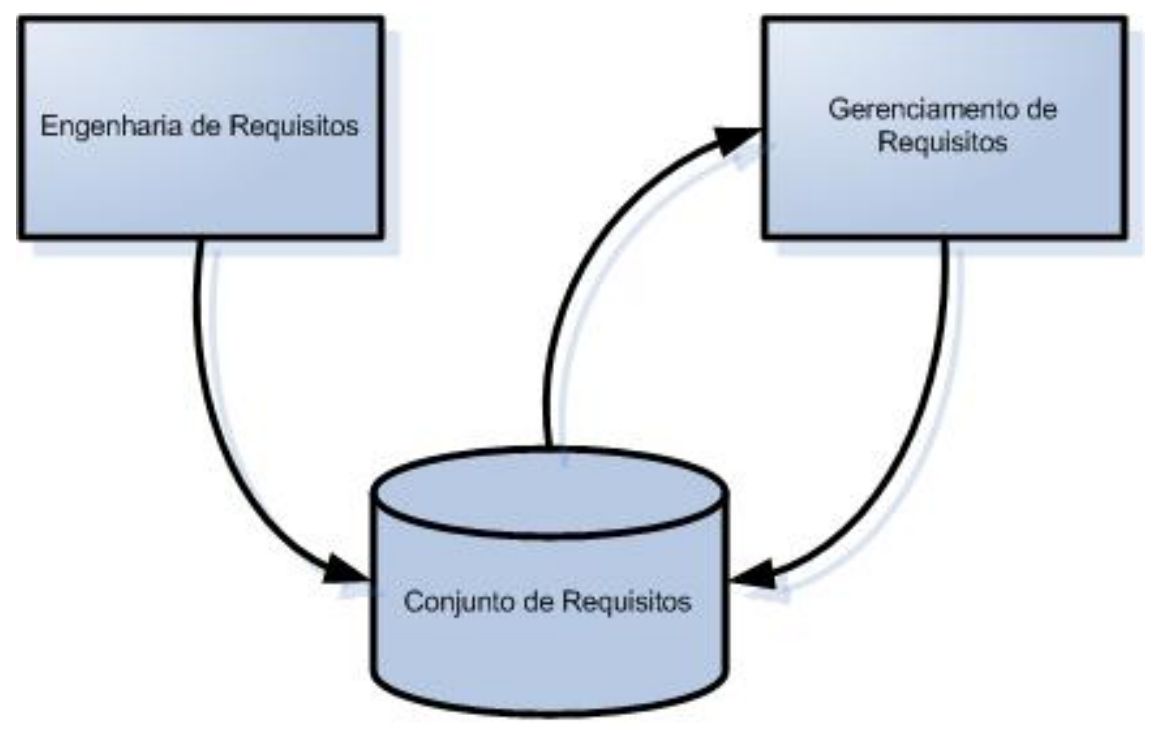

Figura 1 - Processos de Requisitos

Pressman (2005) divide a Engenharia de Requisitos em cinco etapas: o estudo da viabilidade do sistema, a obtenção e a análise de requisitos, a especificação e documentação de requisitos e, finalmente, a validação desses requisitos.

A etapa inicial, denominada estudo da viabilidade do sistema, analisa questões fundamentais para o sucesso do projeto, como a contribuição do sistema para a organização, a integração do sistema com outros sistemas em uso, as restrições de custo e prazo, viabilidade legal, etc. 
Definida a viabilidade do sistema, inicia-se a fase de levantamento e análise dos requisitos, também conhecida como elicitação de requisitos. Esta etapa busca mapear claramente as necessidades dos usuários em um produto de software. Uma das medidas de sucesso de um sistema de software é o grau que ele atinge em relação ao propósito para o qual ele foi desenvolvido (NUSEIBEH \& EATSERBROOK, 2000). Assim, antes que um engenheiro de software projete um sistema, ele precisa saber exatamente o que deve ser feito, ou seja, ele precisa conhecer os requisitos do software. Requisitos de software podem ser definidos como: uma condição ou capacidade que um usuário necessita para resolver um problema ou atingir um objetivo, ou uma condição ou capacidade que precisa ser alcançada para satisfazer um contrato, um padrão, especificação ou um documento formal (IEEE, 1990).

Nessa etapa é importante primeiramente identificar os stakeholders ${ }^{1}$ que atuarão no projeto, bem como os seus interesses e a maneira como estes enxergam a organização. A partir de disso, segue-se uma seqüência genérica de atividades do processo denotada a seguir:

- Compreensão do domínio: Nessa atividade os analistas buscam desenvolver um entendimento do domínio da aplicação;

- Coleta de requisitos: Atividade que visa à interação com os stakeholders para levantar os requisitos;

- Classificação: Organização dos requisitos;

- Resolução de conflitos: Stakeholders diferentes podem possuir interesses e visões diferentes do sistema. Essa atividade visa resolver esses conflitos;

- Definição de prioridades: Define prioridades para os requisitos;

- Verificação dos requisitos: Visa assegurar a completitude e consistência dos requisitos;

Sommerville (2003) divide os requisitos em requisitos do usuário e requisitos do sistema. Os requisitos do usuário são escritos em linguagem natural ou representados por

\footnotetext{
1 Stakeholders são os interessados no desenvolvimento do sistema: clientes, desenvolvedores, fornecedores, empresas terceirizadas, etc.
} 
meio de diagramas. Tais requisitos são lidos por gerentes de clientes, usuários finais de sistemas, engenheiros do cliente, gerentes do fornecedor e arquitetos de sistema. Já os requisitos do sistema são definidos de maneira detalhada, especificando as funcionalidades e restrições do sistema. Os requisitos de sistema podem ainda ser divididos em requisitos funcionais, não funcionais e de domínio. Requisitos funcionais descrevem funções do sistema, como o sistema reage a eventos externos, etc. Os requisitos não funcionais descrevem restrições do sistema, entre as quais se pode citar restrições de tempo, de processo de desenvolvimento, etc. Já os requisitos de domínio são originados do domínio onde o sistema estará inserido e podem ser funcionais ou não funcionais.

Normalmente, os requisitos são especificados em um documento que é chamado de documento de Especificação de Requisitos. As especificações podem ser escritas em linguagem natural, linguagem estruturada, etc.

Finalmente, a validação dos requisitos consiste em assegurar que os requisitos atendam ao que o usuário deseja do sistema. Como resultado desta etapa tem-se uma definição mais precisa do documento de requisitos. Ela é de suma importância, porque um erro de especificação nessa fase pode ter um alto custo de correção em fases posteriores. Existem várias técnicas utilizadas para a validação de requisitos, dentre elas pode-se citar a revisão de requisitos, prototipação, análise automatizada de consistência, etc.

Outra fase do processo de Gestão de Requisitos é a fase denominada Gerenciamento de Requisitos. Nessa fase, são tratados os aspectos referentes à identificação de requisitos, rastreabilidade entre requisitos, métricas e gestão de mudanças de requisitos (SOMMERVILLE\& SAWYER, 1997; SWEBOK, 2004).

Pode-se afirmar que a mudança dos requisitos é um fato concreto no ciclo de vida de um software (SWEBOK, 2004). Elas são causadas por diversas razões, como por exemplo, mudanças na política organizacional, melhor entendimento das necessidades por parte dos stakeholders, mudança no hardware onde o sistema funciona, etc.

Para controlar de maneira sistematizada esse processo, o gerenciamento de requisitos estabelece um planejamento para as suas atividades e políticas para o 
gerenciamento de mudanças. Tal planejamento consiste genericamente das seguintes atividades:

1. Identificação dos requisitos: Os requisitos devem possuir uma identificação única para fins de rastreamento.

2. Processo de gerência de mudanças: Atividades que avaliam o impacto e custo de mudanças solicitadas.

\subsection{MOTIVAÇÃO}

Nos últimos 25 anos, requisitos de software têm sido repetidamente reconhecidos como um problema real no processo de desenvolvimento de software (LAMSWEERDE, 2000). Os processos de engenharia e gerenciamento de requisitos têm um profundo impacto nos custos e funcionalidades do sistema desenvolvido e ainda assim, um número muito grande de organizações tem estes processos mal definidos ou mesmo não definidos (SOMMERVILLE \& RANSOM, 2005).

Estudos realizados por Hall (2002) e outros em 12 organizações desenvolvedoras apontam que dos 268 tipos de problemas encontrados no processo de desenvolvimento, 48\% (128) são problemas ocorridos durante o processo de requisitos. Um levantamento sobre 8000 projetos em 350 empresas americanas constatou que um terço dos projetos nunca são completados e metade apresenta parcialmente as funcionalidades, causando atrasos significativos. Quando questionados sobre o porquê de tais falhas, os gerentes identificaram requisitos pobres ou mal definidos como a maior fonte dos problemas (mais de metade das respostas) - especificamente falta de envolvimento dos stakeholders (13\%), requisitos incompletos (12\%), mudanças nos requisitos (11\%), expectativas irreais (6\%) e objetivos obscuros (5\%) (STA, 1995 apud Lamweerde2000²). Já na Europa um levantamento feito sobre 3800 empresas em 17 países, similarmente concluiu que muitos

2 STA, 1995 - 1st Intl. IEEE Symp. on Requirements Engineering, Jan. The Standish Group, "Software Chaos", http://www.standishgroup.com/chaos.html. 
dos problemas de software têm como fonte o processo de requisitos (IBANEZ \& REMPP, 1996 apud LAMSWEERDE, 2000³).

Os problemas relacionados ao processo de requisitos podem ser classificados de diversas formas. Hofman \& Lehner (2000) classificam os problemas de requisitos como falta de conhecimento de domínio da equipe de gestão de requisitos, falta de gerenciamento de recursos e problemas com o processo em uso. Beechman (2005) e outros dividem os problemas relacionados à gestão de requisitos em técnicos e organizacionais. Hall (2002) e outros categorizam os problemas em organizacionais, de produto e projeto e de desenvolvimento.

Na busca por soluções para os problemas citados, foram elaborados guias de boas práticas de engenharia de requisitos, tais como o livro REGPG - Requirements Engineering Good Pratice Guide, dos autores Sommerville e Sawyer (SOMMERVILLE \& SAWYER, 1997), apresentaram-se padrões de modelos de processo de requisitos (HAGGE \& LAPPE, 2004), frameworks que auxiliam na geração e implantação do processo (JIANG et al, 2004), além dos conhecidos modelos de referência de processos, tais como o CMMI-Dev (SEI, 2006), MPS.BR (MPS.BR, 2006) e a norma internacional ISO/IEC 12207(ISO-A1, 2001), entre outros, sendo que os modelos de processo citados são focados não só na melhoria do processo de requisitos, mas nos processos de desenvolvimento de software como um todo.

Foi constatado que o número de problemas de requisitos enfrentados nas organizações desenvolvedoras de software tende a cair quando cresce o nível de capacidade dos processos de requisitos (HALL et al. op. cit., 2002). Outro estudo demonstra que o crescimento da capacidade do processo de requisitos tende a melhorar também os indicadores de desempenho de negócio das organizações (SOMMERVILLE \& RANSOM, 2005).

Por outro lado, em um trabalho executado em empresas que realizaram ao menos uma avaliação oficial do CMM, foi demonstrado que aquelas que não apresentaram sucesso na melhoria de seus processos atribuem o fracasso, entre vários problemas, ao

${ }^{3}$ IBANEZ \& REMPP, 1996 - IBANEZ, M.; REMPP, H. European User Survey Analysis. Report USV-EUR 2.1, 30 de Janeiro de 1996. 
fato de saber "o que" deve ser feito no processo de melhoria, mas não saber "como" fazer (NIAZI et al, 2004). Somado a isso, tem-se que somente uma avaliação do CMMI, sem contar os custos com consultorias de implantação do modelo, pode custar entre US\$ 40.000 e US $\$ 100.000$, o que pode ser inviável para a maioria das pequenas organizações desenvolvedoras (CUEVAS et al., 2002).

No contexto das pequenas e médias empresas nacionais, pode-se observar por meio de dados da Secretaria de Política de Informática e Tecnologia do Ministério da Ciência e Tecnologia (MCT/SEITEC) divulgados em 2003, que a maioria das empresas brasileiras com certificação SW-CMM ou eram empresas exportadoras de software ou eram empresas de grande porte. A mesma pesquisa constatou ainda que a adequação a modelos de qualidade internacionais tais como o CMMI ou a ISO/IEC 15504 é praticamente inviável, devido aos custos de implantação e certificação (MPS.BR, 2006).

\subsection{OBJETIVOS}

O objetivo geral deste trabalho é reunir em um guia de referência as informações necessárias para que uma pequena organização desenvolvedora de software possa conduzir um programa de melhoria dos seus processos de requisitos, embasada nos principais modelos utilizados mundialmente. Como mencionado anteriormente, a implantação de tais modelos não é viável para a maioria das pequenas e médias empresas nacionais. Nesse sentido, este trabalho visa apoiar as iniciativas que buscam uma melhora na qualidade dos produtos de software nacional e com isso impulsionar o desenvolvimento do setor.

Para atingir o objetivo geral apresentam-se como objetivos específicos:

- Levantar e organizar um conjunto de práticas relativas a aspectos técnicos do processo de requisitos, tais como práticas de elicitação, análise, etc, por meio da consulta a guias, modelos e livros. Com isso objetiva-se disponibilizar um conjunto de conhecimento necessário a organizações que não possuem nenhum processo definido.

- Levantar um conjunto de práticas relativas a aspectos que devem estar presentes em uma organização durante a execução do programa de melhoria de processos; 
- Prover uma abordagem sistemática para a condução do programa de melhoria de processos;

- Prover um método de avaliação para medir a efetividade do programa de melhoria.

\subsection{ORGANIZAÇÃO DA DISSERTAÇÃO}

A monografia está organizada da seguinte forma. No Capítulo 2 é apresentado o referencial teórico para o trabalho, contendo a fundamentação referente ao desenvolvimento e gerenciamento de requisitos presentes em diversas normas, guias, livros e artigos, e que serviram de base para a elaboração da proposta. No Capítulo 3 descreve-se o guia PROREQ que é a principal contribuição deste trabalho. No capítulo 4 descreve-se um estudo de caso de utilização do guia em uma organização desenvolvedora de software brasileira. No capitulo 5 apresenta-se conclusões e trabalhos futuros. 


\section{CAPÍTULO 2 REVISÃo BIBLIOGRÁFICA}

\subsection{CONSIDERAÇÕES INICIAIS}

Com o aumento da complexidade dos sistemas de software, tem sido desenvolvidos modelos de referência cujo intuito é aprimorar o trabalho das organizações e possibilitar que elas entreguem produtos de qualidade e mantenham controle sobre seus custos, prazos e sobre a expectativa de seus clientes, por meio da melhoria de seus processos de produção de software.

O objetivo deste capítulo é apresentar os principais referenciais teóricos para a elaboração do guia PROREQ, de modo a facilitar o entendimento da proposta do guia descrito nesta dissertação. Deste modo, são apresentadas as referências para o levantamento de práticas de requisitos que são: o Capability Matutity Model Integration Development (CMMI-Dev), a norma ISO/IEC 12207, os guias Software Engineering Body Of Knowledge (SWEBOK) e Project Management Body Of Knowledge (PMBOK), os livros Requirements Engineering - A Good Practice Guide (RE-GPG) e Requirements Engineering - Process and Techniques.

São apresentados os conceitos referentes ao modelo de avaliação, ao framework de medidas e a estratégia de implantação de melhorias da norma ISO/IEC 15504. 
Apresenta-se ainda, de forma breve, o modelo MPS.BR do qual se utilizou alguns conceitos para a elaboração do modelo de avaliação do PROREQ.

Ao final do capítulo, são apresentados os trabalhos empíricos que descrevem aspectos que influenciam o sucesso de um programa de melhoria de processo de software e que foram utilizados para a adaptação de uma estratégia de melhoria para o guia.

\subsection{CMMI® FOR DEVELOPMENT, VERSION 1.2 (CMMI-DEV)}

O CMMI-DEV é um conjunto de modelos integrados que representam uma abordagem de melhoria de processos, servindo de guia para a melhoria dos processos de empresas desenvolvedoras de software, por meio de um conjunto estruturado de práticas que descrevem características de processos efetivos (SEI, 2006)

Está dividido em duas arquiteturas denominadas “contínua” e “estagiada”. Ambas as arquiteturas encontram-se divididas em áreas de processos. No entanto, a arquitetura estagiada define quais áreas de processo devem ser melhoradas, enquanto a arquitetura contínua oferece o máximo de flexibilidade, ou seja, a organização pode escolher quais áreas de processo deve utilizar conforme as suas necessidades estratégicas e de negócio.

Cada arquitetura utiliza um tipo de nível para descrever o caminho evolucionário que deve ser seguido por uma organização que deseja melhorar seus processos de desenvolvimento e manutenção de software. A arquitetura contínua utiliza níveis de capacidade e a arquitetura em estágios utiliza níveis de maturidade. Assim, os níveis de capacidade medem a melhoria de áreas de processos individuais enquanto que os níveis de maturidade medem a melhoria de múltiplas áreas de processo (SEI, 2006).

Uma área de processo é um conjunto de práticas de uma determinada área que, quando implementadas coletivamente, devem satisfazer um conjunto de objetivos considerados importantes para a melhoria do processo naquela área (SEI, 2006). Assim, uma área de processo está dividida em objetivos específicos e objetivos genéricos. Os objetivos específicos são atendidos pela execução das suas práticas específicas e respectivas subpráticas. Já os objetivos genéricos são atendidos pela execução das suas práticas genéricas e respectivas subpráticas, conforme exemplificado na Figura 2. 


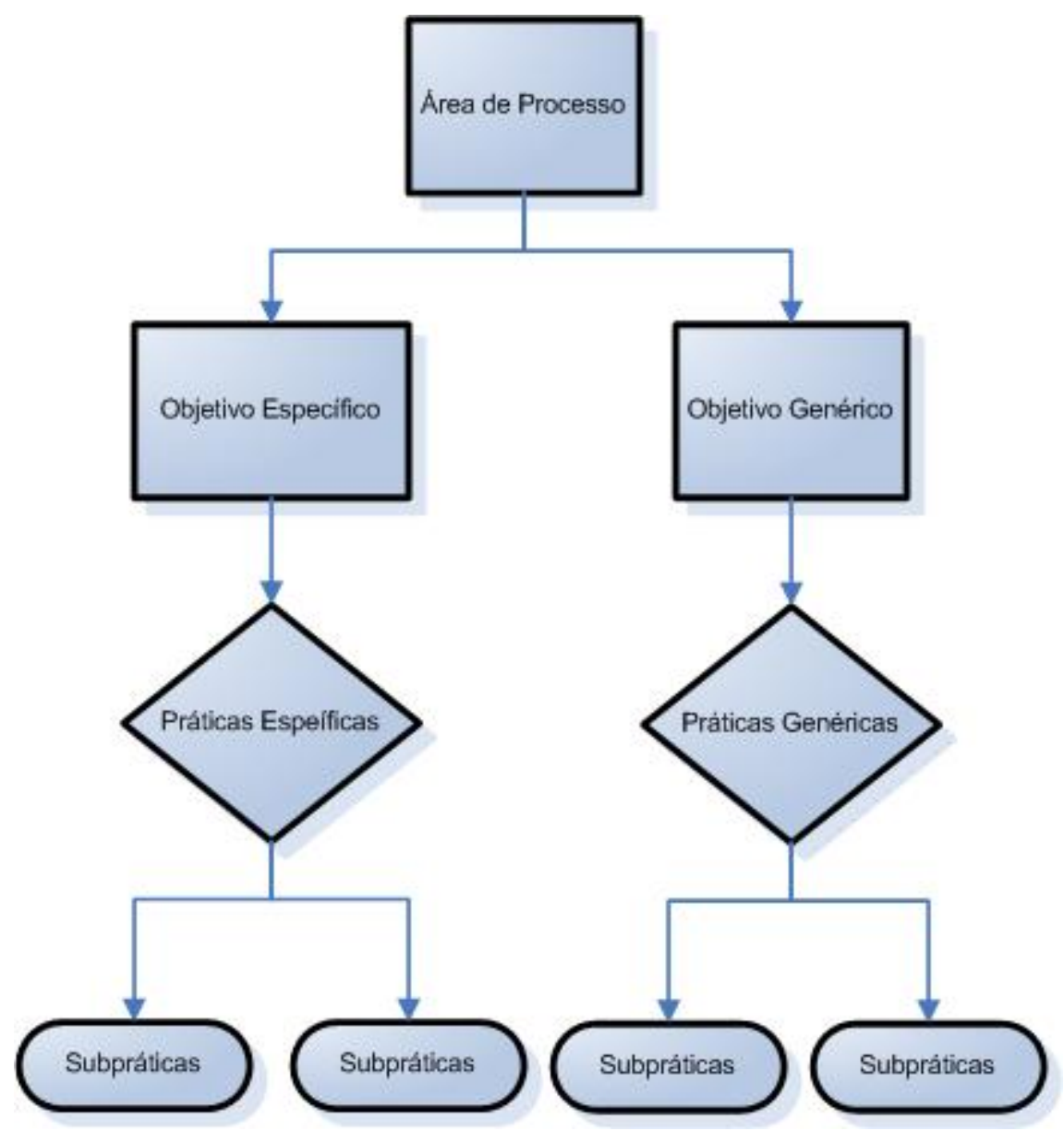

Figura 2 - Estrutura de organização de área de processo do CMMI-Dev

Esse trabalho utiliza especificamente as áreas de processo do CMMI-Dev relacionadas a requisitos, que são Desenvolvimento e Gerenciamento de Requisitos. O foco desse trabalho é o atendimento aos objetivos específicos e genéricos das áreas de processo citadas.

\subsubsection{Desenvolvimento de Requisitos}

Esta área de processo preocupa-se em analisar e produzir três tipos de requisitos que são: requisitos do cliente, do produto e dos componentes do produto, de modo que tomados juntos, eles possam descrever necessidades importantes dos stakeholders, referentes a diferentes fases do ciclo de vida do produto, bem como de atributos do 
produto, tais como usabilidade, manutenibilidade, etc. Para isso são propostas atividades de elicitação, análise, validação e comunicação de necessidades, expectativas e restrições do cliente de modo que se possa obter um entendimento dos fatores de sucesso que o satisfarão.

A área de processo de Desenvolvimento de Requisitos possui três objetivos específicos. O objetivo específico Desenvolver Requisitos do Cliente visa definir um conjunto de requisitos que será utilizado para definir os requisitos do produto. O objetivo específico Desenvolver Requisitos do Produto visa definir os requisitos do produto e de seus componentes para serem usados durante o projeto. O objetivo específico Analisar e Validar Requisitos visa analisar os requisitos do cliente, do produto e dos componentes do produto para definir, derivar e entender os requisitos.

Esta área de processo possui um objetivo genérico para o nível 1 de capacidade que é “Atingir os objetivos específicos”.

\subsubsection{Gerenciamento de Requisitos}

O objetivo dessa área de processo é gerenciar os requisitos dos produtos e dos componentes dos produtos do projeto e garantir consistência entre eles com relação aos planos e produtos de trabalho do projeto. Desta forma, a área de processo constitui-se de um conjunto de atividades que visa assegurar que um conjunto de requisitos acordado com os stakeholders seja gerenciado para apoiar o planejamento e execução das necessidades do projeto.

Quando um requisito é alterado ou um novo requisito é recebido, ele é revisado para resolver problemas e evitar mal entendidos, antes que seja incorporado ao projeto. No caso de uma solicitação de mudança de requisito, é realizado um conjunto de atividades para documentar as mudanças e os raciocínios que levaram a elas e manter a rastreabilidade dos requisitos com relação a suas fontes e aos produtos e componentes dos produtos dos requisitos.

Assim, conforme os requisitos evoluem, as mudanças no conjunto de requisitos são gerenciadas e as inconsistências entre estes e os produtos e planos de trabalho são identificadas. 
A área de processo Gerenciamento de Requisitos possui um objetivo específico denominado Gerenciar Requisitos e um objetivo genérico para o nível 1 de capacidade, que é "Atingir os objetivos específicos”.

\subsection{SEWBOK - SOFTWARE ENGINEERING BODY OF KNOWLEDGE}

O projeto SWEBOK (SWEBOK, 2004) foi iniciado em 1998 como parte de um esforço conjunto entre o IEEE Computer Society e a ACM - Association for Computer Machinery, por um comitê denominado SWECC - Software Engineering Coordinating Committee, para profissionalização da Engenharia de Software. Tem como objetivos prover uma visão consistente da engenharia de software, esclarecer o lugar e os limites da engenharia de software com relação a disciplinas tais como ciência da computação ou gerenciamento de projetos, caracterizar os interesses da disciplina, prover um acesso organizado por tópicos ao corpo de conhecimento da disciplina e prover a base para o desenvolvimento de currículos, certificações individuais e material de licenciamento.

É dividido em dez áreas de conhecimento e um capítulo adicional que provê uma visão geral das áreas de conhecimento por disciplina. A descrição das áreas de conhecimento utiliza uma organização hierárquica para facilitar a busca por tópicos de interesse, ou seja, são divididas em conjuntos de tópicos de interesse que são nomeados de maneira compatível com a nomenclatura encontrada na indústria, na literatura de engenharia de software e nos padrões. O guia utiliza o princípio do "conhecimento geralmente aceito" para distinguir o seu conteúdo do conhecimento especializado e do conhecimento avançado e de pesquisa. Tal princípio foi utilizado pelo PMI - Project Management Institute ${ }^{4}$, para a confecção do PMBOK - Project Management Body of Knowledge (PMBOK, 2004), que afirma que "o conhecimento geralmente aceito são as práticas tradicionais estabelecidas que são recomendadas pela maioria das organizações”.

As áreas de conhecimento que compõem o guia são: Capítulo 2 - Requisitos de software, Capítulo 3 - Projeto de software, Capítulo 4 - Codificação de software, Capítulo 5 - Teste de software, Capítulo 6 - Manutenção de software, Capítulo 7 -

\footnotetext{
${ }^{4}$ http://www.pmi.org
} 
Gerenciamento de configuração de software, Capítulo 8 - Gerenciamento de engenharia de software, Capítulo 9 - Processo de engenharia de software, Capítulo 10 - Métodos e ferramentas de engenharia de software e Capítulo 11 - Qualidade de software.

O presente trabalho utilizou os conceitos contidos na área de conhecimento Requisitos de Software, que tem interesse em todas as atividades relacionadas ao processo de gestão de requisitos. Ela encontra-se dividida em seis tópicos:

- Fundamentos dos requisitos;

- Processos de Gestão;

- Elicitação de requisitos;

- Análise de Requisitos;

- Especificação de Requisitos;

- Validação de requisitos.

\subsection{PMBOK - PROJECT MANAGEMENT BODY OF KNOWLEDGE}

O guia PMBOK (Project Management Body of Knowledge) - Corpo do Conhecimento do Gerenciamento de Projetos (PMBOK, 2004), criado pelo PMI (Project Management Institute), tem o objetivo de identificar e descrever o conjunto de boas práticas da disciplina de gerenciamento de projetos que podem ser consideradas amplamente reconhecidas como tais. Define-se que as boas práticas amplamente reconhecidas são aquelas que são utilizadas na maior parte dos projetos e na maior parte do tempo, existindo consenso sobre o fato de que a utilização de tais conhecimentos certamente aumentará as chances de sucesso dos projetos que as utilizarem (PMBOK, 2004).

Um projeto é definido como sendo o esforço temporário empreendido para criar um produto, serviço ou resultado exclusivo (PMBOK, 2004). Um projeto é temporário por que tem um início e fim bem definidos. É exclusivo por que a presença de elementos repetitivos não faz dele um elemento idêntico, ou seja, pode apresentar patrocinadores, executores e localidades de execução diferentes, entre outros aspectos, para a construção de um mesmo produto. Outra característica importante referente aos projetos é a elaboração progressiva, que significa desenvolver em etapas ou fases e continuar por 
incrementos. Por exemplo, o escopo do projeto inicialmente é definido em alto nível e conforme a equipe de projeto vai adquirindo mais informações sobre o mesmo, ele vai sendo refinado. Os projetos podem ser realizados em qualquer nível da organização e podem envolver uma única pessoa ou muitas delas.

Para que um projeto atenda os seus requisitos é necessário que seja gerenciado corretamente. O gerenciamento de projetos é a aplicação de conhecimentos, habilidades, ferramentas e técnicas as atividades do projeto (PMBOK, 2004). Está dividido em cinco grupos de processo que devem ser aplicados e integrados. São eles: os processos de iniciação, planejamento, execução, monitoramento e controle e encerramento.

O gerenciamento de projetos deve trabalhar com a chamada restrição tripla que se fundamenta nas variáveis, escopo, custo e prazo, para gerenciar as necessidades conflitantes dos projetos (PMBOK, 2004). Um projeto de alta qualidade entrega o produto ou serviço requisitado dentro do escopo, no prazo e dentro do orçamento. Tais variáveis relacionam-se de forma que se uma delas muda, há grande probabilidade de outra também se alterar.

O conjunto de conhecimentos referentes ao gerenciamento de projetos que está contido no guia PMBOK inclui a definição do ciclo de vida e organização do projeto, os cinco grupos de processo do gerenciamento de projetos e as nove áreas de conhecimento que são:

- Gerenciamento de Integração do Projeto: Descreve os elementos e atividades que integram o gerenciamento de projetos. Contém os seguintes processos: Desenvolver o termo de abertura do projeto, Desenvolver a declaração do escopo preliminar do projeto, Desenvolver o plano de gerenciamento do projeto, Orientar e gerenciar a execução do projeto, Monitorar e Controlar o trabalho do projeto, Controle Integrado de mudanças e Encerrar o projeto.

- Gerenciamento de Escopo do projeto: Visa garantir que o projeto inclui somente o trabalho necessário para o atendimento dos requisitos estabelecidos para o sucesso do projeto. Contém os seguintes processos: Planejamento do escopo, Definição de Escopo, Criação EAP (Estrutura Analítica de Projetos), Verificação do Escopo e Controle do Escopo. 
- Gerenciamento de tempo do projeto: Descreve os processos que têm por objetivo final garantir que o projeto termine no prazo correto. Contém os seguintes processos: Definição da Atividade, Sequenciamento da Atividade, Estimativa de Recursos da Atividade, Estimativa de Duração da Atividade, Desenvolvimento do Cronograma e Controle do Cronograma.

- Gerenciamento de Custos do projeto: Descreve os processos que têm por objetivo final garantir que o projeto termine dentro do orçamento aprovado. Contém os seguintes processos: Estimativa de Custos, Orçamentação e Controle de Custos.

- Gerenciamento da qualidade do projeto: Descreve os processos que têm por objetivo final garantir que o projeto vai atingir os seus objetivos. Contém os seguintes processos: Planejamento da qualidade, Realizar garantia da qualidade e Controle da Qualidade.

- Gerenciamento de recursos humanos do projeto: Descreve os processos que organizam e gerenciam a equipe do projeto. Contém os seguintes processos: Planejamento de Recursos humanos, Contratar ou mobilizar a equipe do projeto, Desenvolver a equipe do projeto e Gerenciar a equipe do projeto.

- Gerenciamento de Comunicações do projeto: Descreve os processos que tratam da gestão oportuna e adequada das informações do projeto. Contém os seguintes processos: Planejamento das comunicações, Distribuição das informações, Relatório de desempenho e Gerenciamento das partes interessadas.

- Gerenciamento de riscos do projeto: Descreve os processos que tratam do gerenciamento dos riscos do projeto. Contém os seguintes processos: Planejamento do gerenciamento de riscos, Identificação dos riscos, Análise qualitativa dos riscos, Análise quantitativa dos riscos, Planejamento de resposta a riscos e Monitoramento e Controle de Riscos.

- Gerenciamento de aquisições do projeto: Descreve os processos que gerenciam as aquisições e contratos do projeto. Contém os seguintes processos: Planejar compras e aquisições, Planejar contratações, Solicitar respostas de fornecedores, Selecionar fornecedores, Administração de contrato e Encerramento de Contrato. 
O presente trabalho visa o levantamento de práticas que orientem o planejamento do programa de melhoria proposto pelo PROREQ e dos processos de requisitos eventualmente instanciados.

\subsection{MELHORIA DE PROCESSO DE SOFTWARE BRASILEIRO - MPS.BR VERSÃO}

1.1

Até o ano de 2003, por meio da análise de dados da Secretaria de Política de Informática e Tecnologia do Ministério da Ciência e Tecnologia (MCT/SEITEC), podese constatar que a maioria das empresas brasileiras com certificação SW-CMM ou eram empresas exportadoras de software ou eram empresas de grande porte (MPS.BR, 2006).

No contexto das pequenas e médias empresas nacionais, a adequação a modelos de qualidade internacionais tais como o CMMI ou a ISO/IEC 15504 é praticamente inviável, devido aos custos de implantação e certificação (MPS.BR, 2006).

Com essa preocupação, considerando principalmente o contexto das empresas fornecedoras de software brasileiras, em dezembro de 2003 a sociedade SOFTEX Associação para Promoção da Excelência do Software Brasileiro criou o projeto MPS.BR - Melhoria de Processo de Software Brasileiro (MPS.BR, 2006). Tal modelo é compatível com o CMMI, com a ISO/IEC 15504 e com a ISO/IEC 12207. Ele está dividido em sete níveis de maturidade: A (Em Otimização), B (Gerenciado Quantitativamente), C (Definido), D (Largamente Definido), E (Parcialmente Definido), F (Gerenciado) e G (Parcialmente Gerenciado). Utiliza a representação em estágios do CMMI para melhoria de processo de software.

O guia é composto por um conjunto de documentos que são:

- O Guia Geral;

- O Guia de Implementação;

- O Guia de Aquisição;

- O Guia de Avaliação.

O guia geral apresenta uma visão geral do modelo de referência (MR-MPS) e dos demais guias do modelo. Nele são apresentados todos os processos que compõem o modelo de referência em termos de propósitos e resultados esperados. 
Já o guia de implementação fornece orientações para apoiar a implementação nas organizações dos níveis de maturidade, detalhando os processos e seus resultados esperados (MR-MPS, 2006).

No guia de avaliação estão descritos o método de avaliação MA-MPS e o processo de avaliação do modelo. O propósito do método de avaliação é verificar a maturidade de uma unidade organizacional na execução de seus processos de software (MA-MPS, 2006). O processo de avaliação descreve o conjunto de atividades necessárias para se atingir a este propósito e está dividido em quatro subprocessos, que são:

- Contratar avaliação;

- Planejar a realização da avaliação;

- Realizar a avaliação;

- Documentar os resultados da avaliação;

Cada um dos subprocessos do processo de avaliação é composto por um conjunto de macro atividades que são compostas por um conjunto de atividades. Desta forma, o processo é suficientemente detalhado para possibilitar a avaliação.

O presente trabalho utiliza conceitos do método de avaliação. São utilizados os seguintes conceitos:

1. Indicadores de atributos de processo utilizados pelo mps.Br:

- Indicadores diretos: são o objetivo de uma atividade, ou seja, o produto principal da realização de uma atividade.

- Indicadores Indiretos: são utilizados para confirmar que a organização tem condições de implementar um resultado.

- Afirmações: são obtidas em entrevistas e/ou apresentações e confirmam a implementação do processo, seus resultados e atributos.

2. Escala para a caracterização do grau de implementação de um resultado esperado na execução de um processo. Tal escala está representada no Quadro 1 e foi adaptada para ser utilizada pelo PROREQ conforme descrito na seção 3.3.6, Quadro 27. 


\begin{tabular}{|c|c|}
\hline Grau de implementação & Caracterização \\
\hline Totalmente implementado (T) & $\begin{array}{l}\text { - O produto de trabalho está presente e é julgado } \\
\text { adequado } \\
\text { - } \quad \begin{array}{l}\text { Existe o template (gabarito) do produto de } \\
\text { trabalho confirmando a implementação }\end{array} \\
\text { - } \quad \text { Não foi notado nenhum ponto fraco substancial }\end{array}$ \\
\hline Largamente implementado (L) & $\begin{array}{l}\text { - O produto de trabalho está presente e é julgado } \\
\text { adequado } \\
\text { - } \quad \begin{array}{l}\text { Existe o template (gabarito) do produto de } \\
\text { trabalho confirmando a implementação }\end{array} \\
\text { - } \quad \begin{array}{l}\text { Foi notado um ou mais pontos fracos } \\
\text { substanciais }\end{array}\end{array}$ \\
\hline Parcialmente implementado (P) & $\begin{array}{l}\text { - } \quad \text { O produto de trabalho não está presente ou é } \\
\text { julgado inadequado } \\
\text { - } \quad \text { Artefatos/afirmações sugerem que alguns } \\
\text { aspectos do resultado esperado estão } \\
\text { implementados } \\
\text { - } \quad \text { Pontos fracos foram documentados } \\
\end{array}$ \\
\hline Não implementado(N) & - $\quad$ Qualquer situação diferente das acima \\
\hline Não avaliado (NA) & $\begin{array}{l}\text { - } \begin{array}{l}\text { O projeto não está na fase de desenvolvimento } \\
\text { que permite atender ao resultado ou não faz } \\
\text { parte do escopo do projeto atender ao resultado }\end{array} \\
\end{array}$ \\
\hline Fora do escopo (F) & $\begin{array}{l}\text { O resultado esperado está fora do escopo da } \\
\text { avaliação, conforme documentado no plano da } \\
\text { avaliação. }\end{array}$ \\
\hline
\end{tabular}

Quadro 1 - Regras para caracterização do grau de implementação de um resultado esperado

\subsection{REQUIREMENTS ENGINEERING - A GOOD PRACTICE GUIDE - RE-GPG}

O livro "Engenharia de Requisitos - Um Guia de boas práticas", neste trabalho referido por RE-GPG (SOMMERVILLE \& SAWYER, 1997) é o resultado de um projeto denominado REAIM - Requirements Engineering Adapation and Improvement for safety and dependability ${ }^{5}$, cujo objetivo é desenvolver um framework para melhoria e avaliação dos processos de requisitos no contexto industrial. O RE-GPG contém um conjunto de aproximadamente 50 boas práticas recomendadas para um processo de requisitos. Tais práticas são seguidas de descrições sobre o que significam, por que são úteis, indicações de como podem ser implementadas, possíveis problemas encontrados na implementação, seus custos de implementação, além das classificações referentes aos:

- Custos de introdução: que podem ser Muito Baixo, Baixo, Baixo-moderado, Moderado, Moderado-Alto, Alto ou Bastante Alto.

\footnotetext{
${ }^{5}$ http://www.comp.lancs.ac.uk/computing/research/cseg/projects/reaims/
} 
- Custos de Aplicação: que podem ser Muito Baixo, Baixo, Baixo-moderado, Moderado, Moderado-Alto, Alto ou Bastante Alto.

- Níveis de dificuldade: que podem ser Básica, Básica-intermediária, Intermediária, Intermediária-avançada e Avançada.

\subsection{REQUIREMENTS ENGINEERING - PROCESS AND TECHNIQUES}

O livro "Engenharia de Requisitos - Processos e Técnicas”, neste trabalho referido por RE-PROTEC (KOTONYA \& SOMMERVILLE, 1998) está dividido em duas partes: a primeira parte trata de aspectos orientados a processos e descrevem diferentes atividades dos processos de engenharia e gerenciamento de requisitos. A segunda parte tem o foco em técnicas específicas aplicadas na engenharia e gerenciamento de requisitos. O presente trabalho considera a primeira parte do livro. Nela são apresentados conceitos referentes a modelos de processos, atores do processo, processos de apoio e melhoria do processo, bem como conceitos das atividades de elicitação e análise, validação e gerenciamento de requisitos.

\subsection{A NORMA ISO/IEC 12207}

A norma ISO/IEC 12207 provê um conjunto de processos de engenharia de software que uma organização deve utilizar para adquirir, fornecer, desenvolver ou manter software, ou seja, ela documenta os processos do ciclo de vida de software em um modelo de referência de processos (ISO-A1, 2001; ISO-A1, 2001).

Dentro desse modelo de referência os processos estão agrupados em categorias de processos segundo as atividades realizadas em cada processo. Desta forma, a norma encontra-se dividida em quatro categorias de processo que são: a categoria de processos organizacionais, a categoria de processos fundamentais e a categoria de processos de apoio.

A categoria de processos organizacionais é composta pelos processos que são empregados para estabelecer e implementar processos na organização, com o objetivo de melhorá-la. São empregados fora do domínio de projetos, ou seja, devem ser aplicados ao 
nível de organização como um todo e não somente a projetos pontuais da organização, portanto, existem na ausência de projetos. É composta pelos processos de gerência, de infra-estrutura, de melhoria, de recursos humanos, de gestão de ativos, de gestão de programa de reuso e de engenharia de domínio.

A categoria de processos fundamentais apresenta os processos que a organização precisa executar para que os serviços de desenvolvimento, manutenção e operação do software sejam executados. Tais processos iniciam o ciclo de vida e comandam a execução de todos os outros. São compostos pelos processos de aquisição, fornecimento, desenvolvimento, operação e manutenção.

A categoria de processos de apoio apresenta os processos utilizados por outros processos, com o intuito de contribuir para o sucesso e qualidade dos mesmos. Seus processos podem ser executados por processos fundamentais, organizacionais e até mesmo processos de apoio, mas não são responsáveis pela produção de produtos finais de trabalho. São compostos pelos processos de documentação, gerência de configuração, garantia da qualidade, verificação, validação, revisão conjunta, auditoria, resolução de problemas e usabilidade.

\subsection{A NORMA ISO/IEC 15504}

A ISO/IEC 15504 tem o objetivo de prover uma abordagem estruturada para a avaliação de processos nos contextos de melhoria de processo e determinação de capacidade de processo (ISO/IEC 15504-1, 2003). É composta na forma de um framework de avaliação de processos e possibilita, entre outras coisas, a avaliação de processos de organizações de qualquer tamanho e domínio de aplicação, a classificação dos processos por meio de notas, a visibilidade de pontos fortes e fracos dos processos, além de prover um benchmark objetivo para comparação entre os processos de organizações distintas ou de áreas ou departamentos de uma mesma organização. Com base na análise dos dados de uma avaliação, as organizações obtêm uma visão do estado dos seus processos e da sua capacidade para atender ou não a um determinado cliente. $\mathrm{O}$ diagnóstico dos estados dos processos motiva o desenvolvimento de uma cultura de melhoria contínua. Para manter e apoiar tal cultura, a organização estabelece políticas e 
procedimentos organizacionais que guiam a engenharia de seus processos, a qual gera como resultados a otimização de seus recursos e o atendimento de seus requisitos de negócio.

A norma também pode ser usada por adquirentes que desejam reduzir os riscos inerentes à seleção de seus fornecedores, isto é, para avaliar a capacidade de atendimento dos fornecedores antes de contratá-los para o desenvolvimento de algum projeto.

Pelo fato de prover uma abordagem padronizada para avaliação de processos de qualquer organização, a norma agrega vantagens tais como: ser uma abordagem pública e compartilhada de avaliação de processos, conduzir a um entendimento comum sobre melhoria e determinação de capacidade de processo, e finalmente, ser regulada e controlada à luz da experiência.

Ela é composta por cinco partes, descritas a seguir:

- Parte 1 - Conceitos e Vocabulários: A Parte 1, Conceitos e Vocabulários, é de caráter informativo ${ }^{6}$ e contém um dicionário com todos os termos e conceitos que são utilizados no framework de avaliação (ISO-P1, 2003).

- Parte 2 - Execução de uma avaliação: Esta parte é normativa ${ }^{7}$ e direcionada para os avaliadores ou qualquer outro stakeholder, tal como o patrocinador da avaliação ou um desenvolvedor de método de avaliação. Seu objetivo é definir a base para o processo de avaliação (ISO-P2, 2003). Ela é descrita em maiores detalhes na seção 2.9.1, pois foi utilizada como fonte para a criação de partes do PROREQ.

- Parte 3 - Guia para executar uma avaliação: Esta parte serve de guia para orientar a interpretação dos requisitos mínimos para a execução de uma avaliação objetivando diminuir a subjetividade da interpretação da norma por meio de guias que descrevem em maiores detalhes a norma (ISO-P3, 2003).

- Parte 4 - Guia para usar no processo de melhoria e determinação da capacidade: Esta parte provê um guia de como utilizar os resultados de uma

\footnotetext{
${ }^{6}$ Informativo - parte do material que somente informa, ou seja, não estabelece obrigação de execução

${ }_{7}^{7}$ Normativa - que serve como regra que deve ser seguida para estar de acordo com os requisitos da norma
} 
avaliação de processo em um programa de melhoria ou determinação de capacidade de processo (ISO-P4, 2003). Ela é descrita em maiores detalhes na seção 2.9.2, porque foi utilizada como embasamento para a construção do guia.

- Parte 5 - Um exemplo de um modelo de avaliação baseado na ISO/IEC 12207: Esta parte apresenta um exemplo de modelo de avaliação de processo contendo exemplos de indicadores de avaliação (ISO-P5, 2003). Ela é descrita em maiores detalhes na seção 2.9.3, pois foi utilizada como embasamento para a construção do guia.

\subsubsection{Parte 2 - Execução de uma avaliação}

A Parte 2 - Execução de uma avaliação é normativa ${ }^{8}$ e direcionada para os avaliadores ou qualquer outro stakeholder, tal como o patrocinador da avaliação ou um desenvolvedor de método de avaliação. Seu objetivo é definir a base para o processo de avaliação, apresentando os requisitos mínimos que devem ser atendidos para assegurar que a avaliação é consistente e repetível, que as evidências levantadas sejam suficientes para embasar as classificações dos processos e comprovar o atendimento dos requisitos da avaliação (ISO-P2, 2003). Nessa parte da norma apresenta-se ainda, o framework de medidas, os requisitos para a execução da avaliação, os requisitos para o modelo de referência de processo e para o modelo de avaliação de processos, e os mecanismos para verificar a conformidade do processo de avaliação. A Figura 3 apresenta o arranjo dos elementos normativos desse padrão internacional.

\footnotetext{
${ }^{8}$ Normativa - que serve como regra que deve ser seguida para estar de acordo com os requisitos da norma
} 


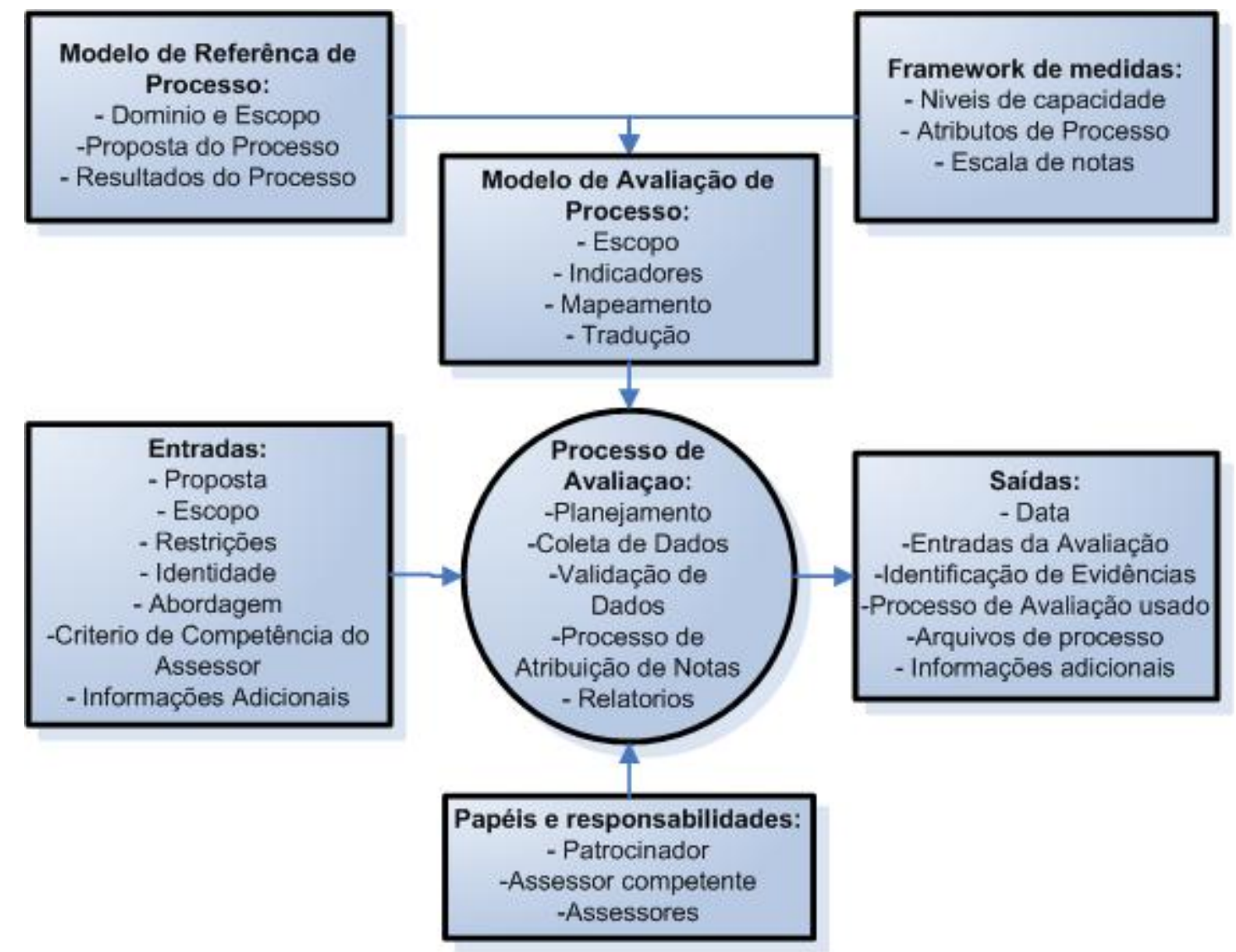

Figura 3 - Elementos normativos do padrão internacional (ISO/IEC 15504-2, 2003)

O "Framework de Medidas" (Figura 3) define os requisitos para a avaliação da capacidade de processo. A capacidade de processo é definida em uma escala que vai do nível 0 - Incompleto até o nível 5 - Em Otimização, sendo que o aumento na escala de níveis de capacidade indica melhora na capacidade dos processos implementados. A medida de capacidade de processo é baseada em conjuntos de atributos de processo, onde cada atributo de processo define características da capacidade do processo. Desta forma, atribui-se a cada um dos processos que serão avaliados, um grupo de atributos de processo. Verifica-se a extensão de atendimento de cada um dos atributos do grupo e, combinando tais informações, atribui-se à classificação do processo dentro de uma escala ordinal dos níveis de capacidade. 
Este trabalho visa atender somente o nível um de capacidade da escala de níveis da norma. Por isso, são apresentados somente os atributos de processo contidos nos níveis de capacidade zero e um. São eles:

- Nível 0 - Incompleto: Nesse nível o processo não está implementado e apresenta pouca ou nenhuma evidência de atendimento sistemático de sua proposta. Não atende a nenhum atributo de processo.

- Nível 1 - Processo Executado: Nesse nível o processo atende a sua proposta. O atendimento da proposta do processo é embasado pelo seguinte atributo de processo:

- PA 1.1 Atributo de execução de processo: Este atributo mede a extensão de atendimento da proposta do processo. O completo atendimento do atributo significa o atendimento dos resultados definidos para o processo, ou seja, o desenvolvimento de todos os produtos de trabalho que o processo deve produzir.

A extensão de atendimento de um atributo de processo é medida usando uma escala ordinal, expressa da seguinte forma:

- N - Não atendido: Há pouca ou nenhuma evidência de atendimento do atributo de processo definido no processo avaliado.

- P - Parcialmente atendido: Há alguma evidência de uma abordagem para o atendimento do atributo de processo definido, no processo avaliado.

- L - Largamente atendido: Há evidência de uma abordagem sistemática e um atendimento significativo do atributo de processo definido no processo avaliado. São relatadas algumas fraquezas no atributo de processo em questão.

- T - Totalmente atendido: Há evidências de uma abordagem completa e sistemática para um completo atendimento do atributo de processo definido no processo avaliado. Não há fraquezas relatadas para o atendimento do atributo.

Cada ponto da escala apresentada deve ser entendido em termos de percentuais, representando o nível de atendimento do atributo, conforme apresentado no Quadro 2. 


\begin{tabular}{|c|c|}
\hline Ponto na escala & Percentual de atendimento \\
\hline N - Não atendido & $0 \%$ até $15 \%$ \\
\hline P - Parcialmente atendido & $>15 \%$ até $50 \%$ \\
\hline L - Largamente atendido & $>50 \%$ até $85 \%$ \\
\hline T - Totalmente atendido & $>85 \%$ até $100 \%$ \\
\hline
\end{tabular}

Quadro 2 - Escala de atendimento de atributos de processo em percentual

Assim, a classificação dos atributos de processo necessária para que um processo atinja o nível de capacidade 1 pode ser observada no Quadro 3.

\begin{tabular}{|c|c|c|}
\hline Escala & Atributos de processo & Classificação \\
\hline Nível 1 & PA 1.1 Execução do Processo & Largamente ou Totalmente \\
& & Atendido \\
\hline
\end{tabular}

Quadro 3 - Classificação de níveis de capacidade abrangidos pelo trabalho

O "Modelo de Avaliação de Processo" representa a base para a coleção de evidências e para a classificação de capacidade de processos. Ele está dividido em duas dimensões, conhecidas como dimensão de processos e dimensão de capacidade. A dimensão de processos é representada por um ou mais modelos de referência de processos externos. A dimensão de capacidade é representada pelo framework de medidas da norma.

Além disso, o modelo de avaliação de processo deve conter uma declaração de propósito, escopo e elementos, bem como um mecanismo consistente de expressão dos resultados.

O "Processo de Avaliação” (Figura 3) deve ser conduzido segundo o documento de avaliação de processo, desenvolvido para atender ao propósito da avaliação. Esse documento deve consistir de um plano de avaliação contendo as entradas requeridas, as atividades a serem executadas durante a avaliação, os recursos e o cronograma atribuídos para essas atividades, a definição e a atribuição das responsabilidades para os participantes da avaliação, os critérios para verificar se os requisitos da norma foram atendidos pela avaliação e a descrição das saídas planejadas. O documento de avaliação deve conter ainda, critérios para coleta e avaliação de dados, assim como critérios para classificação dos atributos de processo e para documentar e relatar os resultados do processo de avaliação. 


\subsubsection{Parte 4 - Guia para usar no processo de melhoria contínua}

A Parte 4 - Guia para usar no processo de Melhoria Contínua, provê um guia de como utilizar os resultados de uma avaliação de processo em um programa de melhoria ou determinação de capacidade de processo (ISO-P4, 2003). Quando uma avaliação é utilizada como parte de um programa de melhoria de processo ela tem o propósito de caracterizar os processos de uma unidade organizacional em termos das suas respectivas capacidades. Desta forma, quando comparados os resultados da avaliação contra os objetivos de negócio da organização, identificam-se forças, fraquezas e riscos relacionados aos processos avaliados.

Para se realizar uma avaliação, o patrocinador deve selecionar um modelo de referência de processo, escolhendo em seguida quais processos do modelo selecionado são úteis aos objetivos da avaliação corrente. Outro aspecto importante para a realização da avaliação é a definição de uma capacidade-alvo para cada processo que será avaliado, ou seja, o patrocinador deve selecionar o processo, definir quais atributos de processo são necessários e quais as classificações para cada atributo selecionado. Isso é chamado de arquivo de processo e é ilustrado no Quadro 4.

\begin{tabular}{|c|c|c|}
\hline $\begin{array}{c}\text { Processo selecionado do modelo de } \\
\text { referência }\end{array}$ & $\begin{array}{c}\text { Atributos de } \\
\text { processo }\end{array}$ & $\begin{array}{c}\text { Classificação requerida do atributo de } \\
\text { processo }\end{array}$ \\
\hline \multirow{2}{*}{ F1.3.1 Elicitação de Requisitos } & PA 1.1 & Completamente Atendido \\
\cline { 2 - 3 } & PA 2.1, PA 2.2 & Largamente Atendido \\
\hline \multirow{2}{*}{ F2.2 Gerenciamento de Configuração } & PA 1.1, PA 2.1, PA & Completamente Atendido \\
\cline { 2 - 3 } & 2.2 & PA 3.1, PA 3.2 \\
\cline { 2 - 3 }
\end{tabular}

Quadro 4 -Arquivo de processo de capacidade alvo

No contexto de um programa de melhoria a norma sugere uma seqüência de passos para estruturar o trabalho. Tal seqüência pode ser observada na Figura 4. 


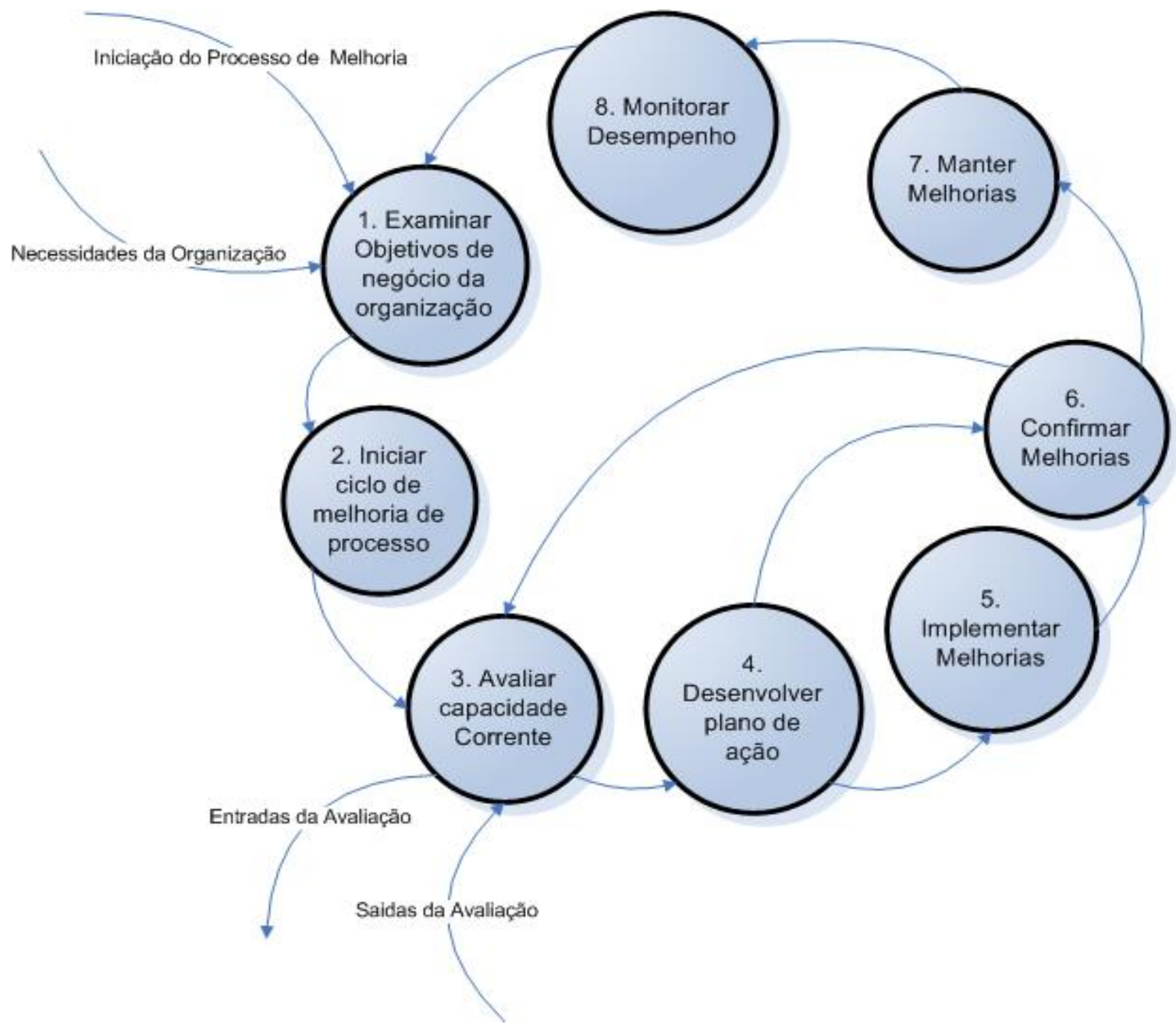

Figura 4 - Passos para um programa de melhoria de processo (ISO/IEC 15504-4, 2003)

O passo 1 consiste em uma análise dos objetivos de negócio da organização, para motivar o desenvolvimento dos objetivos do programa de melhoria. O passo 2 trata do planejamento e iniciação do programa e salienta que o processo de melhoria deve ser encarado como um projeto da organização, ou seja, com planejamento, monitoramento e controle de sua execução. O passo 3 é a realização da avaliação para identificar forças, fraquezas e riscos relacionados aos processos em questão. Dos resultados dessa avaliação segue-se o passo 4, que é a análise para identificação de áreas onde as melhorias podem ser aplicadas, entender melhor as forças e fraquezas identificadas, para definir oportunidades específicas de melhoria e então derivar o plano de ação. Feito o plano de ação, parte-se para o passo 5, que é a implementação das melhorias. O passo 6 é a confirmação das melhorias, ou seja, verificar os objetivos do programa contra o 
atendimento dos critérios de aceitação do plano de implementação para garantir que os objetivos foram atingidos e os benefícios foram conseguidos. O passo 7 consiste em assegurar que as melhorias implantadas são sustentáveis, isto é, monitorar a aplicação das melhorias por todas as partes da organização onde elas são aplicáveis e garantir que elas estão se mantendo na cultura organizacional. O passo 8 , último passo do ciclo, consiste em monitorar o desempenho dos processos organizacionais e, quando necessário, reiniciar o ciclo de melhoria.

\subsubsection{Parte 5 - Um exemplo de modelo de avaliação baseado na norma ISO/IEC 12207}

A Parte 5 - Um exemplo de modelo de avaliação baseado na ISO/IEC 12207 apresenta um exemplo de modelo de avaliação de processo contendo exemplos de indicadores de avaliação (ISO-P5, 2003). O modelo de avaliação é dividido em duas dimensões, a dimensão de processo e a dimensão de capacidade. A dimensão de processo, representada pelo modelo de referência de processo utilizado na composição deste modelo, está definida na norma ISO/IEC 12207 AMD1\&AMD2 (ISO/IEC 12207-1, 2001; ISO/IEC 12207-2, 2001). Já a dimensão de capacidade é representada pelos agrupamentos de atributos de processo definidos em níveis de capacidade.

O modelo de avaliação apresentado nesta parte segue os requisitos exigidos na parte 2 da norma. Como o modelo de referência de processo é derivado diretamente da ISO/IEC 12207 AMD1\&AMD2, ele atende aos requisitos exigidos. Logo, os processos deste modelo são agrupados em 3 categorias de processos que são a categoria de processos fundamentais, a dos processos organizacionais e a dos processos de apoio, conforme é feito na norma ISO/IEC 12207 AMD1\&AMD2. Os Quadros 5 e 6 apresentam um exemplo de como é estruturada a dimensão de processo do modelo. 


\begin{tabular}{|c|c|}
\hline ID do Processo & ENG.4 \\
\hline Nome do Processo & Análise dos requisitos de software \\
\hline Proposta do Processo & $\begin{array}{l}\text { A proposta do processo de Análise dos Requisitos de Software é } \\
\text { estabelecer os requisitos dos elementos de software do sistema. }\end{array}$ \\
\hline Resultados do Processo & $\begin{array}{l}\text { Como resultado de uma implementação de sucesso do processo de Análise } \\
\text { de Requisitos de Software tem-se: } \\
\text { 1) os requisitos alocados para os elementos de software do sistema e suas } \\
\text { interfaces são definidas. } \\
\text { 2) requisitos de software são analisados para garantir corretude e } \\
\text { testabilidade; }\end{array}$ \\
\hline Práticas Base & $\begin{array}{l}\text { ENG.4.BP1: Especificar requisitos de software. Definir, analisar e priorizar } \\
\text { requisitos funcionais e não funcionais dos elementos de software do } \\
\text { sistema e documentá-los em um documento de especificação de requisitos } \\
\text { de software. [Resultados: } 1,2,5 \text { ] [Tarefas: } 4.1 \text { ] } \\
\text { NOTA 1: Características de qualidade de software são descritas na norma } \\
\text { ISO/IEC 9126-1. } \\
\text { ENG.4.BP2: Determinar o impacto da operação do sistema no ambiente } \\
\text { operacional. Determinar as interfaces entre os requisitos de software e } \\
\text { outros elementos do ambiente operacional, e o impacto que os requisitos } \\
\text { terão. [Resultados: } 3 \text { ] } \\
\text { NOTA 2: O ambiente operacional inclui tarefas executadas, ou outros } \\
\text { sistemas usados pelos usuários do produto de software. }\end{array}$ \\
\hline
\end{tabular}

Quadro 5 - Exemplo de dimensão de processo

\begin{tabular}{|l|l|}
\hline \multicolumn{2}{|c|}{ Produtos de trabalho } \\
\hline \multicolumn{1}{|c|}{ Entradas } & \multicolumn{1}{|c|}{ Saídas } \\
\hline $\begin{array}{l}\text { 04-13 Projeto de arquitetura do Sistema [Resultado: } \\
\text { 1] }\end{array}$ & \\
\hline & $\begin{array}{l}\text { 07-02 Relatório de Controle de Mudança } \\
\text { [Resultado: 7] }\end{array}$ \\
\hline 07-03 Requisição de Mudança [Resultado: 6, 7] & \\
\hline 07-04 Requisição do cliente [Resultado: 6, 7] & \\
\hline & 16-04 Registro de Comunicação [Resultado: 8] \\
\hline
\end{tabular}

Quadro 6 - Exemplo de indicadores de avaliação 


\subsection{TRABALHOS EMPÍRICOS DA ÁREA DE MELHORIA DE PROCESSO DE REQUISITOS}

Nesta seção são apresentados os trabalhos empíricos que foram utilizados como fontes para o levantamento de práticas organizacionais. Os trabalhos aqui descritos apresentam resultados empíricos de programas de implantação de melhoria de processos de software em organizações espalhadas pelo mundo.

\subsubsection{An Empirical Study of Industrial Requirements Engineering Process Assessment and Improvement}

Este trabalho, realizado por Sommerville e Ransom (2005), descreve um estudo empírico na industria que visa à avaliação e melhoria dos processos de requisito por meio da utilização dos resultados do projeto REAIM. O modelo é implantado em 9 organizações desenvolvedoras de software que atuam nos mais diversos domínios de aplicação, tais como automação, aeroespacial, etc. O objetivo do trabalho é ajudar as organizações a melhorar seus processos e investigar se a melhoria no desempenho dos objetivos de negócio das organizações pode ser relacionado à melhoria dos processos de ER.

O passo inicial do trabalho foi avaliar as organizações segundo o modelo de avaliação proposto pelo RE-GPG. Nesta etapa foram identificadas as áreas fracas de cada organização e sugeridas melhorias. Depois de implementadas e utilizadas as melhorias em projetos das organizações, realizou-se uma avaliação final e constatou-se uma melhora no nível de maturidade de todas as organizações participantes do experimento.

Observou-se que algumas organizações utilizaram mais as práticas intermediárias e avançadas do que as básicas, sem perda de consistência no processo. Assim, concluiu-se que o modelo de categorização de práticas é arbitrário e que as organizações necessitam de um modelo de melhoria contínuo, ou seja, onde possam escolher livremente as práticas que desejarem utilizar. 
Outra conclusão importante deste trabalho é que quando se melhorou o nível de maturidade dos processos de ER, constatou-se uma melhoria nos indicadores de desempenho de negócios da organização.

\subsubsection{Implementing requirements engineering processes throughout organizations: success factors and challenges}

Este trabalho, realizado por Kauppinen et al. (2004), visa à identificação de fatores que afetam o sucesso de projetos de melhoria de processos de software em organizações desenvolvedoras. Consiste basicamente numa revisão da literatura referente ao assunto melhoria de processos de ER e melhoria de processos de software em geral e um estudo de caso realizado em 3 organizações de software da Finlândia. Para analisar o assunto “melhoria de processo de ER” foram utilizados oito artigos e dois livros. Para analisar o assunto melhoria de processos de software foram usados catorze artigos e três livros. Os estudos de caso das organizações finlandesas foram realizados utilizando a abordagem proposta pelo projeto REAIM para avaliação dos níveis de maturidade dos processos de ER e uma estratégia de melhoria desenvolvida especificamente para o projeto de pesquisa. Ao final, são comparados os resultados e listadas as lições aprendidas do trabalho. As práticas organizacionais retiradas deste trabalho são embasadas nas lições aprendidas.

\subsubsection{Software Process Improvement Problems in Twelve Software Companies: An} Empirical Analysis

Este trabalho, realizado por Beecham (2003) e outros, relata os problemas encontrados em doze programas de melhoria de processo de software de diferentes organizações desenvolvedoras utilizando o framework CMMI como base. Demonstrou-se que há uma relação entre o nível de maturidade das organizações e os padrões de problemas encontrados em cada nível. Neste sentido, os problemas foram classificados em organizacionais, de projeto e de ciclo de vida. Problemas organizacionais são representados por aspectos como gestão de mudanças, pessoas, comunicação, cultura, 
objetivos e política. Problemas de projeto são relativos a custos e estimativas, qualidade, prazos, ferramentas e tecnologias. Problemas de ciclo de vida são relativos a requisitos, projeto, codificação, teste e manutenção de software. Demonstrou-se que os problemas do tipo organizacionais são mais frequentes em organizações com níveis de maturidade a partir do nível três do CMMI e que os problemas de projeto e de ciclo de vida são mais frequentes nos níveis mais baixos de maturidade.

Foram encontrados resultados que demonstram também que diferentes grupos de colaboradores encontram diferentes tipos de problemas. Os gerentes seniores encontram problemas relativos a objetivos, política e cultura, enquanto os gerentes de projeto encontram outros tipos e os desenvolvedores um terceiro conjunto de diferentes problemas.

Por fim, foram apresentados resultados que indicam que a maioria dos problemas organizacionais são relativos a pessoas e à comunicação.

\subsubsection{Defining a Requirements Process Improvement Model}

Este trabalho, desenvolvido por Beecham (2005) e outros, relata a utilização de um modelo especializado em requisitos denominado R-CMM (Requirements Capability Maturity Model) em organizações desenvolvedoras de software. Tal modelo é embasado no modelo CMM e objetiva facilitar a implantação das áreas de processo chave denominadas Desenvolvimento e Gerenciamento de requisitos do modelo em organizações desenvolvedoras de software. Para isto, o R-CMM liga os processos de ER aos níveis de maturidade e os divide em subprocessos que devem ser definidos e avaliados.

Para a definição dos problemas tratados pelo modelo foram utilizados os resultados da pesquisa relatada na seção 2.10.3. Endereçando o tratamento desses problemas foram elaborados questionários utilizando o paradigma GQM - Goal Question Metric (BASILI \& ROMBACH,1988 apud BEECHAM et al., 2005). Assim, o processo de requisitos foi dividido em cinco subprocessos que são: gerenciamento de requisitos, elicitação, análise e negociação, documentação e validação de requisitos. Para cada um desses subprocessos foi associado um conjunto de questões relacionadas aos seus problemas, encontrados em 
cada nível de maturidade, ou seja, para o subprocesso gerenciamento de requisitos, por exemplo, há quatro conjuntos de questões que devem ser utilizadas para cada nível de maturidade que ele objetivar atingir.

\subsection{CONSIDERAÇÕES FINAIS}

Neste capítulo foram apresentados os guias e modelos de maturidade necessários para a realização do trabalho. Inicialmente apresentou-se o SWEBOK - Software Engineering Body of Knowledge, que tenta reunir todo o conhecimento largamente aplicado e conhecido na disciplina de engenharia de software.

Apresentou-se também um referencial sobre o CMMI-DEV, modelo de maturidade de processo criado pelo SEI - Software Engineering Institute, que tem o intuito de servir de guia para as empresas desenvolvedoras de software para melhorar os seus processos por meio de avaliações dos mesmos e melhoria contínua.

Em seguida, apresentou-se a norma ISO/IEC 15504, que normatiza os requisitos para a criação de um modelo de referência de processo, bem como para a avaliação de processos.

Foram apresentados dois livros que tratam especificamente os processos de requisitos. O RE-GPG - Requirements Engineering - A Good Practice Guide e o Requirements Engineering - Process and Techniques, que também serviram de base para o levantamento de práticas. Apresentou-se a estrutura ISO/IEC 12207 e ao final foram apresentados os trabalhos empíricos referentes à melhoria de processos de software em geral e melhoria de processos de requisitos. 


\section{CAPÍTULO 3 O GUIA PROREQ}

\subsection{CONSIDERAÇÕES INICIAIS}

Com o objetivo de facilitar a implantação dos processos de requisitos em uma organização desenvolvedora de software, buscou-se estudar os aspectos que influenciam um programa de melhoria de processo (SPI) e os principais guias para a melhoria. Com base nesses estudos, criou-se o guia PROREQ cujo objetivo é orientar o programa de melhoria dos processos de engenharia e gerenciamento de requisitos.

Na seção 3.2 é apresentada uma visão geral a respeito do problema que se busca resolver com o guia, na seção 3.3 é apresentada o guia PROREQ e seus componentes e na seção 3.4 são apresentadas as considerações finais do capítulo.

\subsection{PROBLEMA A SER RESOLVIDO}

Conforme mencionado anteriormente, os problemas de requisitos causam grandes prejuízos as empresas desenvolvedoras de software. Muitas dessas empresas demonstram interesse em melhorar seus processos de ER por que acreditam que esse processo pode ser a chave para o desenvolvimento de produtos de sucesso (KAUPPINEN et al, 2004). No entanto, alguns autores (WIEGER ,1999 apud KAUPPINEN et al, 2004) dizem que 
melhorar os processos de ER de uma organização não é uma tarefa trivial e que abordagens de melhoria não estruturadas levam a uma melhoria que não se sustenta.

Assim, autores apontam como um grande problema para um programa de melhoria de processos o fato de que as organizações freqüentemente sabem o que deve ser implementado, graças aos modelos existentes como o CMMI-Dev, ISO/IEC 12207, entre outros, mas não sabem como implementar tais atividades (NIAZI et al, 2004). O aspecto “como implementar”, pode ser dividido em dois, sendo uma parte relacionada à implantação das práticas contidas nos modelos de melhoria e outra referente à estratégia de implantação. O objetivo deste guia é apoiar a implantação de melhorias nos processos de ER por meio de um conjunto de boas práticas retirados de guias, livros e trabalhos empíricos da área de requisitos e de melhoria de processo de software, bem como por meio de uma estratégia de implementação das mudanças e de um modelo de avaliação dos processos.

\subsection{COMPONENTES DO GUIA}

O guia contém práticas que devem ser utilizadas para a construção dos processos de ER e também práticas que devem ser utilizadas para a implementação das melhorias. Segundo Strauss e Corbin(1998 apud KAUPPINEN et al, 2004) agrupar conceitos em categorias é importante porque categorias tem o potencial de explicar e predizer sobre o fenômeno em estudo. Sendo assim, as práticas foram agrupadas em práticas fundamentais e práticas organizacionais, seguindo a estrutura de classificação da norma ISO/IEC 12007.

As práticas fundamentais são aquelas relacionadas aos aspectos técnicos do processo de requisitos, tais como, práticas de elicitação, de análise, etc. Elas foram retiradas do SWEBOK, PMBOK, REGPG, RE-PROTEC e ISO/IEC 12207 e foram organizadas segundo a estrutura do CMMI-Dev conforme apresentado na Figura 5. Como o CMMI-Dev é embasado nas melhores práticas derivadas de muitos anos de estudos empíricos (BEECHAM et al, 2005), as práticas fundamentais foram organizadas segundo sua estrutura com o objetivo de utilizar esse conhecimento acumulado como referência para a seleção e priorização das práticas fundamentais que uma empresa precisa para ter 
sucesso em seu programa de melhoria. Assim, o guia propõe que cada uma das práticas específicas e respectivas subpráticas devem ser consideradas no momento de escolher as práticas fundamentais.

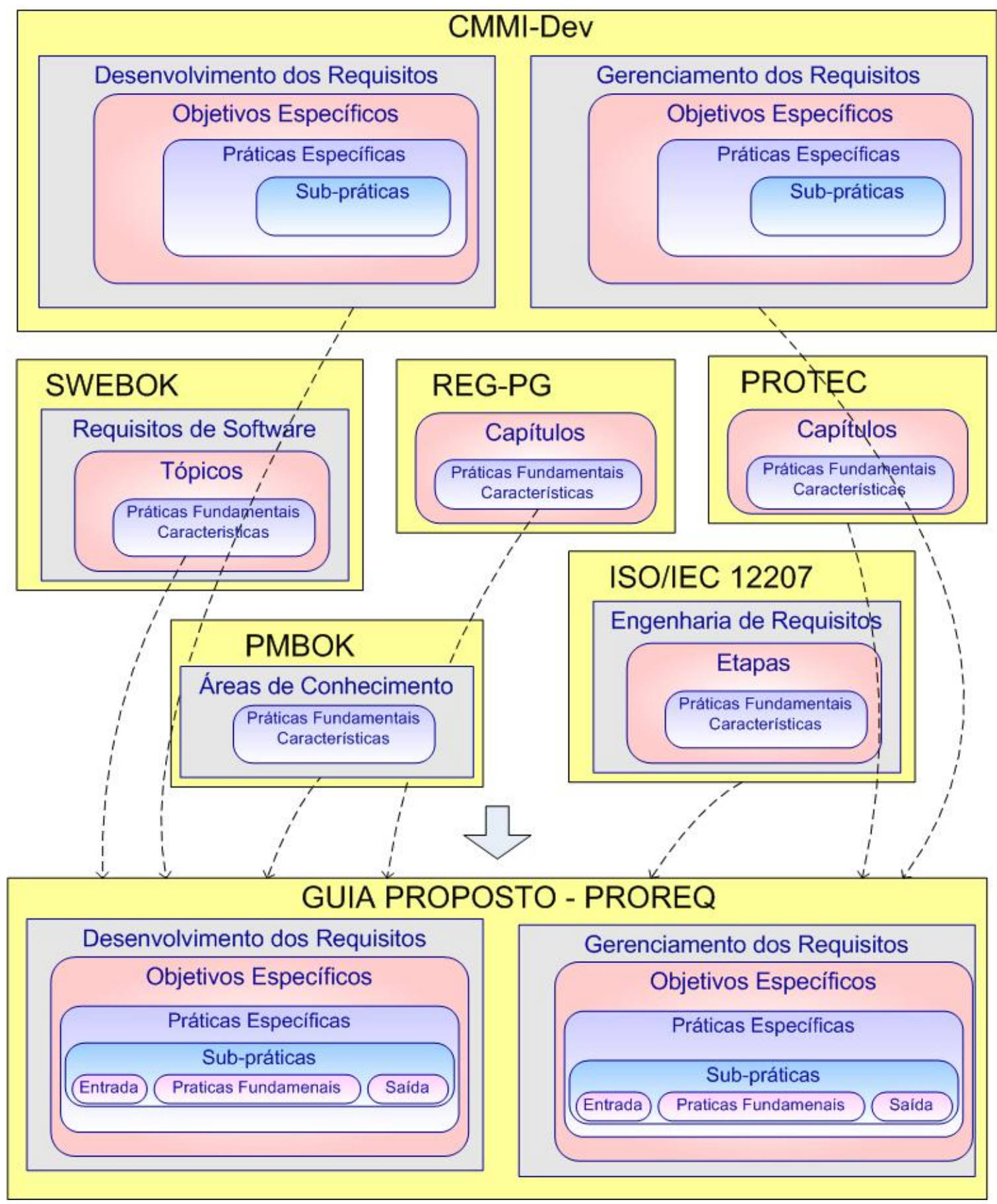

Figura 5 - Contribuição de cada modelo utilizado para o conjunto de práticas fundamentais 
Já as práticas organizacionais visam ao atendimento de fatores que devem existir na organização para que as práticas fundamentais sejam realmente utilizadas e para que se mantenham úteis e necessárias dentro da organização ao longo do tempo, como, por exemplo, o apoio da alta gerência ao projeto de melhoria dos processos.

Há ainda os resultados esperados de cada processo abrangido pelo guia e que foram coletados do guia MPS.BR. O objetivo destes resultados é guiar os usuários do PROREQ no momento de selecionar as práticas fundamentais que são necessárias para o sucesso de seu processo.

Outro aspecto relevante no processo de implementação das mudanças é a estratégia de implementação das melhorias. Sendo assim, foi elaborada uma estratégia de implementação das melhorias com base na estratégia proposta pela norma ISO/IEC 15504 e nas práticas organizacionais.

Foi elaborado também um modelo de avaliação simplificado, embasado no modelo de avaliação de processos proposto na norma ISO/IEC 15504 e no modelo de avaliação do MPS.BR.

Na Figura 6 estão representados todos os componentes do guia e os respectivos referenciais utilizados como embasamento para a construção de cada um deles.

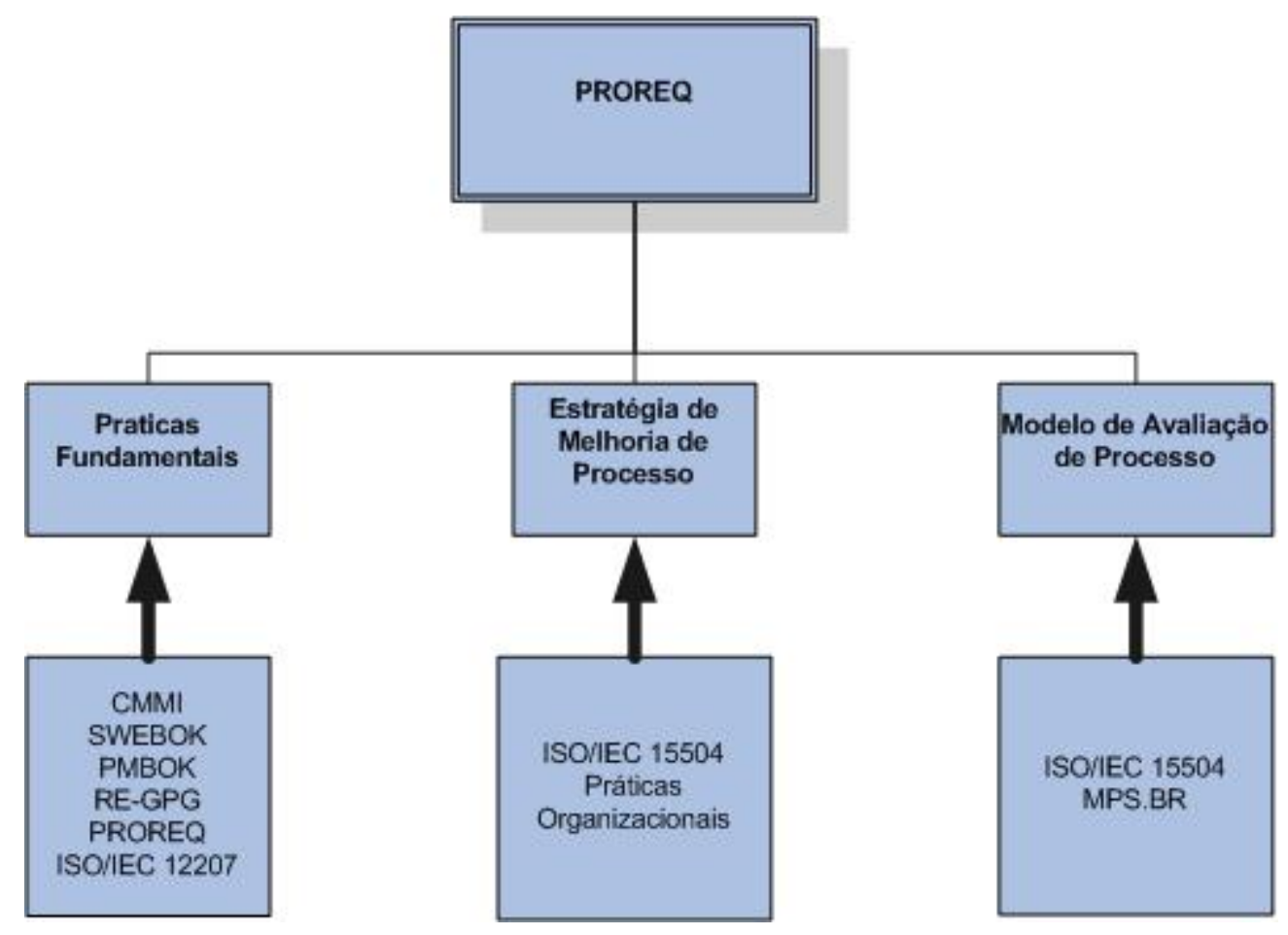

Figura 6 - Componentes do PROREQ e seus referenciais. 


\subsubsection{Práticas fundamentais}

As práticas fundamentais do PROREQ foram retiradas de um conjunto de guias e livros e têm o objetivo de tratar um dos aspectos referentes ao conhecimento necessário para a melhoria dos processos de uma organização. Estas práticas visam diminuir o nível de abstração das práticas propostas pelo CMMI-Dev por meio de descrições mais detalhadas de como se atender aos objetivos das áreas de processo de requisitos. A seguir são ilustrados os conceitos que foram utilizados de cada um dos referenciais citados.

\section{CMMI-Dev}

Do CMMI-Dev foram utilizados os conceitos de objetivos específicos, práticas específicas e as respectivas subpráticas das áreas de processo Desenvolvimento de Requisitos e Gerenciamento de Requisitos. A esses conceitos foi agregado mais um nível, denominado práticas fundamentais, conforme apresentado na Figura 7.

Desta forma, busca-se manter o CMMI-Dev como referência para a definição (seleção e priorização) de práticas do processo de requisitos, mas diminuir o nível de abstração do que deve ser feito para se executar suas práticas específicas e subpráticas e, com isso, atender aos objetivos específicos dos processos.

Por se tratar de um modelo para melhoria de processos de requisitos unicamente, o PROREQ tem por base a arquitetura contínua do modelo e desta forma, foram adotados os conceitos de objetivos genéricos e práticas genéricas para o nível um de capacidade de processos, descritos no Quadro 7.

\begin{tabular}{|l|l|l|}
\hline \multicolumn{1}{|c|}{ Objetivos Genéricos } & \multicolumn{1}{|c|}{ Práticas Genéricas } & \multicolumn{1}{c|}{ Subpráticas } \\
\hline $\begin{array}{l}\text { 1. Atingir os objetivos } \\
\text { específicos }\end{array}$ & $\begin{array}{l}\text { 1. O processo apóia e habilita o } \\
\text { atendimento dos objetivos } \\
\text { específicos da área de processo } \\
\text { por meio da transformação de } \\
\text { produtos de entrada } \\
\text { identificáveis em produtos de } \\
\text { saída identificáveis. }\end{array}$ & $\begin{array}{l}\text { 1. Executar as práticas específicas do } \\
\text { processo para desenvolver produtos de } \\
\text { trabalho e prover serviços para atender } \\
\text { aos objetivos específicos da área de } \\
\text { processo. }\end{array}$ \\
\hline
\end{tabular}

Quadro 7 - Objetivos genéricos, práticas genéricas e subpráticas do CMMI-Dev para o nível 1 


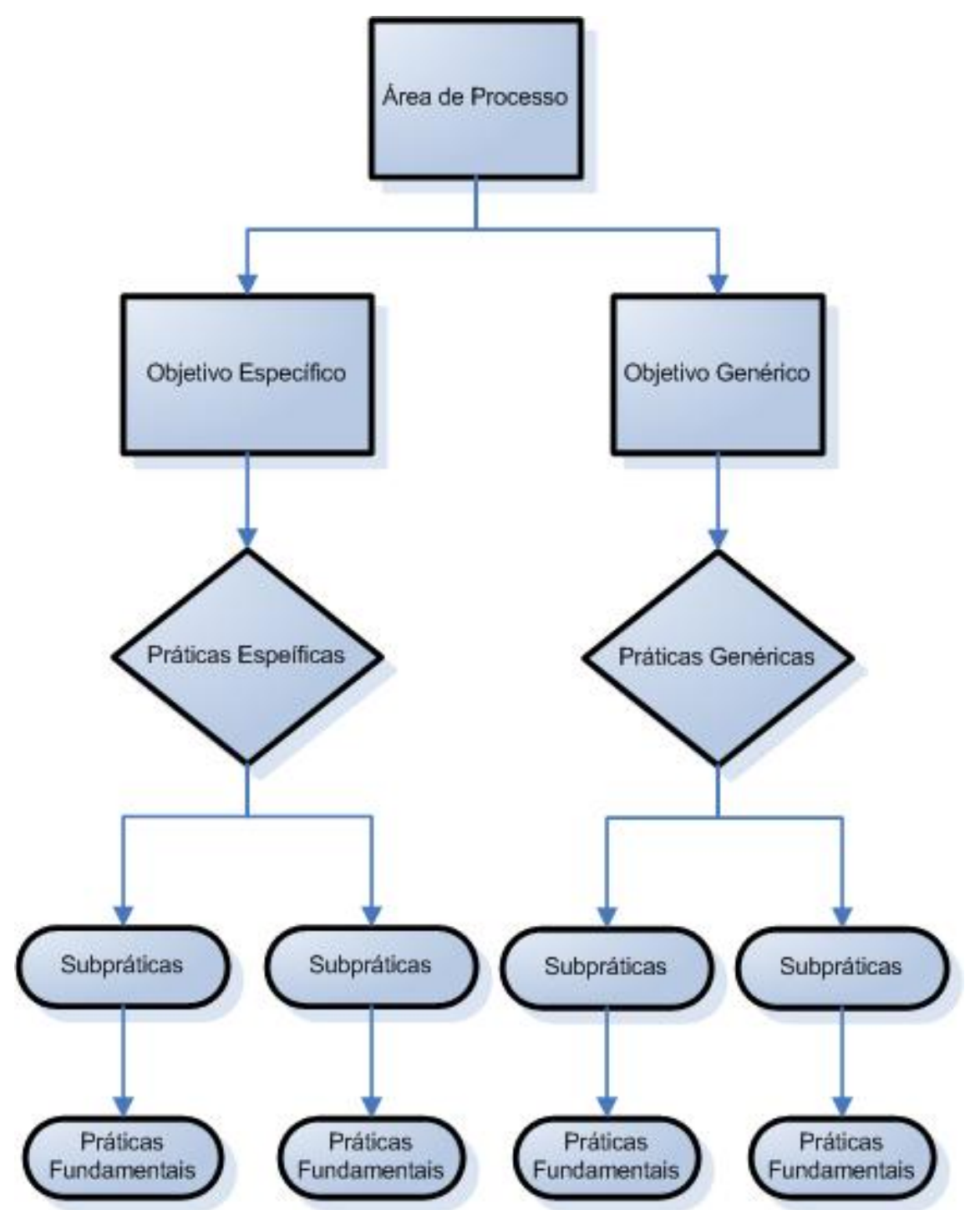

Figura 7 - Estrutura de organização das praticas fundamentais no CMMI-Dev

Como se pode notar, por meio da observação do Quadro 7, a existência dos produtos de trabalho produzidos pela execução de cada prática do processo e que atendam aos objetivos específicos da área de processo indica o atendimento ao objetivo genérico do modelo CMMI-Dev. Sendo assim, para a verificação do atendimento dos objetivos genéricos do modelo, o guia utiliza o modelo de avaliação descrito na seção 3.3.5, que visa à avaliação dos produtos de trabalho produzidos pelo processo proposto, bem como os ativos necessários para garantir que o processo tem condições de produzir todos os seus resultados esperados. 


\section{SWEBOK}

Do SWEBOK foram retiradas as práticas contidas na área de conhecimento denominada Requisitos de Software. Conforme mencionado na seção 2.3, esta área está dividida em seis tópicos. Cada tópico e suas respectivas práticas estão ilustrados no Quadro 8.

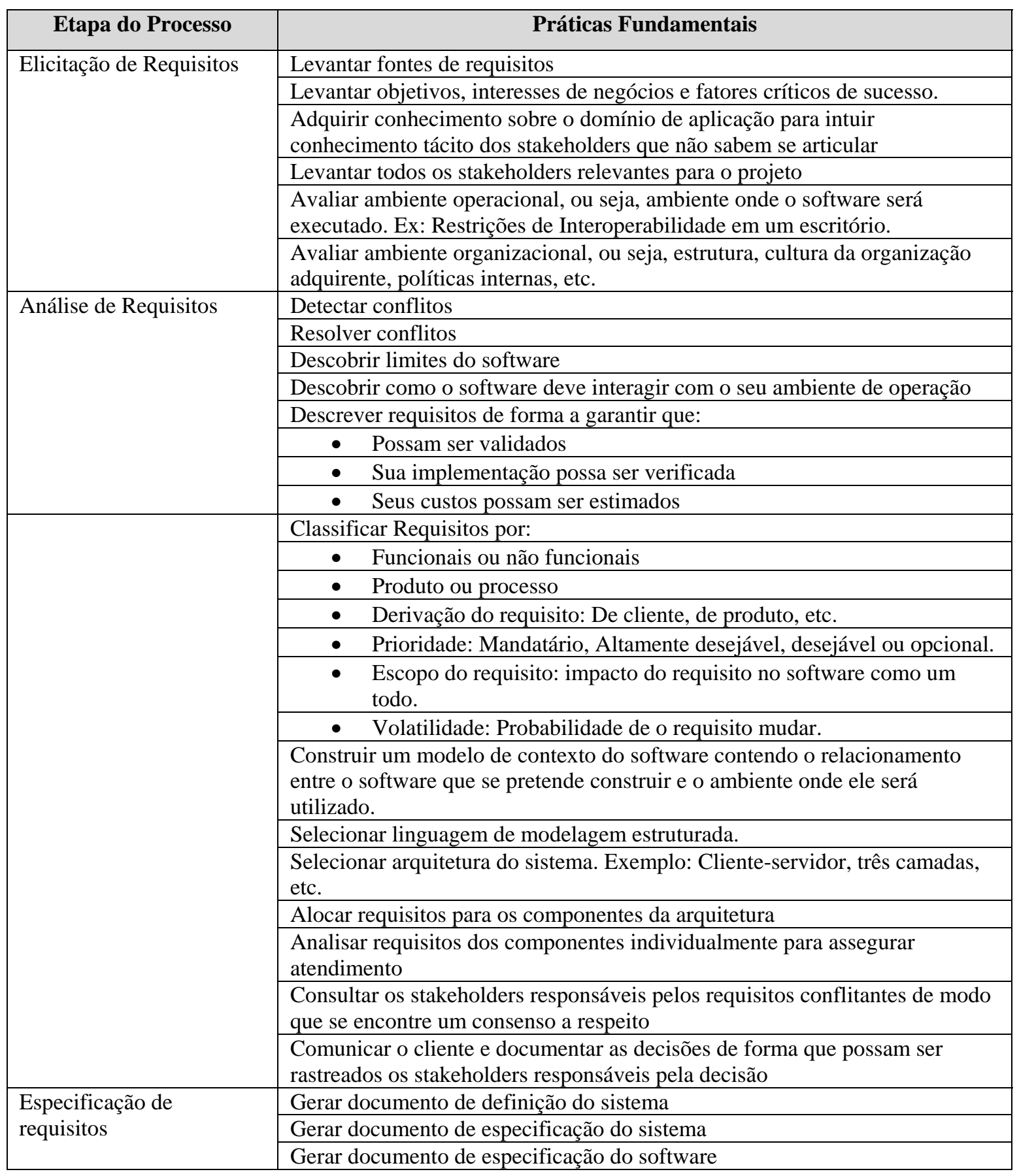




\begin{tabular}{|c|c|}
\hline & Derivar requisitos do sistema para obter requisitos do software \\
\hline & $\begin{array}{l}\text { Selecionar uma notação apropriada para descrição dos requisitos } \\
\text { considerando restrições de treinamento, competência e preferência dos } \\
\text { autores do documento e dos leitores do mesmo. }\end{array}$ \\
\hline & Definir indicadores de qualidade para requisitos individualmente \\
\hline & $\begin{array}{l}\text { Definir indicadores de qualidade para o documento de especificação de } \\
\text { requisitos de software. }\end{array}$ \\
\hline & $\begin{array}{l}\text { Definir indicadores de qualidade para o documento de requisitos de software } \\
\text { com relação a outras variáveis do projeto }\end{array}$ \\
\hline \multirow[t]{7}{*}{ Validação de Requisitos } & Revisar documento de requisitos \\
\hline & Elaborar checklists para revisar requisitos \\
\hline & Elaborar protótipos para validar requisitos \\
\hline & Validar modelos conceituais \\
\hline & Elaborar testes de aceitação \\
\hline & - $\quad$ Planejar testes de aceitação \\
\hline & - $\quad$ Projetar testes de aceitação \\
\hline \multirow{7}{*}{$\begin{array}{l}\text { Gerenciamento de } \\
\text { Requisitos }\end{array}$} & Documentar fonte dos requisitos. \\
\hline & Documentar o histórico de mudanças do requisito. \\
\hline & Definir uma forma de identificação única dos requisitos. \\
\hline & $\begin{array}{l}\text { Rastrear histórico de requisitos com relação as suas fontes: requisitos e fontes } \\
\text { que os originou. }\end{array}$ \\
\hline & $\begin{array}{l}\text { Rastrear futuro de requisitos com relação aos componentes de projeto e } \\
\text { módulos de código que os implementa }\end{array}$ \\
\hline & $\begin{array}{l}\text { Definir uma métrica para cálculo de tamanho de software utilizando os } \\
\text { requisitos do mesmo. }\end{array}$ \\
\hline & Estimar o tamanho do software com base em seus requisitos \\
\hline
\end{tabular}

Quadro 8 - Práticas fundamentais do SWEBOK

\section{PMBOK}

Partindo-se do princípio de que o processo de requisitos deve ser encarado como um projeto, utilizou-se o PMBOK como fonte de práticas fundamentais que orientassem o planejamento e controle dos processos de requisitos. As práticas retiradas do PMBOK estão ilustradas no Quadro 9. Este quadro pode ser utilizado por qualquer outro processo que venha a ser utilizado na produção de software ou mesmo para ajudar no planejamento do programa de melhoria utilizado pelo PROREQ.

\begin{tabular}{|l|l|}
\hline \multicolumn{1}{|c|}{$\begin{array}{c}\text { Área de } \\
\text { Conhecimento }\end{array}$} & \multicolumn{1}{c|}{ Práticas Fundamentais } \\
\hline $\begin{array}{l}\text { Gerenciamento } \\
\text { da Integração } \\
\text { do projeto }\end{array}$ & \begin{tabular}{l} 
Desenvolver declaração de escopo preliminar do projeto \\
\cline { 2 - 2 }
\end{tabular} \\
$\begin{array}{l}\text { serviços } \\
\text { associados, além dos métodos de aceitação e controle do escopo }\end{array}$ \\
\cline { 2 - 2 } & $\begin{array}{l}\text { Definir um processo que auxilie o desenvolvimento e controle das mudanças da } \\
\text { declaração do escopo preliminar do projeto }\end{array}$ \\
\hline
\end{tabular}




\begin{tabular}{|c|c|}
\hline & $\begin{array}{l}\text { Prover um software de informações de gerenciamento de projetos para apoiar a } \\
\text { geração de uma declaração do escopo preliminar do projeto, facilitar o feedback } \\
\text { conforme o documento é refinado, controlar as mudanças da declaração do escopo do } \\
\text { projeto e liberar o documento aprovado }\end{array}$ \\
\hline & Prover opinião especializada \\
\hline Gerenciamento & Planejar escopo \\
\hline $\begin{array}{l}\text { do Escopo do } \\
\text { projeto }\end{array}$ & $\begin{array}{l}\text { A declaração do escopo detalhada do projeto aprovada, e a Estrutura analitica de } \\
\text { projeto (EAP) e o dicionário da EAP associados a ela, constituem a linha de base do } \\
\text { escopo do projeto. }\end{array}$ \\
\hline & Analisar as informações contidas no termo de abertura do projeto \\
\hline & Analisar a declaração do escopo preliminar do projeto \\
\hline & Analisar a última versão aprovada do plano de gerenciamento do projeto \\
\hline & Analisar informações históricas contidas nos ativos de processos organizacionais \\
\hline & Analisar quaisquer fatores ambientais relevantes para a empresa \\
\hline & $\begin{array}{l}\text { Fornecer orientação sobre como o escopo do projeto será definido, documentado, } \\
\text { verificado, gerenciado e controlado pela equipe de gerenciamento de projetos. }\end{array}$ \\
\hline & Definir Escopo \\
\hline & $\begin{array}{l}\text { Analisar necessidades, desejos e expectativas das partes interessadas e converter em } \\
\text { requisitos }\end{array}$ \\
\hline & Analisar as premissas e restrições do projeto \\
\hline & Analisar as partes interessadas para identificar a influência e os interesses das mesmas \\
\hline & Documentar necessidades, desejos e expectativas \\
\hline & $\begin{array}{l}\text { Selecionar, priorizar e quantificar as necessidades, desejos e expectativas para criar os } \\
\text { requisitos }\end{array}$ \\
\hline & Criar EAP \\
\hline & Identificar as entregas e do trabalho relacionado \\
\hline & Estruturar e organizar a EAP \\
\hline & Reutilizar dados históricos de EAP e dicionários de EAP \\
\hline & Decompor os níveis mais altos da EAP em componentes detalhados de nível mais baixo \\
\hline & Desenvolver e atribuir códigos de identificação aos componentes da EAP \\
\hline & Verificar se o grau de decomposição do trabalho é necessário e suficiente \\
\hline & Utilizar opinião especializada para identificar todo o trabalho \\
\hline & $\begin{array}{l}\text { Definir pacotes de trabalho em termos de como o trabalho do projeto será realmente } \\
\text { executado e controlado }\end{array}$ \\
\hline & Descrever componentes da EAP em um dicionário da EAP \\
\hline & Verificar escopo \\
\hline & $\begin{array}{l}\text { Obter a aceitação formal pelas partes interessadas do escopo do projeto terminado e } \\
\text { das entregas associadas. }\end{array}$ \\
\hline & $\begin{array}{l}\text { Rever as entregas para garantir que cada uma delas foi terminada de forma } \\
\text { satisfatória }\end{array}$ \\
\hline & $\begin{array}{l}\text { Inspecionar por meio de atividades como medição, exame e verificação para } \\
\text { determinar se o trabalho e as entregas atendem aos requisitos e aos critérios de aceitação } \\
\text { do produto. }\end{array}$ \\
\hline & Documentar as entregas terminadas que foram aceitas \\
\hline & $\begin{array}{l}\text { Documentar as entregas terminadas que não foram aceitas juntamente com as razões } \\
\text { da não aceitação }\end{array}$ \\
\hline & $\begin{array}{l}\text { Documentar reconhecimento da aceitação das entregas do projeto pelas partes } \\
\text { interessadas }\end{array}$ \\
\hline & Controlar escopo \\
\hline & $\begin{array}{l}\text { Definir os procedimentos para efetuar mudanças no escopo do projeto e no escopo do } \\
\text { produto }\end{array}$ \\
\hline & Determinar causas de variação em relação à linha de base do escopo \\
\hline & Decidir se são necessárias ações corretivas \\
\hline & Efetuar modificações na EAP e no dicionário da EAP, caso necessário \\
\hline
\end{tabular}




\begin{tabular}{|c|c|}
\hline & Fornecer procedimentos para obtenção da situação das entregas \\
\hline & $\begin{array}{l}\text { Garantir que as mudanças solicitadas no escopo do projeto e no escopo do produto } \\
\text { serão cuidadosamente consideradas e documentadas }\end{array}$ \\
\hline \multirow{33}{*}{$\begin{array}{l}\text { Gerenciamento } \\
\text { de Tempo do } \\
\text { Projeto }\end{array}$} & Definir atividades do projeto \\
\hline & Identificar e documentar o trabalho planejado para ser realizado \\
\hline & Decompor pacotes de trabalho em atividades do cronograma \\
\hline & Analisar premissas e restrições para planejar atividades do cronograma \\
\hline & Analisar fatores ambientais da empresa para planejar atividades do cronograma \\
\hline & Analisar ativos de processos organizacionais para planejar atividades do cronograma \\
\hline & Utilizar modelos de listas de atividades de projetos anteriores com perfil parecido \\
\hline & Sequenciamento de atividades \\
\hline & $\begin{array}{l}\text { Identificar e documentar os relacionamentos lógicos entre as atividades do } \\
\text { cronograma, baseado no documento de requisitos }\end{array}$ \\
\hline & Identificar relações de dependência entre as atividades do cronograma \\
\hline & São tipos de dependência: \\
\hline & $\begin{array}{l}\text { Término para início. A iniciação da atividade sucessora depende do término da } \\
\text { atividade predecessora. }\end{array}$ \\
\hline & $\begin{array}{l}\text { Término para término. O término da atividade sucessora depende do término } \\
\text { da atividade predecessora. }\end{array}$ \\
\hline & $\begin{array}{l}\text { Início para início. A iniciação da atividade sucessora depende da iniciação da } \\
\text { atividade predecessora. }\end{array}$ \\
\hline & $\begin{array}{l}\text { Início para término. O término da atividade sucessora depende da iniciação da } \\
\text { atividade predecessora. }\end{array}$ \\
\hline & Identificar dependências obrigatórias \\
\hline & Identificar dependências arbitradas \\
\hline & Identificar dependências externas \\
\hline & $\begin{array}{l}\text { Identificar atrasos e antecipações que podem influenciar o sequenciamento de } \\
\text { atividades }\end{array}$ \\
\hline & Estimar recursos da atividade \\
\hline & $\begin{array}{l}\text { Determinar os recursos (pessoas, equipamentos ou material) e as quantidades de cada } \\
\text { recurso que serão } \\
\text { usados e quando cada recurso estará disponível para realizar as atividades do projeto }\end{array}$ \\
\hline & $\begin{array}{l}\text { Utilizar as informações sobre disponibilidade de recursos de infra-estrutura incluídas } \\
\text { nos fatores ambientais da empresa }\end{array}$ \\
\hline & Considerar a disponibilidade, capacidades e habilidades dos recursos humanos \\
\hline & $\begin{array}{l}\text { Considerar o tipo, quantidade, disponibilidade e capacidade, quando aplicáveis, } \\
\text { dos recursos de equipamentos e material }\end{array}$ \\
\hline & $\begin{array}{l}\text { Utilizar ativos de processos organizacionais para apoiar a definição de estimativas de } \\
\text { recursos da atividade. Exemplos de ativos são: políticas da organização executora } \\
\text { relativas a pessoal e a aluguel ou compra de suprimentos e equipamentos }\end{array}$ \\
\hline & $\begin{array}{l}\text { Utilizar a lista de atividades para elaborar as estimativas de recursos para cada } \\
\text { atividade }\end{array}$ \\
\hline & Considerar dependências entre as atividades para estimativas de recursos \\
\hline & Estimar duração da atividade \\
\hline & $\begin{array}{l}\text { Estimar a quantidade de esforço de trabalho necessária para terminar as atividades do } \\
\text { cronograma }\end{array}$ \\
\hline & $\begin{array}{l}\text { Estimar a quantidade prevista de recursos a ser aplicada para terminar a atividade do } \\
\text { cronograma }\end{array}$ \\
\hline & $\begin{array}{l}\text { Estimar o número de períodos de trabalho necessário para terminar a atividade do } \\
\text { cronograma }\end{array}$ \\
\hline & $\begin{array}{l}\text { Utilizar como base para o calcula da estimativa os calendários de projeto e os } \\
\text { calendários de recursos }\end{array}$ \\
\hline & $\begin{array}{l}\text { Considerar fatores ambientais da empresa tais como bancos de dados de estimativas } \\
\text { de duração }\end{array}$ \\
\hline
\end{tabular}




\begin{tabular}{|c|c|}
\hline & Desenvolver cronograma \\
\hline & Determinar as datas de início e término planejadas das atividades do projeto \\
\hline & Reexaminar estimativas de duração e as estimativas de recursos \\
\hline & Considerar datas impostas nos inícios ou términos das atividades \\
\hline & Considerar riscos para definir as datas do cronograma \\
\hline & Controlar cronograma \\
\hline & Determinar o andamento atual do cronograma do projeto \\
\hline & Controlar os fatores que criam mudanças no cronograma \\
\hline & Determinar por que o cronograma do projeto mudou \\
\hline & Gerenciar as mudanças conforme elas efetivamente ocorrem. \\
\hline \multirow{23}{*}{$\begin{array}{l}\text { Gerenciar } \\
\text { Recursos } \\
\text { Humanos do } \\
\text { Projeto }\end{array}$} & Planejar recursos humanos \\
\hline & Considerar requisitos necessários para a atribuição de papeis e responsabilidades \\
\hline & $\begin{array}{l}\text { Documentar funções, responsabilidades, autoridades e competência de cada membro } \\
\text { da equipe }\end{array}$ \\
\hline & Garantir que não haja ambigüidade quanto ao proprietário de cada pacote de trabalho \\
\hline & Definir necessidades de recrutamento e seleção \\
\hline & Definir número de horas previstas para cada papel \\
\hline & Definir critérios de liberação de recursos \\
\hline & Definir necessidades de treinamento \\
\hline & Definir políticas de reconhecimento e premiação \\
\hline & Contratar ou mobilizar equipe de projeto \\
\hline & $\begin{array}{l}\text { Considerar disponibilidade, capacidade, experiência, interesses e custo das pessoas } \\
\text { necessárias }\end{array}$ \\
\hline & Negociar, caso necessário, as designações de pessoas \\
\hline & Desenvolver a equipe do projeto \\
\hline & Aprimorar habilidades de membros da equipe, se possível \\
\hline & Aprimorar sentimentos de confiança e coesão entre os membros da equipe \\
\hline & Equilibrar carga de trabalho dos membros da equipe \\
\hline & Avaliar o desempenho da equipe \\
\hline & Gerenciar equipe do projeto \\
\hline & Gerenciar conflitos na equipe \\
\hline & Registrar problemas e pessoas que resolveram \\
\hline & Efetuar mudanças de pessoal, caso necessário \\
\hline & Efetuar ações corretivas, caso necessário \\
\hline & Documentar lições aprendidas \\
\hline \multirow{11}{*}{$\begin{array}{l}\text { Gerenciamento } \\
\text { de Custos do } \\
\text { Projeto }\end{array}$} & Estimar custos \\
\hline & $\begin{array}{l}\text { Desenvolver uma aproximação dos custos dos recursos necessários para terminar } \\
\text { cada atividade do } \\
\text { cronograma }\end{array}$ \\
\hline & $\begin{array}{l}\text { Considerar as possíveis causas de variação das estimativas de custos, inclusive os } \\
\text { riscos }\end{array}$ \\
\hline & Identificar e a considerar as diversas alternativas de custos \\
\hline & Considerar restrições, premissas e requisitos \\
\hline & $\begin{array}{l}\text { Fazer estimativas análogas, ou seja, utilizar dados de projetos anteriores para fazer a } \\
\text { estimativa atual }\end{array}$ \\
\hline & Determinar os valores de custo de recursos \\
\hline & $\begin{array}{l}\text { Estimar os custos de pacotes de trabalho individuais ou de } \\
\text { atividades do cronograma individuais com o nível mais baixo de detalhes }\end{array}$ \\
\hline & $\begin{array}{l}\text { Incluir as reservas, também denominadas provisões para contingências, como custos } \\
\text { em várias estimativas de custos da atividade do cronograma. }\end{array}$ \\
\hline & Orçamentar custos \\
\hline & $\begin{array}{l}\text { Agregar as estimativas de custos da atividade do cronograma por pacotes de trabalho } \\
\text { de acordo com a EAP }\end{array}$ \\
\hline
\end{tabular}




\begin{tabular}{|c|c|}
\hline & $\begin{array}{l}\text { Agregar as estimativas de custos da atividade do cronograma dos pacotes de trabalho } \\
\text { para os componentes de mais alto nível da EAP }\end{array}$ \\
\hline & Controlar custos \\
\hline & Controlar os fatores que criam mudanças na linha de base dos custos \\
\hline & Garantir que houve um acordo em relação às mudanças solicitadas \\
\hline & Monitorar as mudanças reais quando e conforme ocorrem \\
\hline & $\begin{array}{l}\text { Garantir que os possíveis estouros nos custos não ultrapassam o financiamento } \\
\text { autorizado periodicamente e no total para o projeto }\end{array}$ \\
\hline & $\begin{array}{l}\text { Monitorar o desempenho de custos para detectar e compreender as variações em } \\
\text { relação à linha de base dos custos }\end{array}$ \\
\hline & $\begin{array}{l}\text { Registrar exatamente todas as mudanças adequadas em relação à linha de base } \\
\text { dos custos }\end{array}$ \\
\hline & $\begin{array}{l}\text { Evitar que mudanças incorretas, inadequadas ou não aprovadas sejam incluídas } \\
\text { nos custos relatados ou na utilização de recursos }\end{array}$ \\
\hline & Informar as partes interessadas adequadas sobre as mudanças aprovadas \\
\hline & Agir para manter os estouros nos custos esperados dentro dos limites aceitáveis \\
\hline Gerenciamento & Planejar da qualidade \\
\hline $\begin{array}{l}\text { da qualidade do } \\
\text { projeto }\end{array}$ & $\begin{array}{l}\text { Identificar os padrões de qualidade relevantes para o projeto e a determinação de } \\
\text { como satisfazê-los }\end{array}$ \\
\hline & Considerar o equilíbrio entre custo e benefício \\
\hline & $\begin{array}{l}\text { Comparar as práticas de projeto reais ou planejadas às de outros projetos para gerar } \\
\text { idéias de melhoria e para fornecer uma base pela qual deve ser medido o desempenho. }\end{array}$ \\
\hline & $\begin{array}{l}\text { Estimar os custos da qualidade que são: os custos totais incorridos pelo investimento } \\
\text { em prevenção } \\
\text { de não conformidade com os requisitos, avaliação do produto ou serviço em relação à } \\
\text { conformidade com os requisitos e não atendimento dos requisitos (retrabalho). }\end{array}$ \\
\hline & $\begin{array}{l}\text { Utilizar lista de verificação para verificar se foi executado um conjunto de etapas } \\
\text { necessárias }\end{array}$ \\
\hline & Realizar a garantia da qualidade \\
\hline & $\begin{array}{l}\text { Aplicação de atividades de qualidade planejadas e sistemáticas para garantir que o } \\
\text { projeto irá empregar todos os processos necessários para atender aos requisitos }\end{array}$ \\
\hline & Fornecer uma base para a melhoria contínua dos processos \\
\hline & Identificar e revisar os processos de negócios da organização \\
\hline & $\begin{array}{l}\text { Identificar políticas, processos e procedimentos ineficientes e ineficazes em uso no } \\
\text { projeto }\end{array}$ \\
\hline & Identificar as melhorias necessárias do ponto de vista organizacional e técnico. \\
\hline & Realizar o controle da qualidade \\
\hline & $\begin{array}{l}\text { Monitorar os resultados específicos do projeto a fim de determinar se eles estão de } \\
\text { acordo com os padrões } \\
\text { relevantes de qualidade }\end{array}$ \\
\hline & Identificar maneiras de eliminar as causas de resultados insatisfatórios \\
\hline & $\begin{array}{l}\text { Elaborar diagramas de causa e efeito para ilustrar como diversos fatores podem ser } \\
\text { ligados a } \\
\text { possíveis problemas ou efeitos }\end{array}$ \\
\hline & Elaborar fluxogramas para analisar como os problemas ocorrem \\
\hline & Determinar se as entregas estão corretas \\
\hline Gerenciamento & Planejamento das comunicações \\
\hline & Determina as necessidades de informações e comunicações das partes interessadas \\
\hline $\begin{array}{l}\text { Comunicações } \\
\text { do projeto }\end{array}$ & $\begin{array}{l}\text { Identificar as necessidades de informações das partes interessadas e determinar uma } \\
\text { maneira adequada para atender a essas necessidades. }\end{array}$ \\
\hline & $\begin{array}{l}\text { Considerar o número de canais ou caminhos de comunicação possíveis como um } \\
\text { indicador da complexidade das comunicações em um projeto }\end{array}$ \\
\hline & $\begin{array}{l}\text { Determinar e limitar quem se comunicará com quem e quem receberá quais } \\
\text { informações }\end{array}$ \\
\hline
\end{tabular}




\begin{tabular}{|c|c|}
\hline & Planejar comunicações inclui determinar: \\
\hline & Os requisitos de comunicação das partes interessadas \\
\hline & $\begin{array}{l}\text { As informações que serão comunicadas, inclusive o formato, conteúdo e nível de } \\
\text { detalhes }\end{array}$ \\
\hline & A pessoa responsável pela comunicação das informações \\
\hline & A pessoa ou os grupos que receberão as informações \\
\hline & $\begin{array}{l}\text { Os métodos ou tecnologias usados para transmitir as informações, como } \\
\text { memorandos, e-mail e/ou comunicados à imprensa }\end{array}$ \\
\hline & A freqüência da comunicação, como, por exemplo, semanal \\
\hline & $\begin{array}{l}\text { Os prazos para identificar processos para aumentar o nível e a cadeia gerencial } \\
\text { (nomes) para levar para níveis mais altos problemas que não podem ser resolvidos em } \\
\text { um nível hierárquico mais baixo }\end{array}$ \\
\hline & $\begin{array}{l}\text { O método para atualizar e refinar o plano de gerenciamento das comunicações } \\
\text { conforme o projeto se desenvolve e avança }\end{array}$ \\
\hline & Glossário da terminologia comum. \\
\hline & Distribuir as informações \\
\hline & $\begin{array}{l}\text { Colocar as informações à disposição das partes interessadas no projeto no momento } \\
\text { oportuno }\end{array}$ \\
\hline & Documentar lições aprendidas \\
\hline & Elaborar reunião de apresentação do projeto \\
\hline & Obter feedback das partes interessadas \\
\hline & Elaborar relatório de desempenho \\
\hline & $\begin{array}{l}\text { Coletar todos os dados de linha de base e a distribuição das informações sobre o } \\
\text { desempenho às partes interessadas }\end{array}$ \\
\hline & Gerenciar as partes interessadas \\
\hline & $\begin{array}{l}\text { Gerenciar as comunicações para satisfazer as necessidades das partes interessadas no } \\
\text { projeto e resolver problemas com elas. }\end{array}$ \\
\hline & $\begin{array}{l}\text { Documentar e monitorar a resolução de problemas por meio de registros de } \\
\text { problemas }\end{array}$ \\
\hline Gerenciamento & Planejar Gerenciamento de Riscos \\
\hline $\begin{array}{l}\text { de Riscos do } \\
\text { Projeto }\end{array}$ & $\begin{array}{l}\text { Decidir como abordar e executar as atividades de gerenciamento de riscos de um } \\
\text { projeto }\end{array}$ \\
\hline & $\begin{array}{l}\text { Garantir que o nível, tipo e visibilidade do gerenciamento de riscos estejam de acordo } \\
\text { com o risco e a importância do projeto em relação à organização }\end{array}$ \\
\hline & $\begin{array}{l}\text { Fornecer tempo e recursos suficientes para as atividades de gerenciamento de } \\
\text { riscos }\end{array}$ \\
\hline & Estabelecer uma base acordada de avaliação de riscos \\
\hline & $\begin{array}{l}\text { Considerar as atitudes e tolerância aos riscos das organizações e pessoas envolvidas } \\
\text { no projeto }\end{array}$ \\
\hline & Realizar analises e reuniões de planejamento de riscos \\
\hline & $\begin{array}{l}\text { Desenvolver elementos de custos de riscos e atividades do cronograma de riscos para } \\
\text { serem incluídas no orçamento e cronograma do projeto }\end{array}$ \\
\hline & Identificar riscos do projeto \\
\hline & Determinar os riscos que podem afetar o projeto e documentar suas características \\
\hline & Revisar documentos do projeto \\
\hline & Realizar reuniões para levantamento de riscos \\
\hline & Utilizar categorias de riscos para classificá-los \\
\hline & Listar possíveis respostas aos riscos levantados \\
\hline & Analisar Qualitativamente os Riscos \\
\hline & Priorizar os riscos identificados \\
\hline & Avaliar a prioridade dos riscos identificados: \\
\hline & Usar a probabilidade deles ocorrerem \\
\hline & O impacto correspondente nos objetivos do projeto \\
\hline
\end{tabular}




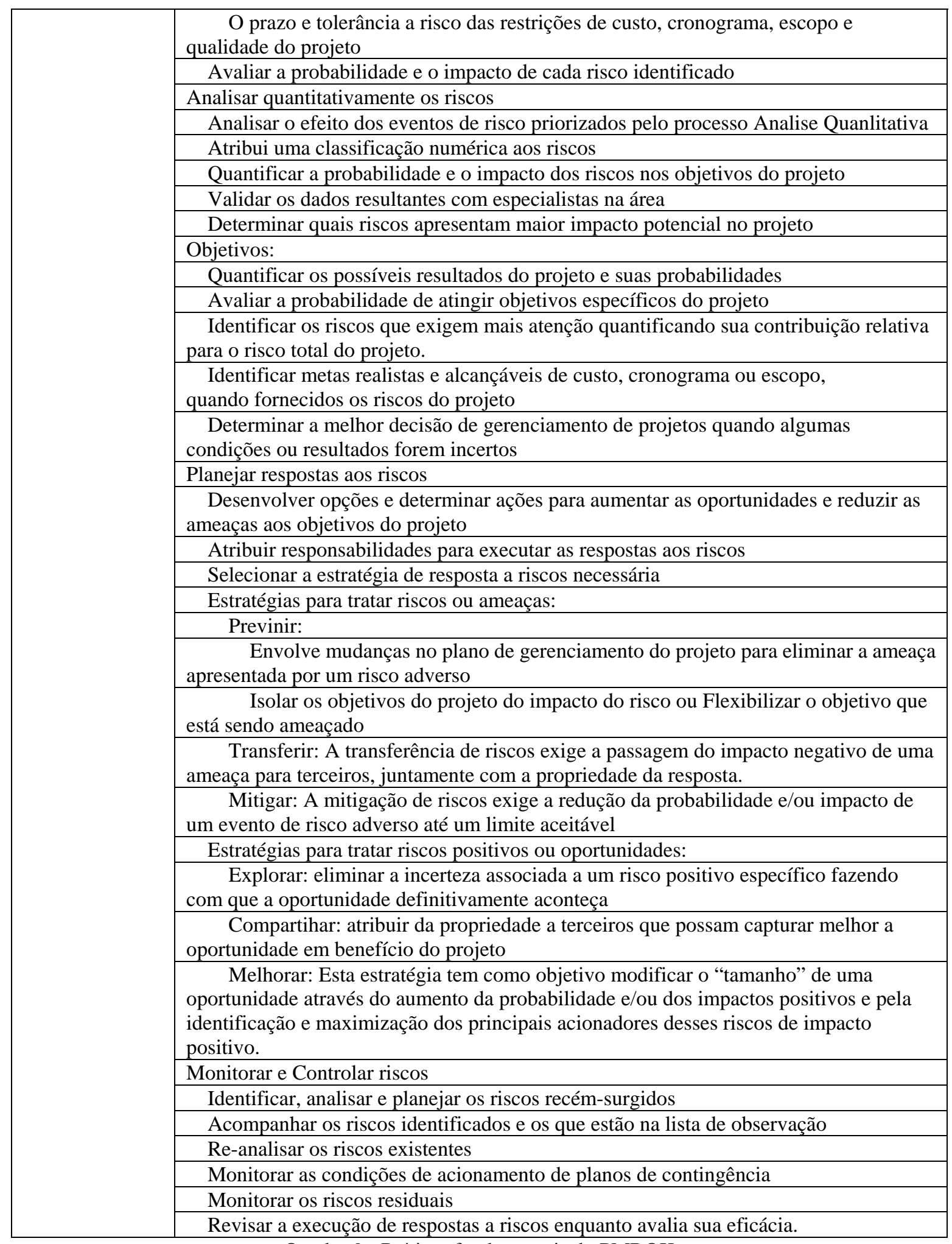
Quadro 9 - Práticas fundamentais do PMBOK 
Norma ISO/IEC 12207

Da norma ISO/IEC 12207 foram retiradas somente práticas fundamentais contidas nos processos relacionados diretamente a ER. Todas as práticas retiradas da norma estão ilustradas no Quadro 10.

\begin{tabular}{|c|c|}
\hline Etapa do Processo & Práticas Fundamentais \\
\hline \multirow[t]{5}{*}{ Elicitação de Requisitos } & Estabelecer uma comunicação contínua com o cliente \\
\hline & Definir e criar uma linha de referência dos requisitos do cliente \\
\hline & $\begin{array}{l}\text { Estabelecer um mecanismo para avaliar e incorporar mudanças no conjunto } \\
\text { de requisitos definido baseado em mudanças nas necessidades do cliente }\end{array}$ \\
\hline & $\begin{array}{l}\text { Estabelecer um mecanismo para o monitoramento constante das } \\
\text { necessidades do cliente }\end{array}$ \\
\hline & $\begin{array}{l}\text { Gerenciar impactos de mudanças ocasionadas por mudanças no conjunto de } \\
\text { requisitos do cliente. }\end{array}$ \\
\hline \multirow[t]{7}{*}{$\begin{array}{l}\text { Análise de Requisitos de } \\
\text { Sistema }\end{array}$} & $\begin{array}{l}\text { Estabelecer um conjunto definido de requisitos funcionais e não funcionais } \\
\text { de sistema que descrevam o problema a ser resolvido }\end{array}$ \\
\hline & $\begin{array}{l}\text { Analisar requisitos do sistema para assegurar corretude e testabilidade dos } \\
\text { mesmos }\end{array}$ \\
\hline & Entender o impacto dos requisitos do sistema no ambiente operacional \\
\hline & Priorizar, aprovar e quando necessário atualizar os requisitos. \\
\hline & $\begin{array}{l}\text { Estabelecer consistência e rastreabilidade entre os requisitos do sistema e os } \\
\text { requisitos do software }\end{array}$ \\
\hline & $\begin{array}{l}\text { Avaliar as mudanças na baseline de requisitos segundo os parâmetros de } \\
\text { custo, prazo e impacto técnico. }\end{array}$ \\
\hline & $\begin{array}{l}\text { Criar baseline dos requisitos do sistema e comunicá-los para todas as partes } \\
\text { (stakeholders) afetadas }\end{array}$ \\
\hline \multirow[t]{8}{*}{$\begin{array}{l}\text { Projeto arquitetural do } \\
\text { sistema }\end{array}$} & $\begin{array}{l}\text { Definir um projeto arquitetural do sistema que identifica os elementos do } \\
\text { sistema e encontra os requisitos definidos }\end{array}$ \\
\hline & Endereçar os requisitos funcionais e não funcionais \\
\hline & Alocar requisitos do sistema aos elementos do projeto arquitetural \\
\hline & Definir interfaces internas e externas de cada elemento do sistema \\
\hline & $\begin{array}{l}\text { Efetuar verificação entre os requisitos do sistema e os elementos do projeto } \\
\text { arquitetural }\end{array}$ \\
\hline & $\begin{array}{l}\text { Estabelecer rastreabilidade entre os requisitos alocados aos elementos do } \\
\text { sistema e suas interfaces com os requisitos do cliente definidos na baseline } \\
\text { de requisitos }\end{array}$ \\
\hline & $\begin{array}{l}\text { Manter consistência e rastreabilidade entre os requisitos do sistema e o } \\
\text { projeto arquitetural do sistema }\end{array}$ \\
\hline & $\begin{array}{l}\text { Comunicar a todos os stakeholders os requisitos do sistema, o projeto } \\
\text { arquitetural e os respectivos relacionamentos entre si. }\end{array}$ \\
\hline \multirow[t]{3}{*}{$\begin{array}{l}\text { Análise de Requisitos de } \\
\text { Software }\end{array}$} & $\begin{array}{l}\text { Definir os requisitos de software alocados para os elementos do sistema e } \\
\text { suas interfaces }\end{array}$ \\
\hline & Analisar requisitos de software para garantir corretude e testabilidade \\
\hline & Entender o impacto dos requisitos de software no ambiente operacional \\
\hline
\end{tabular}




\begin{tabular}{|l|l|}
\hline \multirow{y}{*}{} & $\begin{array}{l}\text { Estabelecer consistência e rastreabilidade entre os requisitos de software e } \\
\text { os requisitos de sistema }\end{array}$ \\
\cline { 2 - 2 } & Definir prioridade para implementação dos requisitos de software \\
\cline { 2 - 2 } & Aprovar e atualizar os requisitos de software quando necessário \\
\cline { 2 - 2 } & $\begin{array}{l}\text { Avaliar mudanças na baseline dos requisitos de software segundo os } \\
\text { parâmetros de custo, prazo e impacto técnico. }\end{array}$ \\
\cline { 2 - 3 } & $\begin{array}{l}\text { Criar baseline dos requisitos de software e comunicá-los a todos os } \\
\text { stakeholders }\end{array}$ \\
\hline
\end{tabular}

Quadro 10 - Práticas fundamentais da ISO/IEC 12207

\section{REGPG}

As práticas fundamentais retiradas do REGPG encontram-se ilustradas no Quadro 11.

\begin{tabular}{|c|c|}
\hline Etapa do processo & Práticas Fundamentais \\
\hline \multirow{13}{*}{ Elicitação de Requisitos } & Avaliar Viabilidade Financeira \\
\hline & Estar sensível a considerações políticas e organizacionais. \\
\hline & Identificar e consultar stakeholders do sistema \\
\hline & Registrar fontes de requisitos \\
\hline & Definir o ambiente operacional do sistema \\
\hline & Utilizar os interesses de negócio para dirigir a elicitação \\
\hline & Procurar por restrições do domínio de aplicação \\
\hline & Registrar raciocínio que levou ao requisito \\
\hline & Coletar requisitos de múltiplos pontos de vista \\
\hline & Criar protótipos para requisitos não esclarecidos \\
\hline & Usar cenários para elicitar requisitos \\
\hline & Definir processo operacional \\
\hline & Reutilizar requisitos \\
\hline \multirow{14}{*}{$\begin{array}{l}\text { Análise e negociação de } \\
\text { requisitos }\end{array}$} & Definir limites do sistema \\
\hline & Usar checklist para análise de requisitos \\
\hline & Prover apoio de software para as negociações \\
\hline & Elaborar planejamento para resolução de conflitos \\
\hline & Priorizar requisitos \\
\hline & Classificar requisitos utilizando uma abordagem multidimensional \\
\hline & Usar matrizes de interação para detectar conflitos e sobreposições \\
\hline & Avaliar riscos dos requisitos \\
\hline & Desenvolver modelos complementares do sistema \\
\hline & Modelar ambiente onde o sistema vai operar \\
\hline & Modelar arquitetura do sistema \\
\hline & Utilizar métodos estruturados para a modelagem do sistema \\
\hline & Utilizar dicionário de dados \\
\hline & $\begin{array}{l}\text { Documentar as ligações entre os requisitos dos stakeholders e os modelos de } \\
\text { sistema }\end{array}$ \\
\hline \multirow{8}{*}{$\begin{array}{l}\text { Conteúdo e formatação do } \\
\text { documento de requisitos }\end{array}$} & Definir uma estrutura padrão para o documento. \\
\hline & - Introdução: Seção explicativa de como se usa o documento. \\
\hline & - Sumário: Seção incluindo um sumário dos requisitos. \\
\hline & - Seção incluindo casos de negócio para o sistema. \\
\hline & - Glossário: Seção incluindo definições de termos especializados \\
\hline & Projetar o documento para facilitar a sua leitura. \\
\hline & Ajudar leitores a encontrar a informação \\
\hline & Projetar o documento para ser fácil de ser modificado \\
\hline
\end{tabular}




\begin{tabular}{|c|c|}
\hline \multirow{5}{*}{ Descrição dos requisitos } & Definir templates padrão para descrever os requisitos \\
\hline & Usar uma linguagem simples, consistente e concisa. \\
\hline & Usar diagramas apropriadamente \\
\hline & Complementar linguagem natural com outras descrições dos requisitos \\
\hline & Especificar requisitos quantitativamente \\
\hline \multirow{8}{*}{ Validação de Requisitos } & $\begin{array}{l}\text { Checar se os requisitos documentados estão aderentes aos padrões } \\
\text { estabelecidos na organização }\end{array}$ \\
\hline & Organizar inspeções formais de requisitos \\
\hline & Montar times multidisciplinares para a revisão de requisitos \\
\hline & Definir checklist para validação de requisitos \\
\hline & Utilizar protótipos para animar os requisitos \\
\hline & Escrever um rascunho do manual do usuário \\
\hline & Propor casos de teste de requisitos \\
\hline & Descrever textualmente os requisitos \\
\hline \multirow{8}{*}{$\begin{array}{l}\text { Gerenciamento de } \\
\text { Requisitos }\end{array}$} & Identificar unicamente cada requisito \\
\hline & Definir políticas para o gerenciamento de requisitos \\
\hline & Definir políticas de rastreabilidade \\
\hline & Utilizar uma base de dados para gerenciar requisitos \\
\hline & Definir políticas para o gerenciamento de mudanças \\
\hline & Identificar requisitos globais do sistema \\
\hline & Identificar requisitos voláteis \\
\hline & Registrar requisitos rejeitados \\
\hline
\end{tabular}

\section{PROTEC}

As práticas fundamentais retiradas do PROTEC encontram-se ilustradas no Quadro 12.

\begin{tabular}{|l|l|}
\hline \multicolumn{1}{|c|}{ Etapa do Processo } & \multicolumn{1}{c|}{ Práticas Fundamentais } \\
\hline \multirow{4}{*}{ Elicitação de Requisitos } & Definir objetivos de negócio \\
\cline { 2 - 2 } & Definir problema a ser resolvido \\
\cline { 2 - 2 } & Definir restrições do sistema \\
\cline { 2 - 2 } & Definir estrutura organizacional \\
\cline { 2 - 2 } & Definir domínio de aplicação \\
\cline { 2 - 2 } & Definir sistemas existentes \\
\cline { 2 - 2 } & Identificar stakeholders \\
\cline { 2 - 2 } Requisitos & Priorizar objetivos \\
\cline { 2 - 2 } & Filtrar conhecimento de domínio \\
\hline Validação de Requisitos & Discutir requisitos \\
\cline { 2 - 2 } & Priorizar requisitos \\
\cline { 2 - 2 } & Ganhar comprometimento dos stakeholders com os requisitos \\
\cline { 2 - 2 } & Executar revisão de requisitos \\
\cline { 2 - 2 } & Elaborar protótipos \\
\cline { 2 - 2 } & Utilizar checklists para validar requisitos \\
\cline { 2 - 2 } & Desenvolver manual de usuário \\
\cline { 2 - 2 } & Validar modelos conceituais \\
\cline { 2 - 2 } & Elaborar testes dos requisitos \\
\cline { 2 - 2 } & Gerenciar mudanças nos requisitos acordados: \\
\hline \multirow{5}{*}{$\begin{array}{l}\text { Gerenciamento de } \\
\text { requisitos }\end{array}$} & Validar requisição de mudança \\
\hline
\end{tabular}




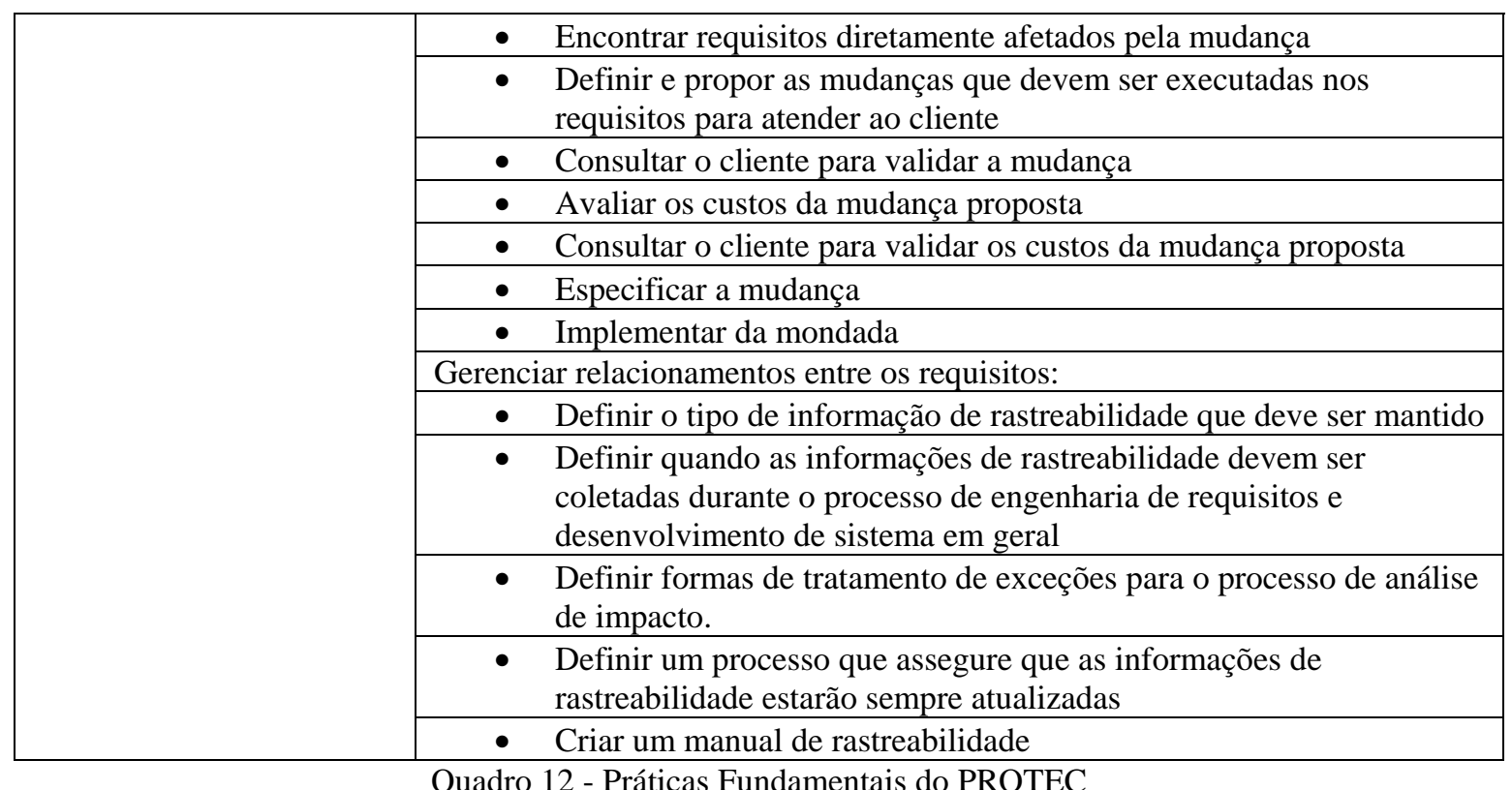

MPS.BR

Do MPS.Br foram retirados os resultados esperados para os processos de Gerenciamento de Requisitos e Desenvolvimento de requisitos, apresentados no Quadro 13. Além disso, o método de avaliação do modelo (MA-MPS) também foi utilizado como fonte para a criação do modelo de avaliação do PROREQ. Dele foram usados os conceitos de indicadores de atributos de processo e os conceitos relativos à atribuição de grau de implementação dos processos.

\begin{tabular}{|c|l|}
\hline Processo & \multicolumn{1}{|c|}{ Resultados esperados } \\
\hline \multirow{4}{*}{$\begin{array}{c}\text { Gerenciamento dos } \\
\text { Requisitos }\end{array}$} & Uma comunicação contínua com os fornecedores de requisitos é estabelecida; \\
\cline { 2 - 3 } & O entendimento dos requisitos é obtido; \\
\cline { 2 - 3 } & A aceitação dos requisitos é estabelecida por meio de critérios objetivos; \\
\cline { 2 - 3 } & $\begin{array}{l}\text { O comprometimento com os requisitos é estabelecido e mantido; } \\
\text { A rastreabilidade entre os requisitos, os planos do projeto e os produtos de } \\
\text { trabalho é estabelecida e mantida; }\end{array}$ \\
\cline { 2 - 3 } $\begin{array}{l}\text { Inconsistências entre os planos do projeto, os produtos de trabalho e os } \\
\text { requisitos são identificadas e corrigidas; }\end{array}$ \\
\cline { 2 - 3 } Requisitos & Mudanças nos requisitos são gerenciadas ao longo do projeto. \\
\hline \multirow{7}{*}{$\begin{array}{l}\text { As necessidades e expectativas, restrições e requisitos de interface do cliente } \\
\text { são identificadas; }\end{array}$} \\
\cline { 2 - 3 } $\begin{array}{l}\text { Um conjunto definido de requisitos funcionais e não-funcionais que } \\
\text { descrevem a solução do problema a ser resolvido é estabelecido a partir das } \\
\text { necessidades, expectativas, restrições e requisitos do cliente e da interface ; }\end{array}$ \\
\cline { 2 - 2 } & $\begin{array}{l}\text { Os requisitos do cliente são refinados, elaborados e alocados para o } \\
\text { desenvolvimento dos requisitos do produto e dos componentes do produto; }\end{array}$ \\
\cline { 2 - 2 } & Conceitos operacionais e cenários são desenvolvidos; \\
\cline { 2 - 2 } & A definição das funcionalidades requeridas é desenvolvida e mantida; \\
\hline
\end{tabular}




\begin{tabular}{|l|l|}
\hline & $\begin{array}{l}\text { Os requisitos são analisados para assegurar que são necessários e suficientes e } \\
\text { para balancear as necessidades dos interessados com as restrições existentes; }\end{array}$ \\
\cline { 2 - 2 } & Os requisitos são validados. \\
\hline
\end{tabular}

Quadro 13 - Resultados esperados dos processos de requisitos do mps.Br

ISO/IEC 15504

Da norma ISO/IEC 15504 foram utilizados, para fim de comparação, os produtos de trabalho gerados pela execução das práticas propostas pelo modelo de processo e as características de cada produto de trabalho, bem como a estrutura de organização destas informações. Utilizou-se também o framework de medidas da norma para embasar a criação de um modelo de avaliação simples que pudesse medir a evolução das melhorias do processo. Além disso, utilizou-se a estratégia de implementação das melhorias proposta pela norma de modo que se pudesse propor uma estratégia simplificada para a implementação das melhorias propostas pelo guia no contexto de pequenas organizações.

\subsubsection{Organização das práticas fundamentais}

As práticas fundamentais apresentadas na seção 3.3.1 representam uma forma menos abstrata de "como" fazer "o que” o CMMI-Dev sugere que seja feito. Com o intuito de esclarecer um pouco mais a implantação das práticas em questão, realizou-se uma comparação entre os possíveis produtos de trabalho produzidos por meio da execução das práticas e subpráticas do CMMI-Dev das áreas de processo Desenvolvimento e Gerenciamento de Requisitos, com relação aos produtos de trabalho da norma ISO/IEC 15504-5 para os processos de requisitos e aqueles produzidos a partir da execução das práticas fundamentais do PROREQ, de modo que se pudesse classificar a execução de cada uma delas como um requisito necessário ou desejável para o atendimento de um objetivo específico do CMMI-Dev ou mais especificamente, classificar cada uma das práticas fundamentais dentro das subpráticas do CMMI-Dev.

O primeiro passo dessa etapa do trabalho consistiu em organizar as práticas fundamentais como processos, onde cada prática apresenta características de entrada e características de saída. O Quadro 14 representa um exemplo da organização citada. O quadro completo encontra-se no Apêndice A. 


\begin{tabular}{|l|l|l|}
\hline Entradas & Prática Fundamental & Saídas \\
\hline $\begin{array}{l}\text { Solicitação de proposta, relatório } \\
\text { de entrevista com o cliente. }\end{array}$ & $\begin{array}{l}\text { Levantar objetivos ou interesses } \\
\text { de negócios ou fatores críticos } \\
\text { de sucesso. }\end{array}$ & $\begin{array}{l}\text { Documentação contendo } \\
\text { interesses ou objetivos de } \\
\text { negócio e fatores críticos de } \\
\text { sucesso. }\end{array}$ \\
\hline
\end{tabular}

Quadro 14 - Exemplo de prática fundamental, entradas e saídas

Feito isso, foram então alinhados os possíveis produtos de trabalho do CMMIDev, com os produtos da norma ISO/IEC 15504-5 e as características geradas da execução de cada prática fundamental. Deste alinhamento, foi possível agrupar práticas fundamentais dentro de cada subprática das áreas de processo relacionadas do CMMIDev.

Para representar essa informação, adaptou-se o modelo de representação de processo utilizado na parte 5 da norma ISO/IEC 15504. Tal adaptação resultou no quadro cujo exemplo é ilustrado pelo Quadro 15. Para ver o quadro completo consulte o Apêndice A.

\begin{tabular}{|c|c|}
\hline Área de Processo & Desenvolvimento de Requisitos \\
\hline Objetivo Específico & 1. Desenvolver Requisitos do Cliente \\
\hline Prática Específica & $\begin{array}{l}\text { 1. Elicitar necessidades dos stakeholders, expectativas, restrições e } \\
\text { interfaces para todas as fases do ciclo de vida do produto. }\end{array}$ \\
\hline Subpráticas & Práticas Fundamentais \\
\hline \multirow{9}{*}{$\begin{array}{l}\text { 1. Engajar stakeholders } \\
\text { relevantes usando métodos para } \\
\text { elicitar necessidades, } \\
\text { expectativas, restrições e } \\
\text { interfaces. }\end{array}$} & $\begin{array}{l}\text { Levantar objetivos ou interesses de negócios ou fatores críticos de } \\
\text { sucesso }\end{array}$ \\
\hline & Utilizar os interesses de negócio para dirigir a elicitação \\
\hline & $\begin{array}{l}\text { Adquirir conhecimentos de background } \\
\text { - Avaliar ambiente organizacional, ou seja, estrutura, cultura } \\
\text { da organização adquirente, políticas internas, etc. } \\
\text { - Adquirir conhecimento sobre o domínio de aplicação para } \\
\text { intuir conhecimento tácito dos stakehorlders que não } \\
\text { sabem se articular. } \\
\text { - Adquirir sistemas existentes }\end{array}$ \\
\hline & Identificar e consultar todos os stakehoders do projeto \\
\hline & Levantar e registrar fontes de requisitos \\
\hline & Procurar por restrições do domínio de aplicação \\
\hline & Estabelecer uma comunicação contínua com o cliente. \\
\hline & $\begin{array}{l}\text { Estabelecer um mecanismo para o monitoramento constante das } \\
\text { necessidades do cliente }\end{array}$ \\
\hline & Estar sensível a considerações políticas e organizacionais \\
\hline
\end{tabular}




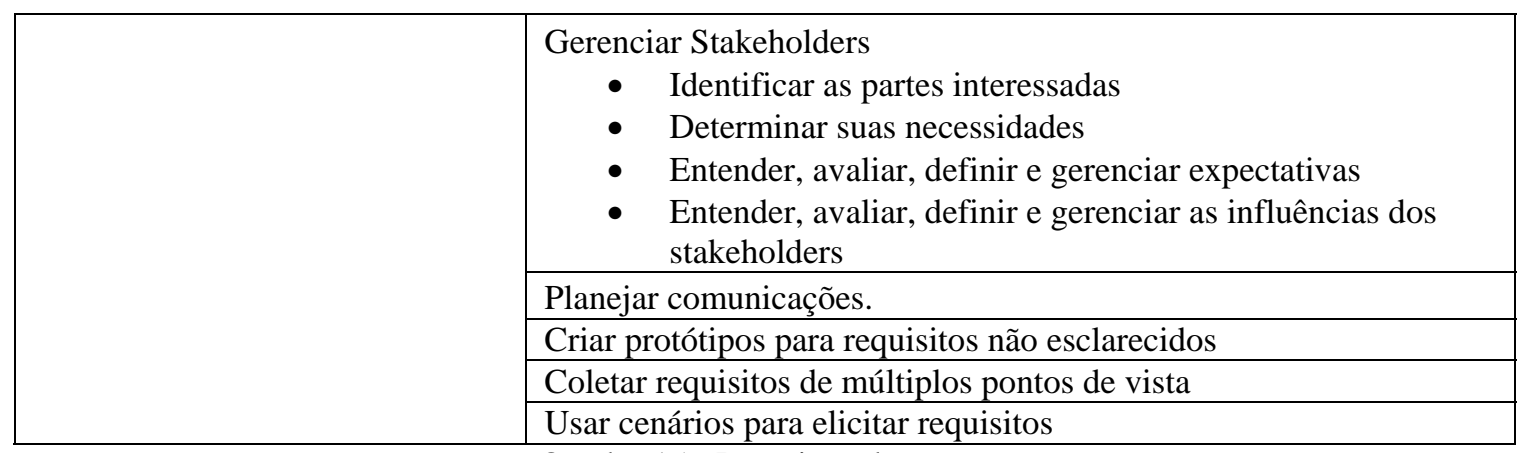

Quadro 15 - Descrição de processo

Com esta estrutura de organização da informação pretende-se facilitar a seleção de práticas utilizando como referencial o modelo CMMI-Dev e todo o seu conhecimento agregado em anos de utilização. Outro aspecto interessante desta estrutura é que ela é bem parecida com a estrutura do modelo de avaliação exemplificado pela norma ISO/IEC 15504, o que pode facilitar a avaliação dos processos instanciados.

\subsubsection{Práticas de organizacionais}

As práticas organizacionais foram retiradas de trabalhos empíricos, relatados na seção 2.10, relacionados à área de melhoria de processo de requisitos ou melhoria de processos de software em geral. As práticas organizacionais e suas respectivas fontes estão listadas no Quadro 16.

\begin{tabular}{|c|c|}
\hline Práticas Organizacionais & Fontes \\
\hline Identificar melhoria com o melhor custo-benefício & \multirow{9}{*}{$\begin{array}{l}\text { (SOMMERVILLE\& } \\
\text { RAMSOM, 2005) }\end{array}$} \\
\hline Considerar habilidades, receptividade e experiência do pessoal envolvido. & \\
\hline Disponibilizar tempo e recursos para o projeto de melhoria do processo & \\
\hline $\begin{array}{l}\text { Assegurar que o projeto de melhoria não causará impactos negativos nos objetivos } \\
\text { de negócio da organização e que não terá custos excessivos }\end{array}$ & \\
\hline Focar melhorias em áreas fracas do processo de RE da organização & \\
\hline Consolidar e padronizar práticas que já estão em uso na organização & \\
\hline Somente introduzir novas práticas quando o custo de introdução for baixo & \\
\hline $\begin{array}{l}\text { Observar fatores técnicos, de negócio, econômicos e políticos no projeto de } \\
\text { melhoria dos processos de RE }\end{array}$ & \\
\hline Criar guias de melhorias baseados em guias de boas práticas & \\
\hline
\end{tabular}




\begin{tabular}{|c|c|}
\hline $\begin{array}{l}\text { Motivar, ganhar comprometimento e entusiasmar o pessoal envolvido: } \\
\text { - Enfatizar que a proposta dos novos processos é ajudar os patrocinadores a } \\
\text { - } \text { Eser seu trabalho. } \\
\text { Esclarecer a necessidade dos processos de requisitos para o pessoal de } \\
\text { desenvolvimento e gerenciamento de produtos } \\
\text { Esclarecer ao pessoal de desenvolvimento de produtos o que significam os } \\
\text { processos de RE e como eles podem se beneficiar da utilização das novas } \\
\text { práticas. }\end{array}$ & \\
\hline $\begin{array}{l}\text { Ganhar comprometimento da gerência por meio do esclarecimento da necessidade } \\
\text { do processo de RE. }\end{array}$ & \\
\hline Demonstrar resultados das melhorias em curto prazo. & \\
\hline Demonstrar para cada pessoa envolvida, a melhora na sua rotina de trabalho. & \\
\hline $\begin{array}{l}\text { Demonstrar por meio de dados empíricos a melhora no atendimento de objetivos de } \\
\text { negócio para todos os níveis da organização. }\end{array}$ & \\
\hline Modelar processo de forma simples. & \\
\hline Efetuar treinamento rápido do processo: máximo de um dia. & \\
\hline Elaborar processo flexível o suficiente para se adequar às necessidades do projeto & \\
\hline $\begin{array}{l}\text { Desenvolver templates e guias/instruções práticas para apoiar a execução das } \\
\text { práticas }\end{array}$ & AL, 2004 \\
\hline $\begin{array}{l}\text { Desenvolver exemplos práticos de documentos preenchidos para apoiar a execução } \\
\text { das práticas }\end{array}$ & \\
\hline Desenvolver plano de implementação & \\
\hline Observar o tamanho da mudança: não pode ser grande & \\
\hline $\begin{array}{l}\text { Desenvolver uma abordagem de implementação da mudança sistemática, } \\
\text { incremental e orientada a pessoas }\end{array}$ & \\
\hline $\begin{array}{l}\text { Envolver todos os grupos de usuários que utilizam ou produzem produtos para o } \\
\text { processo de requisitos, no desenvolvimento do mesmo. }\end{array}$ & \\
\hline Aplicar projetos pilotos antes de se utilizar o processo em toda a organização & \\
\hline Alocar tempo para que a organização realmente mude as suas práticas & \\
\hline $\begin{array}{l}\text { Alocar várias pessoas para efetuar a mudança de modo a eliminar o risco de o } \\
\text { processo desaparecer caso uma pessoa alocada saia da organização. }\end{array}$ & \\
\hline $\begin{array}{l}\text { Alocar pessoas com conhecimento em requisitos para dar treinamento e suporte a } \\
\text { implantação do processo }\end{array}$ & \\
\hline $\begin{array}{l}\text { Treinar todas as pessoas envolvidas com o processo de requisitos para facilitar a } \\
\text { comunicação. }\end{array}$ & \\
\hline $\begin{array}{l}\text { Considerar fatores humanos, sociais e culturais no planejamento do programa de } \\
\text { melhoria de processos. }\end{array}$ & $\begin{array}{l}\text { BEECHAM ET AL, } \\
2003\end{array}$ \\
\hline $\begin{array}{l}\text { Efetuar treinamento prático: produzir pelo menos um de cada produto de trabalho } \\
\text { do processo }\end{array}$ & $\begin{array}{l}\text { KAUPPINEN ET } \\
\text { AL, } 2004\end{array}$ \\
\hline
\end{tabular}

Quadro 16 - Práticas Organizacionais 


\subsubsection{Estratégia de Melhoria}

As práticas organizacionais foram utilizadas juntamente com a estratégia de melhoria de processo proposta pela norma ISO/IEC 15504, para adaptar uma estratégia de melhoria simplificada para o guia. Dessa forma, criou-se o modelo representado na Figura 8.

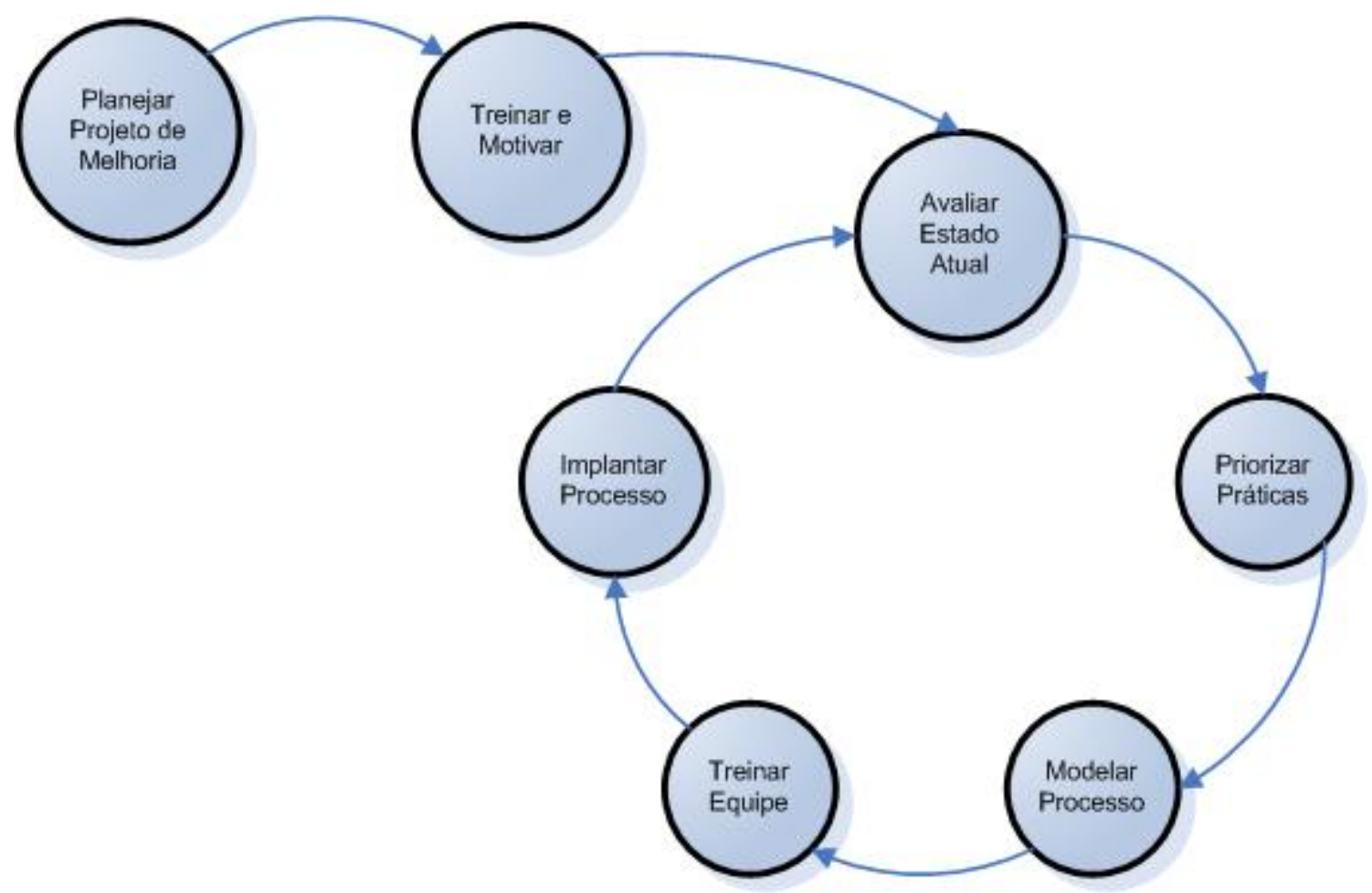

Figura 8 - Estratégia de implementação do PROREQ

Conforme o modelo da Figura 8 o primeiro passo para iniciar o ciclo de melhoria é planejar o projeto de melhoria. 
Passo 1: Planejar o projeto de melhoria

Partindo-se do princípio de que a organização definiu como um objetivo de negócio a melhoria dos seus processos de requisitos, inicia-se então um programa de melhoria dos processos na mesma. Esse programa deve ser tratado como um projeto e possuir início, meio e fim. Assim, o primeiro passo na execução do programa é o passo de planejamento do mesmo. Neste passo devem ser consideradas as práticas descritas no Quadro 17.

\begin{tabular}{|l|}
\hline \multicolumn{1}{|c|}{ Passo 1: Planejar projeto de melhoria } \\
\hline Considerar habilidades, receptividade e experiência do pessoal envolvido. \\
\hline Disponibilizar tempo e recursos para o projeto de melhoria do processo. \\
\hline Elaborar planejamento do projeto de melhoria. \\
\hline Considerar fatores humanos, sociais e culturais no planejamento do programa de melhoria de processos. \\
\hline Utilizar abordagem de implementação da mudança sistemática, incremental e orientada a pessoas. \\
\hline Observar fatores técnicos, de negócio, econômicos e políticos no projeto de melhoria dos processos de RE. \\
\hline Desenvolver plano de implementação \\
\hline Alocar tempo para que a organização realmente mude as suas práticas \\
\hline $\begin{array}{l}\text { Alocar várias pessoas para efetuar a mudança de modo a eliminar o risco de o processo desaparecer caso } \\
\text { uma pessoa alocada saia da organização. }\end{array}$ \\
\hline $\begin{array}{l}\text { Envolver todos os grupos de usuários que utilizam ou produzem produtos para o processo de requisitos, no } \\
\text { desenvolvimento do mesmo. }\end{array}$ \\
\hline
\end{tabular}

Quadro 17 - Práticas organizacionais do passo de planejamento

Como resultado deste passo deve-se obter um plano de projetos. Pode-se utilizar como fonte de orientação para a produção do plano de projeto o Quadro 9, que retrata as práticas PMBOK-Project Management Body of Knowledge.

Passo 2: Treinar e Motivar

O próximo passo visa à facilitação do processo de melhoria e consiste num treinamento inicial de motivação das pessoas envolvidas no projeto. Partindo-se do fato de que no passo anterior as pessoas que trabalharão no programa de melhoria foram escolhidas, neste passo elas devem receber um treinamento referente à área de 
conhecimento de requisitos de software. Este passo consiste na execução das práticas organizacionais descritas no Quadro 18.

Segundo Kauppinen(2004) e outros, o treinamento deve elucidar:

- A importância do processo de requisitos

- Visão geral do processo de requisitos

- Como o processo de RE se relaciona com o processo de desenvolvimento da organização

\begin{tabular}{|c|}
\hline Passo 2: Treinar e Motivar \\
\hline Efetuar treinamento rápido: duração máxima de um dia. \\
\hline Considerar habilidades, receptividade e experiência do pessoal envolvido. \\
\hline $\begin{array}{l}\text { Motivar, ganhar comprometimento e entusiasmar o pessoal envolvido: } \\
\text { - Enfatizar que a proposta dos novos processos é ajudar os patrocinadores a fazer seu trabalho. } \\
\text { - } \\
\text { Esclarecer a necessidade dos processos de requisitos para o pessoal de desenvolvimento e } \\
\text { - } \quad \text { Esclarecer ao pessoal de desenvolvimento de produtos o que significam os processos de ER e } \\
\text { como eles podem se beneficiar da utilização das novas práticas }\end{array}$ \\
\hline Ganhar comprometimento da alta gerência. \\
\hline Ganhar comprometimento de todas as pessoas envolvidas no projeto. \\
\hline Alocar pessoas com conhecimento em requisitos para dar treinamento e suporte a implantação do processo \\
\hline
\end{tabular}

Passo 3: Avaliar o estado atual

Esse passo consiste em avaliar o estado atual dos processos. Ele pode ser dividido em duas partes. A primeira parte deve ser utilizada durante o primeiro ciclo de melhoria e consiste na consulta ao guia, com o intuito de identificar quais práticas fundamentais são utilizadas na organização. Para auxiliar a realização desta parte foi criado um questionário, baseado no modelo de avaliação do RE-GPG, que é exemplificado no Quadro 19.

\begin{tabular}{|l|l|}
\hline \multicolumn{2}{|l|}{ Prática Fundamental: Avaliar Viabilidade Financeira } \\
\hline Entrada & Saída \\
\hline Requisitos do cliente & Relatório de Viabilidade Financeira do projeto \\
\hline
\end{tabular}


Qual a freqüência de utilização desta boa prática na organização?

( ) nunca usada

( ) Pouco usada - usada por alguns indivíduos

( ) Normalmente - usada por muitos times mas de maneiras diferentes

( ) Padronizada - usada na organização de forma padronizada

Quadro 19 - Exemplo de questionário utilizado para avaliação de utilização de práticas fundamentais

A segunda parte deve ser utilizada somente a partir do segundo ciclo de melhoria e visa à avaliação do processo já definido no ciclo anterior, utilizando o processo de avaliação do guia, descrito na seção 3.3.5. O terceiro passo visa o atendimento das práticas descritas no Quadro 20.

\begin{tabular}{|l|}
\hline \multicolumn{1}{|c|}{ Passo 3: Avaliar o estado atual } \\
\hline Identificar melhoria com o melhor custo-benefício - Primeira e segunda parte. \\
\hline Consolidar e padronizar práticas que já estão em uso na organização - Primeira e segunda parte. \\
\hline Demonstrar resultados das melhorias em curto prazo - Segunda parte. \\
\hline Demonstrar para cada pessoa envolvida, a melhora na sua rotina de trabalho - Segunda parte. \\
\hline $\begin{array}{l}\text { Demonstrar por meio de dados empíricos a melhora no atendimento de objetivos de negócio para todos os } \\
\text { níveis da organização - Segunda parte. }\end{array}$ \\
\hline
\end{tabular}

Quadro 20 - Práticas organizacionais do passo de avaliação do estado atual

\section{Passo 4: Selecionar e Priorizar práticas}

Este passo consiste em selecionar e priorizar as práticas que são úteis à organização com base em seu contexto de projetos. Para isso, é necessário que se classifique cada uma das práticas e suas características de produtos de trabalho conforme exemplificado no Quadro 21. Para facilitar a priorização das práticas pode-se criar planilhas digitais.

\begin{tabular}{|l|l|}
\hline \multicolumn{2}{|l|}{ Boa Prática: Avaliar Viabilidade Financeira } \\
\hline Entrada & Saída \\
\hline Requisitos do cliente & Relatório de Viabilidade Financeira do projeto \\
\hline $\begin{array}{l}\text { Prioridade: Qual a importância desta boa prática e seu produto de trabalho para o contexto da empresa? } \\
\text { ( ) Irrelevante ( ) Pouca Importância ( )Importante ( )Muito Importante }\end{array}$ \\
\hline \multicolumn{1}{|c}{ Quadro 21 - Exemplo de questão de priorização de prática fundamental }
\end{tabular}

Neste passo devem ser considerados quatro aspectos de igual importância para o sucesso do programa de melhoria da organização: 
- O contexto de projetos da organização, que envolve uma série de fatores como a área de aplicação, a criticidade dos projetos, as técnicas já conhecidas, etc.

- Os resultados esperados dos processos: a organização deve utilizar como parâmetro essencial na escolha de suas práticas os resultados esperados dos processos de requisitos, listados no Quadro 13, pois tais resultados representam evidência de atendimento dos objetivos dos processos.

- A estrutura de organização do conjunto de práticas fundamentais: o conjunto está organizado segundo a estrutura de áreas de processo do CMMI-Dev, porque considera suas áreas de processo relacionadas a requisitos como um referencial de práticas que devem ser executadas para ter sucesso no processo de requisitos. Portanto, é importante que se considere todas as práticas e subpráticas do CMMIDev no momento de selecionar quais práticas fundamentais devem ser usadas.

- $\quad$ As práticas organizacionais do passo que estão contidas no Quadro 22.

\begin{tabular}{|l|}
\hline \multicolumn{1}{|c|}{ Passo 4: Priorizar Práticas } \\
\hline Identificar melhoria com o melhor custo-benefício \\
\hline $\begin{array}{l}\text { Assegurar que o projeto de melhoria não causará impactos negativos nos objetivos de negócio da } \\
\text { organização e que não terá custos excessivos }\end{array}$ \\
\hline Consolidar e padronizar práticas que já estão em uso na organização \\
\hline Somente introduzir novas práticas quando o custo de introdução for baixo. \\
\hline Observar o tamanho da mudança: não pode ser grande \\
\hline Considerar habilidades, receptividade e experiência do pessoal envolvido. \\
\hline Focar melhorias em áreas fracas do processo de RE da organização. \\
\hline $\begin{array}{l}\text { Envolver todos os grupos de usuários que utilizam ou produzem produtos para o processo de requisitos, no } \\
\text { desenvolvimento do mesmo. }\end{array}$ \\
\hline $\begin{array}{l}\text { Alocar várias pessoas para efetuar a mudança de modo a eliminar o risco de o processo desaparecer caso } \\
\text { uma pessoa alocada saia da organização. }\end{array}$ \\
\hline
\end{tabular}

Quadro 22 - Práticas organizacionais do passo de priorização de práticas

\section{Passo 5: Modelar o processo}

Uma vez definidas as práticas prioritárias, deve-se registrar as práticas selecionadas e modelar o processo de forma que ele possa ser consultado e utilizado pelos seus usuários de maneira padronizada. Para isso, deve-se considerar as práticas do 
Quadro 23. O padrão de modelagem de processo a se utilizar não está inserido no escopo deste trabalho.

\begin{tabular}{|l|}
\hline \multicolumn{1}{|c|}{ Passo 5: Modelar o processo } \\
\hline Modelar o processo de forma simples. \\
\hline Elaborar processo flexível o suficiente para se adequar às necessidades do projeto \\
\hline $\begin{array}{l}\text { Envolver todos os grupos de usuários que utilizam ou produzem produtos para o processo de requisitos, no } \\
\text { desenvolvimento do mesmo. }\end{array}$ \\
\hline $\begin{array}{l}\text { Alocar várias pessoas para efetuar a mudança de modo a eliminar o risco de o processo desaparecer caso } \\
\text { uma pessoa alocada saia da organização. }\end{array}$ \\
\hline Criar guias de melhorias baseados em guias de boas práticas \\
\hline Desenvolver templates e guias/instruções práticas para apoiar a execução das práticas \\
\hline Desenvolver exemplos práticos de documentos preenchidos para apoiar a execução das práticas \\
\hline Quadro 23 - Práticas organizacionais do passo de modelagem de processo
\end{tabular}

Um aspecto importante neste passo é a criação dos templates (gabaritos) dos produtos de trabalho. No PROREQ os produtos de trabalho são as principais evidências de atendimento dos resultados do processo, pois sua produção adequada significa que as práticas fundamentais do processo foram corretamente executadas para atender aos objetivos do processo.

Os produtos de trabalho são definidos como conjuntos de características de produtos de trabalho. A execução das práticas fundamentais gera uma ou mais características de produtos de trabalho ou até produtos de trabalho inteiros. Uma característica de produto de trabalho é uma informação que se encontra num produto e, portanto, pode ser facilmente verificada, como por exemplo, uma seção no documento de requisitos referente a requisitos de usabilidade do software. Desta forma, características de produtos de trabalho devem ser agrupadas de forma a se construir um produto de trabalho. Um exemplo de registro de agrupamento de características em um produto de trabalho pode ser observado pelo Quadro 24.

\begin{tabular}{|l|rl|}
\hline \multicolumn{2}{|c|}{ Produto de trabalho: Lista de fontes de requisitos } \\
\hline Características & $\bullet$ & Pessoas e respectivos cargos \\
& $\bullet$ & Documentos e respectivas origens \\
& $\bullet$ & Sistemas e respectivas origens \\
\hline
\end{tabular}

Quadro 24 - Exemplo de constituição de produto de trabalho

Passo 6: Treinar a equipe 
Modelado o processo, deve-se então elaborar outro treinamento, para tratar do aprendizado do processo definido. Este treinamento deve objetivar o atendimento das práticas descritas no Quadro 25.

\begin{tabular}{|l|}
\hline \multicolumn{1}{|c|}{ Passo 6: Treinar equipe } \\
\hline Considerar habilidades, receptividade e experiência do pessoal envolvido. \\
\hline Efetuar treinamento rápido do processo: máximo de um dia. \\
\hline Efetuar treinamento prático: produzir pelo menos um de cada produto de trabalho do processo. \\
\hline $\begin{array}{l}\text { Motivar, ganhar comprometimento e entusiasmar o pessoal envolvido: } \\
\text { • } \\
\text { - } \\
\text { Enfatizar que a proposta dos novos processos é ajudar os patrocinadores a necessidade dos processos de requisitos para o pessoal de desenvolvimento e } \\
\text { gerenciamento de produtos } \\
\text { Esclarecer ao pessoal de desenvolvimento de produtos o que significam os processos de RE e } \\
\text { como eles podem se beneficiar da utilização das novas práticas. }\end{array}$ \\
\hline Desenvolver exemplos práticos de documentos preenchidos para apoiar a execução das práticas. \\
\hline Treinar todas as pessoas envolvidas com o processo de requisitos para facilitar a comunicação. \\
\hline
\end{tabular}

Passo 7: Implantar processo

Realizado o treinamento, é iniciado então, o último passo do ciclo que consiste na utilização do processo dentro da organização. Neste passo devem ser consideradas as práticas organizacionais contidas no Quadro 26.

\begin{tabular}{|l|}
\hline \multicolumn{1}{|c|}{ Passo 7: Implantar processo } \\
\hline Implementar projetos pilotos antes de aplicar o processo em toda a organização \\
\hline Ganhar comprometimento da alta gerência \\
\hline Ganhar comprometimento de todas as pessoas envolvidas no projeto \\
\hline Alocar tempo para que a organização realmente mude as suas práticas \\
\hline Alocar pessoas com conhecimento em requisitos para dar treinamento e suporte a implantação do processo \\
\hline
\end{tabular}

\subsubsection{Processo de Avaliação}

O PROREQ visa à melhoria das áreas de processo de Desenvolvimento e Gerenciamento de requisitos. O limite máximo da melhoria, para este guia, é representado pelo nível um de capacidade de cada um dos processos. Conforme descrito 
no MPS.BR, a capacidade de processo é a caracterização da habilidade de um processo em atingir os seus objetivos de negócio e está relacionada ao atendimento dos atributos de processo para o nível de capacidade pretendido (MPS.BR, 2006). Sendo assim, seguindo o padrão estabelecido no framework de medidas da ISO/IEC 15504, o processo deve atender ao atributo de processo denominado "PA 1.1 Atributo de execução de processo" descrito a seguir:

- PA 1.1 Atributo de execução de processo: Este atributo mede a extensão de atendimento da proposta do processo. O completo atendimento do atributo significa o atendimento dos resultados definidos para o processo, ou seja, o desenvolvimento de todos os produtos de trabalho que o processo deve produzir.

Os atributos de processo possuem um conjunto de indicadores de atributos de processo associados, os quais dão uma indicação da extensão de atendimento do atributo no processo instanciado. Tais indicadores podem ser atividades, recursos ou resultados associados ao atendimento do atributo proposto pelo processo (ISO-P5, 2004).

O presente trabalho utiliza a classificação de indicadores de atributos de processo do método de avaliação do MPS.Br, denominado MA-MPS. No método em questão existem três indicadores:

- Indicadores diretos: são o objetivo de uma atividade, ou seja, o produto principal da realização de uma atividade.

- Indicadores Indiretos: são utilizados para confirmar que a organização tem condições de implementar um resultado.

- Afirmações: são obtidas em entrevistas e/ou apresentações e confirmam a implementação do processo, seus resultados e atributos.

O PROREQ utiliza os indicadores diretos como sendo os produtos de trabalho produzidos e os indicadores indiretos como sendo os templates (gabaritos) dos produtos de trabalho e registros de práticas utilizadas. Já as afirmações são utilizadas como indicadores de execução de práticas fundamentais que não geram produtos de trabalho explícitos, como por exemplo, "Utilizar interesses de negócio para dirigir elicitação".

Assim, a escala para a caracterização do grau de atendimento de um atributo de processo do PROREQ, adaptou-se a lógica do modelo de avaliação do MPS.BR, para a 
caracterização do grau de atendimento dos resultados esperados, conforme descrito no Quadro 27.

\begin{tabular}{|c|c|}
\hline Grau de implementação & Caracterização \\
\hline Totalmente implementado $(\mathrm{T})$ & $\begin{array}{l}\text { - O produto de trabalho está presente e é } \\
\text { - } \quad \text { Eulgado adequado } \\
\text { trabalho confirmando a implementação } \\
\text { - Existe registro das práticas fundamentais } \\
\text { selecionadas do guia } \\
\text { - Não foi notado nenhum ponto fraco } \\
\text { substancial }\end{array}$ \\
\hline Largamente implementado (L) & $\begin{array}{l}\text { - O produto de trabalho está presente e é } \\
\text { - } \quad \text { Exigado adequado } \\
\text { trabalho confirmando a implementação } \\
\text { - Não existe registro das práticas } \\
\text { fundamentais selecionadas do guia } \\
\text { - Foi notado um ou mais pontos fracos } \\
\text { substanciais }\end{array}$ \\
\hline Parcialmente implementado $(P)$ & $\begin{array}{l}\text { - O produto de trabalho não está presente } \\
\text { ou é julgado inadequado } \\
\text { - } \quad \text { Artefatos/afirmações sugerem que alguns } \\
\text { aspectos do resultado esperado estão } \\
\text { implementados } \\
\text { - } \quad \text { Não existe registro das práticas } \\
\text { - fundamentais selecionadas do guia } \\
\text { - Pontos fracos foram documentados }\end{array}$ \\
\hline Não implementado(N) & - Qualquer situação diferente das acima \\
\hline Não avaliado (NA) & $\begin{array}{l}\text { O projeto não está na fase de } \\
\text { desenvolvimento que permite atender ao } \\
\text { resultado ou não faz parte do escopo do } \\
\text { projeto atender ao resultado. }\end{array}$ \\
\hline Fora do escopo (F) & $\begin{array}{l}\text { - O resultado esperado está fora do escopo } \\
\text { da avaliação, conforme documentado no } \\
\text { plano da avaliação. }\end{array}$ \\
\hline
\end{tabular}

Quadro 27 - Caracterização do grau de atendimento de atributo de processo

Portanto, os atributos de processo do PROREQ são constituídos de produtos de trabalho, os respectivos templates de produtos de trabalho e as afirmações relativas as práticas fundamentais que não geram características explicitamente verificáveis.

Desta forma, criou-se a seguinte lógica: 
- Produtos de trabalho produzidos: Para verificar a produção adequada de um produto de trabalho, deve-se verificar a existência de todas as suas características esperadas, por meio da verificação das práticas fundamentais que o produzem.

- Templates (gabaritos) de produtos de trabalho: as características dos produtos de trabalho devem refletir o resultado de todas as práticas fundamentais contidas no processo instanciado. Sendo assim, cada prática fundamental do processo instanciado deve possuir pelo menos uma característica associada.

- Registros de práticas utilizadas: Para verificar a utilização de práticas fundamentais, deve-se também verificar se há registros de quais delas foram selecionadas do PROREQ e se estão descritas de forma a facilitar o trabalho para os usuários do processo.

- Afirmações: as afirmações são utilizadas para o levantamento de evidências de utilização de práticas que não produzem nenhuma característica diretamente, mas que auxiliam na execução do processo, como por exemplo, a prática fundamental "Utilizar interesses de negócio para dirigir elicitação".

Para o PROREQ, a atribuição de capacidade é realizada com foco no projeto que instanciou o(s) processo(s), o que significa que cada processo de cada projeto terá uma nota atribuída. Assim sendo, utilizando a estrutura do framework da norma ISO/IEC 15504, o processo será classificado como estando no nível um de capacidade se todos os seus atributos estiverem pontuando nas escalas L(largamente implementado) ou $\mathrm{T}$ (Totalmente implementado).

\subsection{CONSIDERAÇÕES FINAIS}

Neste capítulo foram apresentados os principais componentes do guia PROREQ e a sua forma de utilização. Foram listadas as práticas fundamentais e organizacionais, bem como as origens de cada uma delas, a forma de organização das práticas com relação ao CMMI-Dev e as suas características de entrada e saída.

Descreveu-se o modelo de avaliação proposto pelo guia, adaptado do método de avaliação do MA-MPS e da norma ISO/IEC 15504. Foi descrita a estratégia de melhoria de processos proposta pelo guia, adaptada da estratégia de melhoria da norma ISO/IEC 
15504 adicionada das práticas organizacionais levantadas de trabalhos empíricos da área de melhoria de processos de software e de processos de requisitos.

\section{CAPÍTULO 4 ESTUDO DE CASO}

\subsection{CONSIDERAÇÕES INICIAIS}

Neste capítulo são descritos os principais resultados de um estudo de caso que relata a utilização do PROREQ em projetos-piloto em uma pequena organização desenvolvedora de software. São relatados os resultados positivos e negativos identificados no estudo realizado.

\subsection{PLANEJAMENTO E EXECUÇÃO DO ESTUDO}


O objetivo inicial da organização desenvolvedora de software onde se executou o estudo de caso descrito neste capítulo era simplesmente melhorar os seus processos de requisitos. Nesta seção são descritos os dois ciclos de melhoria realizados na área de negócios da organização que foi alvo do estudo de caso. É importante ressaltar que não havia interesse imediato em se certificar no modelo CMMI-Dev ou qualquer outro e esse fato influenciou no programa de melhorias.

Assim, seguindo a estratégia de melhoria de processo proposta pelo guia PROREQ, descreve-se a seguir os dois ciclos de melhoria realizados.

\subsubsection{Primeiro ciclo de melhoria}

Passo 1: Planejar o programa de melhoria

Neste passo foi realizado o planejamento do projeto de melhoria da organização e para isso utilizou-se a tabela de boas práticas do PMBOK. O planejamento baseou-se na estratégia de implantação do PROREQ e os marcos do cronograma produzido refletiam os passos da estrtatégia. As tarefas foram listadas com base nesses marcos.

Foi alocado um gerente de projetos para a execução das tarefas do programa de melhoria. O prazo inicial estipulado para o primeiro ciclo de melhoria foi de dois meses.

Passo 2: Treinar e motivar equipe

Durante o planejamento, o responsável pelo projeto decidiu por não executar este passo, pois a equipe já se considerava motivada e com entendimento suficiente a respeito da necessidade de melhoria dos processos de requisitos da organização, devido aos constantes problemas enfrentados. Sendo assim, após o planejamento iniciou-se o levantamento do estado atual do processo.

Passo 3: Avaliar o estado atual 
Para auxiilar na execução deste passo e do próximo, foi elaborada uma planilha contendo todas as práticas fundamentais em uma coluna, suas respectivas entradas e saídas em duas outras colunas, a frequência de utilização e a prioridade de cada prática para a organização em duas outras colunas. Utilizando tal planilha, foram então identificadas as práticas utilizadas na organização.

Como resultado, observou-se que havia uma única prática fundamental padronizada na organização que era “Levantar objetivos e interesses de negócio”. As atividades de desenvolvimento restantes eram realizadas com base nas informações coletadas nesta etapa, que geralmente ficava armazenada em um documento que não apresentava nenhuma identificação explícita dos requisitos e não possuía detalhamento suficiente para apoiar o desenvolvimento do produto de software.

As práticas restantes que foram identificadas eram utilizadas com pouca frequência e de forma esporádica e aleatória, ou seja, de acordo com as habilidades e conhecimentos da equipe responsável pelo desenvolvimento do produto.

Para o levantamento destas questões foram questionados o diretor executivo, o gerente de vendas, um coordenador de projetos e dois desenvolvedores.

A principal reclamação do diretor executivo e do gerente de vendas foi referente ao número de interrupções a que estavam sujeitos em sua rotina de trabalho, para esclarecimento de dúvidas de desenvolvedores, devido à ausência de um documento de requisitos onde os requisitos estivessem reunidos em um nível de detalhes suficiente para embasar o trabalho.

Passo 4: Selecionar e Priorizar práticas

Com base nos resultados da avaliação do estado atual dos processos de requisitos da organização, neste passo foram selecionadas as práticas fundamentais necessárias ao processo da organização, segundo a visão da equipe que utilizaria o processo no desenvolvimento do projeto piloto. As práticas eram apresentadas aos membros da equipe e quando necessárias, as dúvidas eram esclarecidas pelo responsável pelo projeto de melhoria. 
Assim, foram atribuídas prioridades às práticas selecionadas e em seguida, foram priorizadas as práticas fundamentais mais importantes. Pelo fato de não buscar a certificação CMMI-Dev, decidiu-se desconsiderar as indicações de se utilizar as práticas do modelo como referência para seleção e priorização de práticas fundamentais. O resultado desta etapa foi a seleção das seguintes práticas:

- Levantar objetivos e interesses de negócio;

- Definir uma estrutura padrão para o documento de requisitos;

- Definir gabaritos-padrão para descrever os requisitos;

- Usar uma linguagem simples, consistente e concisa;

- Identificar unicamente cada requisito;

- Levantar requisitos por meio de entrevistas;

- Utilizar interesses de negócio para dirigir elicitação;

- Modelar arquitetura do sistema;

- Alocar requisitos para os componentes da arquitetura;

Passo 5: Modelar o processo

Com base nas práticas fundamentais selecionadas no passo anterior e nas práticas organizacionais relacionadas a este passo, foi modelada uma primeira versão do processo da empresa, que focou-se na adoção de um gabarito (template) de documento de requisitos, bem como a definição de como seria a descrição de cada requisito individualmente.

Neste passo, constatou-se que existem casos em que uma característica de produto de trabalho necessária em um documento pode ser a responsável pela criação de uma prática de trabalho no processo. Como exemplo, pode-se citar que durante utilização da prática que pede a criação de gabaritos-padrão (templates) para descrição de requisitos individuais, foram levantadas características de produtos de trabalho que não estavam explicitamente definidas no conjunto de caracteristicas previstas pelo guia. Com isso, ao se modelar o processo foram adicionadas práticas que diziam respeito a tais 
características, como por exemplo, "Elaborar Detalhamento das Telas especificando o tipo, o tamanho e a obrigatoriedade dos campos de cada tela na tabela correspondente”.

Os produtos de trabalho criados nesta primeira versão do processo foram uma proposta técnica e um documento de requisitos.

Passo 6: Treinar a equipe no processo

Definida a primeira versão do processo, foi elaborado um treinamento rápido para o processo. Foram envolvidos todos os profissionais que seriam responsáveis pela execução do projeto-piloto de implantação do processo. O treinamento durou três horas e foi focado na construção dos produtos de trabalho definidos.

Passo 7: Implantar processo

Neste passo, o processo foi utilizado pela equipe. O gerente de projetos responsável pelo programa de melhoria foi alocado para dar suporte à utilização do

processo criado. Foram selecionados dois projetos-piloto com duração de dois meses cada um. Todos os produtos de trabalho previstos no processo foram produzidos.

\subsubsection{Segundo ciclo de melhoria}

Conforme definido pela estratégia de melhoria do PROREQ (Figura 7), a partir do segundo ciclo executam-se somente os passos 3 a 7, já que os passos 1 e 2 não fazem parte do ciclo.

Passo 3: Avaliar estado atual

Finalizados os projetos-piloto, realizou-se então uma avaliação do estado atual do processo, com base no processo instanciado no primeiro ciclo. Constatou-se que os produtos de trabalho do processo foram produzidos corretamente, no entanto, foram constatados sérios problemas em razão da falta de inspeções de validação de requisitos e também da falta de implantação de políticas de gerenciamento de requisitos. Com isso, 
percebeu-se que a adoção de práticas que tratassem de validação poderia resolver uma série de problemas relacionados a retrabalho e insatisfação dos clientes.

Cabe ressaltar que os problemas relacionados à falta de validação poderiam não ter acontecido caso a equipe tivesse considerado dois referenciais sugeridos para a seleção de suas práticas que são: o CMMI-Dev e os resultados esperados dos processos levantados do MPS.BR .

Como aspecto positivo, por meio da comparação entre o percentual médio do número de horas de retrabalho de projetos da empresa com o percentual de número de horas de retrabalho dos projetos-piloto, constatou-se a redução de aproximadamente 30\% do retrabalho.

Passo 4: Selecionar e priorizar práticas

Constatados os resultados da implantação das boas práticas básicas iniciais, houve maior motivação por parte do patrocinador do projeto de melhoria. Nesse novo ciclo, foram usados os dados da avaliação anterior e foram priorizadas as práticas que solucionassem problemas relativos à validação e gerenciamento de requisitos entre outros. Como resultado dessa etapa foram selecionadas vinte práticas fundamentais:

- Utilizar necessidades de negócio para dirigir elicitação;

- Identificar fontes de requisitos;

- Realizar entrevistas para levantar requisitos;

- Registrar raciocínio que levou ao requisito;

- Consultar fontes de requisitos;

- Definir processo operacional;

- Definir ambiente operacional;

- Definir limites do sistema;

- Desenvolver requisitos em termos técnicos necessários para o projeto do produto e dos componentes do produto;

- Documentar rastreabilidade entre requisitos do cliente e do produto;

- Modelar arquitetura do sistema;

- Alocar requisitos para os componentes da arquitetura; 
- Priorizar requisitos;

- Detectar conflitos;

- Resolver conflitos;

- Comunicar decisões de resolução de conflitos;

- Verificar se os requisitos atendem as necessidades e objetivos do negócio;

- Montar times multidisciplinares para a revisão de requisitos;

- Definir checklists para validação de requisitos;

- Utilizar protótipos para animar os requisitos;

\section{Passo 5: Modelar o processo}

Nesse novo ciclo de melhoria, o contexto era diferente, pois paralelamente ao programa de melhoria do processo de requisitos iniciou-se um programa de melhoria para os outros processos da organização. Com isso, as atividades das áreas de processo de requisitos foram embutidas no processo da organização.

\begin{tabular}{|c|c|}
\hline Atividade & V05 - Definir requisitos do Cliente \\
\hline Objetivo & $\begin{array}{l}\text { Levantar as necessidades, expectativas e restrições do cliente } \\
\text { com relação ao produto. }\end{array}$ \\
\hline Papéis & $\begin{array}{l}\text { Engenheiro de Requisitos } \\
\text { Equipe de Vendas }\end{array}$ \\
\hline Entradas & $\begin{array}{l}\text { Solicitação de Proposta, Gabarito de Documento de } \\
\text { Rastreabilidade, Gabarito de Proposta Técnica, Gabarito de } \\
\text { Documento de Entrevista. }\end{array}$ \\
\hline Saídas & Proposta Técnica, Documento de Rastreabilidade. \\
\hline Recursos & MS Word, MS Excel. \\
\hline Tarefas & $\begin{array}{l}\text { - Analisar necessidades de negócio contidas na } \\
\text { Solicitação de Proposta para dirigir o levantamento de } \\
\text { requisitos. } \\
\text { - Identificar fontes de requisitos, criar Documento de } \\
\text { Rastreabilidade e preencher a aba "Lista de Fontes". São } \\
\text { exemplos de fontes: pessoas, documentos, sistemas } \\
\text { legados, etc. } \\
\text { - Caso necessário, consultar sistemas legados e } \\
\text { documentação relacionada, para levantar requisitos do } \\
\text { cliente. } \\
\text { - Levantar requisitos do cliente por meio de entrevistas. }\end{array}$ \\
\hline
\end{tabular}




\begin{tabular}{|l|l|}
\hline • Preparar entrevistas antecipadamente com base \\
nas necessidades de negócio. \\
• Criar Proposta Técnica e documentar requisitos do \\
cliente na seção "Requisitos Preliminares e \\
Funcionalidades Gerais” em linguagem natural, de forma \\
que o cliente possa entendê-los. \\
• Gerar modelo conceitual do sistema na seção "Modelo \\
Conceitual" da Proposta Técnica. Uma sugestão de \\
modelo conceitual é o mapa do site. \\
• No Documento de Rastreabilidade, preencher a aba \\
"Lista de Interações" com as fontes de requisitos do \\
cliente e o raciocínio que levou ao requisito.
\end{tabular}

Quadro 28 - Exemplo de atividade do Processo Vender

O resultado deste passo foi a modelagem das práticas, agrupadas em atividades de processo, conforme exemplificado no Quadro 28. As atividades criadas que tratam as áreas de processo de requisitos estão divididas entre dois processos particulares da empresa, chamados “Vender” e “Engenharia de Requisitos”.

Foram criadas cinco atividades de requisitos, cada uma tratando um conjunto de práticas e consequentemente gerando um conjunto de produtos de trabalho. As figuras de 9 a 13 listam cada uma das atividades resultantes, contendo suas boas práticas e seus produtos de trabalho.

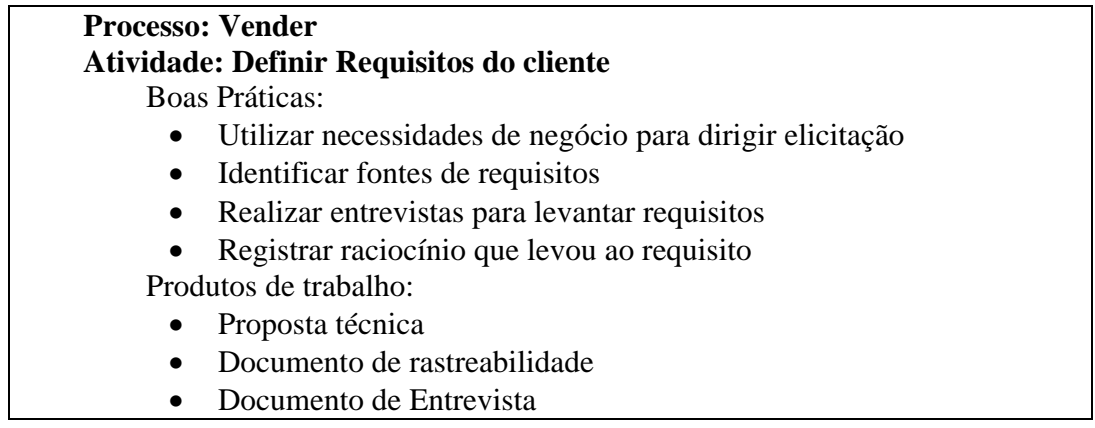

Figura 9 - Atividade Definir Requisitos do Cliente

Processo: Vender

Atividade: Definir Requisitos do cliente

Boas Práticas:

- Consultar fontes de requisitos

- Definir processo operacional

- Definir ambiente operacional

- Definir limites do sistema

- Derivar requisitos do cliente em requisitos do produto

- Documentar rastreabilidade entre requisitos do cliente e do produto Produtos de trabalho:

- Documento de rastreabilidade

- Documento de Requisitos

Figura 10 - Atividade Definir Requisitos do Produto 


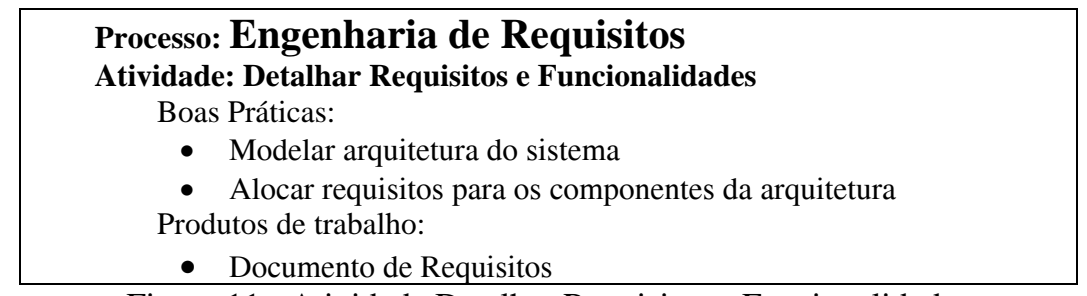

Figura 11 - Atividade Detalhar Requisitos e Funcionalidades

\section{Processo: Engenharia de Requisitos}

Atividade: Analisar criticamente os requisitos

Boas Práticas:

- Priorizar requisitos

- Detectar conflitos

- Resolver conflitos

- Comunicar decisões de resolução de conflitos

- Verificar se os requisitos atendem as necessidades e objetivos do negócio

Produtos de trabalho:

- Documento de Requisitos

- Documento de rastreabilidade

- Lista de Conflitos

Figura 12 - Atividade Analisar criticamente os requisitos

\section{Processo: Engenharia de Requisitos \\ Atividade: Verificar e validar os requisitos}

Boas Práticas:

- Montar times multidisciplinares para a revisão de requisitos

- Definir checklists para validação de requisitos

- Utilizar protótipos para animar os requisitos

Produtos de trabalho:

- Documento de Requisitos

- Checklist de verificação

Figura 13 - Atividade verificar e validar os requisitos

Passo 6: Treinar a equipe no processo

A equipe foi novamente treinada no processo. O treinamento foi focado no desenvolvimento de exemplos práticos dos documentos criados pela equipe responsável pelo programa de melhoria.

Passo 7: Implantar o processo

Foram utilizados dois projetos-piloto para a instanciação do processo, referidos neste trabalho como A e B. Os projetos já foram finalizados. 
O projeto A tratou da especificação dos requisitos para uma organização que visava melhorar seus processos de comunicação internos e externos por meio de um sistema Web. Este projeto tratou apenas da fase de engenharia de requisitos de um projeto maior. Foi um projeto extenso, onde a previsão de duração era de três meses e realizou-se em doze meses. Como aspecto positivo desse piloto tem-se que todos os produtos do processo foram gerados adequadamente. Dois aspectos negativos foram o atraso e a inviabilidade na constatação da efetividade do processo de requisitos, visto que ainda não se iniciou o desenvolvimento do produto final.

O projeto B visava à construção de um sistema para a execução de testes médicos. Devido à maturidade do cliente adquirente desse projeto, foi necessário acrescentar documentos ao processo, tais como um manual de usuário. Vale lembrar que durante o passo quatro desse segundo ciclo de melhoria, a prática "Elaborar rascunhos de manual de usuário" foi selecionada para compor o processo, no entanto, a prioridade atribuída à mesma não foi suficiente para que ela entrasse no processo modelado.

Como resultados positivos, esse piloto apresentou todos os produtos de trabalho propostos e outros mais, como por exemplo o manual de usuário e os planos de teste, baseados no documento de requisitos. Como resultado negativo constatou-se a alocação subestimada do esforço necessário para a execução dos processos de requisitos do projeto. Esta estimativa incorreta ocasionou problemas de gerenciamento de requisitos, tais como mudanças não rastreadas e conseqüente retrabalho de desenvolvimento.

A inclusão de documentos ao processo instanciado, para atender a solicitação do cliente, reforça a idéia de que o guia PROREQ precisa ser utilizado para a criação de processos para cada projeto da organização, podendo-se reutilizar processos para projetos com as mesmas características.

\subsection{CONSIDERAÇÕES FINAIS}

Neste capítulo foram apresentados os resultados de um estudo de caso realizado em uma pequena organização desenvolvedora de software, cujo objetivo era validar a facilidade de uso e a utilidade do PROREQ. 
Por meio dos resultados foram identificadas forças e fraquezas do guia que orientarão os possíveis futuros trabalhos de melhoria do mesmo.

Pode-se notar que os principais problemas encontrados relacionam-se com erros na estimativa de esforço e duração necessários para a execução do processo de requisitos e também problemas relacionados ao não cumprimento das sugestões do guia.

\section{CAPÍTULO 5 CONCLUSÕES E TRABALHOS FUTUROS}

\subsection{SÍNTESE DO TRABALHO}

Inicialmente foi levantado um conjunto de boas práticas. Esse conjunto foi então classificado como práticas fundamentais e organizacionais, seguindo a classificação de processos proposta pela ISO/IEC 12207. As práticas fundamentais estão relacionadas a aspectos técnicos dos processos de requisitos. Elas foram classificadas segundo a estrutura das áreas de processo do CMMI-Dev de modo a não perder o conhecimento acumulado em anos de trabalhos empíricos utilizando o modelo. A elas são associadas as características e/ou os produtos de trabalho esperados pela sua execução, o que possibilita um melhor entendimento de como atender aos objetivos específicos do CMMI-Dev. Tais práticas foram listadas com o objetivo de descrever de forma mais detalhada as atividades que devem ser realizadas para aumentar o nível de capacidade dos processos de requisitos da organização, segundo o modelo CMMI-Dev. 
Já as práticas organizacionais, relacionam-se aos aspectos que devem estar presentes em um programa de melhoria de processo de software em geral, ou seja, podem ser reutilizadas para qualquer programa de melhoria de processos de software, como por exemplo, para a melhoria do processo de gerenciamento de configuração ou qualquer outra área de processo do CMMI-Dev.

O modelo de avaliação proposto pelo PROREQ é embasado no framework de avaliação da norma ISO/IEC 15504 e no método de avaliação do MPS.BR. Deste modo, o usuário do guia, ao usá-lo, tem a possibilidade de ter um contato inicial com conceitos de avaliação de processos da norma ISO/IEC 15504 e do método de avaliação do MPS.BR. Outro aspecto importante a ser considerado é que caso uma organização esteja objetivando melhorar seus processos de forma a atingir o nível um capacidade do CMMIDev, a execução de uma avaliação utilizando o modelo de avaliação do PROREQ será responsável por indicar que os objetivos genéricos do modelo para as áreas de processo avaliadas, sejam ou não atendidos.

Por fim, adaptou-se uma estratégia de melhoria de processo utilizando-se como base a estratégia proposta pela norma ISO/IEC 15504 e as práticas organizacionais. Tal estratégia tem o objetivo de orientar os usuários do PROREQ no que diz respeito ao conjunto de atividades que devem ser seguidas para que o programa de melhoria dos processos de requisitos obtenha sucesso. Com ela, tenta-se resolver o problema de orientar as organizações em como efetuar a mudança em seus processos de desenvolvimento e manutenção.

Os resultados do estudo de caso indicaram forças e fraquezas do guia. Como aspectos positivos da utilização do guia percebeu-se que a melhoria dos processos de requisitos foi responsável pela diminuição de $30 \%$ do retrabalho dos projetos na área de negócios da organização que realizou o estudo. Em contrapartida, foram constatadas fraquezas tais como a ausência de parâmetros concretos de priorização de práticas, ou seja, quais práticas são essenciais para cada contexto; ausência de parâmetros concretos para que a organização mensure o número de práticas limitante para cara ciclo do seu processo de mudança e ausência de parâmetros concretos para auxiliar a organização a mensurar o esforço e a duração necessários para cada ciclo de mudança. 


\subsection{CONTRIBUIÇÕES DO TRABALHO}

Conforme mencionado anteriormente, a implantação de modelos de qualidade internacionalmente conhecidos como o CMMI-Dev ou a ISO/IEC 15504, tem-se apresentado inviável para a maioria das pequenas e médias empresas nacionais. Com o intuito de facilitar a implantação dos processos de requisitos em uma organização que não possui capacidade financeira para contratar uma consultoria externa, foram estudados os principais fatores que causam as dificuldades inerentes a um programa de melhoria de processos de software de uma organização e os resultados deste estudo foram utilizados como embasamento para a construção de um guia para a melhoria dos processos de requisitos.

Nesse sentido, o presente trabalho contribui por meio de um conjunto de práticas fundamentais que pode embasar a criação de processos em uma organização que não tem nenhum conhecimento de requisitos. Somado a isso, no PROREQ as práticas fundamentais encontram-se organizadas segundo a estrutura do modelo CMMI-Dev, de modo a possibilitar que sejam utilizadas as práticas do modelo como referenciais para a escolha das práticas fundamentais que irão compor o processo da organização executora do programa de melhoria.

O PROREQ contribui também com a proposição de uma abordagem sistemática para a melhoria dos processos. Tal abordagem é atendida por meio da estratégia de melhoria proposta, que se utiliza da estratégia de melhoria da norma ISO/IEC 15504 e do conjunto práticas organizacionais. Essa estratégia pode ser utilizada como base para a condução de programas de melhoria de processo de software de qualquer área de processo e o conjunto de práticas organizacionais pode ser utilizado para desenvolver outras estratégias de melhoria.

Outra contribuição importante do PROREQ diz respeito aos seus referenciais de construção, ou seja, ele foi construído com base em um conjunto de guias, livros, modelos e normas utilizados internacionalmente. Desta forma, soma aspectos positivos de cada um deles e retira aspectos negativos já testados na prática, como por exemplo, a dificuldade das organizações em descobrir como realizar as melhorias de processo utilizando o CMMI-Dev. 
O modelo de avaliação proposto pelo PROREQ contribui para completar o guia, pois é por meio dele que se atesta a efetividade dos processos instanciados.

Finalmente, os resultados do estudo de caso indicam que a utilização do guia resultou em melhorias nos processos de requisitos e consequentemente houve reduções no percentual relativo de horas de retrabalho dos projetos da organização executora do estudo de caso.

\subsection{TRABALHOS FUTUROS}

Pretende-se, como trabalhos futuros, aplicar o PROREQ em outras organizações de desenvolvimento de software objetivando validar a utilidade do modelo e também melhorar a sua lógica de utilização.

Pretende-se ainda, estudar os aspectos relacionados à priorização das práticas utilizadas por cada organização, ao numero limitante de práticas selecionadas para cada um dos ciclos de mudança e ao tempo necessário para cada ciclo de mudança, proporcionalmente ao número de recursos humanos envolvidos nos projetos pilotos.

Há o ímpeto de disponibilizar o trabalho em uma wiki para facilitar a sua utilização e torná-la pública de modo a se criar um REBOK - Requirements Engineeging Body Of Knowledge, seguindo a idéia de guias como o SWEBOK - Software Engineering Body of Knowledge, PMBOK - Project Management Body of Knowledge e o recentemente criado CMBOK - Configuration Management Body Of Knowledge.

Outro possível trabalho futuro é abranger um maior número de áreas de processo do CMMI-Dev que se relacionam com as estudadas neste trabalho, tais como Gerenciamento de Configuração e Solução Técnica. 


\section{REFERÊNCIAS}

BEECHAM, S., HALL, T., RAINER, A. Defining a Requirements Process Improvement Model, In Software Quality Journal, 247-279, Inc. Manufactured in the Netherlands, 2005.

BEECHAM, S.; HALL, T.; RAINER, A. Software Process Improvement Problems in Twelve Software Companies: An Empirical Analysis, Empirical Software Engineering, 8, 7-42, 2003.

C1-MPS.BR Apostila do Curso de Introdução ao MPS.BR. 2006. 123p. 
CARVALHO, A. E. S.; TAVARES, H. C.; CASTRO, J. B. Uma Estratégia para Implantação de uma Gerência de Requisitos Visando a Melhoria dos Processos de Software, In: IV Workshop em Engenharia de Requisitos, Buenos Aires, Argentina, p.32-54, Novembro, 2001.

CMMI-SE/SW - CMMI for Systems Engineering/Software Engineering, SEI - Software Engineering Institute, Staged Representation Version 1.1, Technical report CMU/SEI2002-TR-02. Pittsburgh, PA: Software Engineering Institute, Carnegie Mellon University, 2002.

CUEVAS, G.; SERRANO, A.; SERRANO, A. Assessment of the requirements management process using a two-stage questionnaire, Proceedings of the Fourth International Conference on Quality Software (QSIC’04), 2004.

GIMENES, I. M. S., WEISS, G. M., HUZITA, E. H. M. Um Padrão para Definição de um Gerenciador de Processos de Software, II Workshop Iberoamericano de Requisitos y Ambientes Software (IDEAS’99), San José, Costa Rica, Março, 1999.

HAGGE, L.; LAPPE, K. Patterns for the RE Process, In: Requirements Engineering Conference, Proceedings of the 12th IEEE International Requirements Engineering Conference, p. 90-99, 2004.

HALL, T.; BEECHAM, S.; RAINER A. Requirements problems in twelve software companies: an empirical analysis, IEE Proc-Softw., Vol. 149, No.5, Outubro 2002.

HOFFMANN, H. F.; LEHNER, Franz, Requirements Engineering as a Success Factor In Software Projects, IEEE Software, p. 58-66, Julho/Agosto 2001.

IBANEZ, M.; REMPP, H. European User Survey Analysis. Report USV-EUR 2.1, 30 de Janeiro de 1996. 
IEEE std.610.12, IEEE Standard Glossary of Software Engineering Terminology. Relatório Técnico, IEEE, 1990.

ISO-A1 - ISO/IEC 12207 Amendment: Information Technology - Amendment 1 to ISO/IEC 12207, The International Organization for Standardization and the International Electrotechnical Commission, Geneve: ISO, 2001.

ISO-A2 - ISO/IEC 12207 Amendment: Information Technology - Amendment 2 to ISO/IEC 12207, The International Organization for Standardization and the International Electrotechnical Commission, Geneve: ISO, 2004.

ISO/IEC 9126, Software product evaluation - Quality characteristics and guidelines for their use, International Organization for Standardization, 1991.

ISO/IEC 14598, Information Technology - Evaluation of Software Products - Part 1 General guide, International Organization for Standardization, 1998.

ISO-P1 - The International Organization for Standardization and the International Electrotechnical Commission. ISO/IEC FDIS 15504-1: Information Technology Process Assessment - Part 1 - Concepts and Vocabulary, Geneve: ISO, 2003.

ISO-P2 - The International Organization for Standardization and the International Electrotechnical Commission. ISO/IEC FDIS 15504-2: Information Technology Process Assessment - Part 2 - Performing an Assessment, Geneve: ISO, 2003.

ISO-P3 - The International Organization for Standardization and the International Electrotechnical Commission. ISO/IEC FDIS 15504-3: Information Technology Process Assessment - Part 3 - Guidance on Performing an Assessment, Geneve: ISO, 2003. 
ISO-P4 - The International Organization for Standardization and the International Electrotechnical Commission. ISO/IEC FDIS 15504-4: Information Technology Process Assessment - Part 4 - Guidance on use for Process Improvement and Process Capability Determination, Geneve: ISO, 2003.

ISO-P5 - The International Organization for Standardization and the International Electrotechnical Commission. ISO/IEC FCD 15504-5: Information Technology - Process Assessment - Part 5: An exemplar Process Assessment Model, Montreal: ISO/IEC JTC1 SC7, 2004.

JIANG, L.; EBERLEIN, A.; B. H., FAR A Methodology for Requirements Engineering Process Development, In: Proceedings of the 11th IEEE International Conference and Workshop on the Engineering of Computer-Based Systems (ECBS’04), v. 00, p. 263, 2004.

KAUPPINEN, M.; VARTIAINEN, M.; KONTIO, J.; KUJALA, S.; SUPONEN, R. Implementing requirements engineering processes throughout organizations: success factors and challenges, Information and Software Technology, v.14, n. 46, p. 937-953 Maio, 2004.

KOTONYA, G.; SOMMERVILLE, I. Requirements Engineering: Process and Techniques, John Wiley and Sons, 1998.

LAMSWEERDE, A. V., Requirements Engineering in the Year 00: A Research Perspective, In: 22nd International Conference on Software Engineering (ICSE '00), Limerick, Ireland, p. 5, 2000.

MPS.BR - Guia de Geral, versão 1.1, Associação para a promoção da excelência do software brasileiro - SOFTEX, 2006. Disponível em: < http://www.softex.br/mpsbr/_guias/default.asp>. Acesso em: 01 agosto de 2006. 
MA-MPS - Guia de Avaliação, versão 1.0, Associação para a promoção da excelência do software brasileiro - SOFTEX, 2006. Disponível em: < http://www.softex.br/mpsbr/_guias/default.asp>. Acesso em: 01 agosto de 2006, 2006.

MR-MPS - Guia de Implementação, Parte 1: Nivel G, versão 1.0, Associação para a promoção da excelência do software brasileiro - SOFTEX, 2006. Disponível em: < http://www.softex.br/mpsbr/_guias/default.asp>. Acesso em: 01 agosto de 2006.

NIAZI, M.; WILSON, D.; ZOWGHI, D.; WONG, B. A Model for the Implementation of Software Process Improvement: An Empirical Study, PROFES 2004, LNCS 3009, pp. 116,2004

NUSEIBEH B.; EATSERBROOK S. Requirements Engineering: A Roadmap, In: International Conference on Software Engineering, Proceedings of the Conference on The Future of Software Engineering, ACM, p. 35-46, 2000.

PMBOK - Project Management Body of Knowledge, PMI - Project Management Institute. A guide to the project management body of knowledge. Syba: PMI Publishing Division, 2004.

PRESSMAN, R. S. Software engineering : a practitioner's approach, 6th ed, Boston, Mass : McGraw-Hill, c2005.

SEI - Software Engineering Institute, CMMI ${ }^{\circledR}$ for Development, Version 1.2, CMU/SEI2006-TR-008 ESC-TR-2006-008, Improving processes for better products, August, 2006. SOMMERVILLE, I. Engenharia de Software, Sexta edição. São Paulo: Addison Wesley, 2003.

SOMMERVILLE, I.; SAWYER, P. Requirements Engineering - A Good Practice Guide, New York: John Wiley \& Sons, 1997. 
SOMMERVILLE, I., RANSOM, J. An Empirical Study of Industrial Requirements Engineering Process Assessment and Improvement, In ACM Transactions on Software Engineering and Methodology, Vol. 14, No. 1, Pages 85-117, January, 2005

STA - 1st Intl. IEEE Symp. on Requirements Engineering, Jan. The Standish Group, "Software Chaos", Disponivel em: <http://www.standishgroup.com/chaos.html> , 1995.

STRAUSS A.; CORBIN J. Basics of Qualitative Research: Techniques and Procedures for Developing Grounded Theory, Second ed., Sage Publications, Inc, Thousand Oaks, CA, USA, 1998.

SWEBOK - Guide to the Software Engineering Body of Knowledge, A project of the IEEE Computer Society Professional Practices Committee, 2004. Disponivel em: $<$ http://www.swebol.org > . Acesso em: 25 novembro de 2005.

TSUKUMO, A. N.; RÊGO, C. M.; SALVIANO, C. F.; AZEVEDO, G. F.; MENEGHETTI, L. K.; COSTA, M. C. C.; CARVALHO, M. B.; COLOMBO, R. M. T. Qualidade de Software: Visões de Produto e de Processo. In: II Escola Regional de Informática da Sociedade Brasileira de Computação Regional de São Paulo, II ERI da SBC - Piracicaba , SP , págs: 173 - 189, Junho de 1997.

WEBER, K. C.; ROCHA, A.R.; ALVES, A.; AYAlA, A. M.; GONÇALVES A.; PARET, B.; SALVIANO, C.; MACHADO, C. F.; SCALET, D.; PETIT, D.; ARAÚJO, E.; BARROSO, M. G.; OLIVEIRA, K.; OLIVEIRA, L. C. A.; AMARAL M. P.; CAMPELO, R. E. C. ; MACIEL, T. Modelo de Referência para Melhoria de Processo de Software: uma abordagem brasileira, XXX Conferencia Latino-americana de Informatica (CLEI2004), Arequipa - Peru, Setembro,2004.

WIEGERS K. Software Process Improvement in Web Time, IEEE Software 16 (4) 7886, 1999. 


\section{GLOSSÁRIO}

Atributo de processo: Uma característica mensurável da capacidade do processo aplicável a qualquer processo [ISO/IEC 15504-1, 2004].

Avaliação: Uma determinação sistemática do grau de atendimento de uma entidade em relação aos critérios para ela estabelecidos [ABNT, 1998].

Avaliação de processo: Uma avaliação disciplinada dos processos da organização em relação a um modelo de avaliação de processo [ISO/IEC 15504-1, 2004].

Avaliar objetivamente: Rever atividades e produtos de trabalho com base em critérios que minimizem a subjetividade e o viés do revisor. Um exemplo de avaliação objetiva é 
uma auditoria de requisitos, padrões ou procedimentos por uma função de garantia da qualidade independente [SEI, 2002].

Capacidade do processo: Uma caracterização da habilidade do processo atingir os objetivos de negócio atuais ou futuros [ISO/IEC 15504-1, 2004].

Evidência objetiva: dados que demonstram a existência ou veracidade de alguma coisa [ISO/IEC 15504-1, 2004].

Nota: Evidência objetiva pode ser obtida por observação, medição, teste ou outros meios.

Modelo de referência de processo: Um modelo que compreende definições de processos no ciclo de vida descrito em termos de propósitos e resultados, junto com uma arquitetura que descreve as relações entre os processos [ISO/IEC 15504-1, 2004].

Nível de maturidade: Grau de melhoria de processo para um predeterminado conjunto de processos no qual todos os resultados esperados do processo e dos atributos dos processos são atendidos.

Processo: Um conjunto de atividades inter-relacionadas ou interativas, que transforma insumos (entradas) em produtos (saídas) [ABNT, 2000].

Processo de avaliação: Determinação da extensão com que o processo padrão da organização contribui para alcançar seus objetivos de negócio e para ajudar a organização a focar a necessidade de melhoria de processo contínua [ISO/IEC 15504-1, 2004].

Produto de trabalho: Um artefato associado à execução de um processo [ISO/IEC 15504-1, 2004].

Nota 1: Um produto de trabalho pode ser usado, produzido ou alterado por um processo. 
Propósito do processo: O objetivo geral da execução do processo. Convém que a implementação do processo forneça benefícios tangíveis aos envolvidos [ISO/IEC 12207:1995/Amd 1:2002].

Registro da avaliação: Uma coleção documentada de informações as quais são pertinentes para avaliação e é importante para o entendimento e verificação do perfil de processo gerado pela avaliação [ISO/IEC 15504-1, 2004].

Resultado esperado do processo: Um resultado observável do sucesso do alcance do propósito do processo [ISO/IEC 12207:1995/Amd 1:2002].

Nota 1: Um resultado pode ser: um artefato produzido, uma mudança significativa de estado e o atendimento das especificações, como por exemplo: requisitos, metas etc.

Nota 2: Uma lista com os principais resultados do processo faz parte da descrição de cada processo no Modelo de Referência. 
APÊNDICE A - Guia PROREQ - Facilitador de programa de melhoria de processo de software para os processos de requisitos

\section{Guia PROREQ}

\section{Facilitador de programa de melhoria de processo de software para os processos de requisitos}

Versão 1.0

Autor: Alfraino de Souza Diniz 